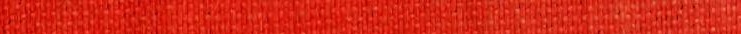




$$
\delta
$$






\title{
ESSAYS
}

\author{
ON
}

\section{PEAT, MUCK,}

A N D

\section{COMNERCIAL IIANURES,}

BY SAMUEL W. JOHNSON, CHEMIST to THE CONNECTICUT STATE AGRICULTURAL SOCIETY AND PROFESSOR OF ANALytical AND agricultural Chemistry iN yaLe COLLEGE.

HARTFORD:

PUBLISHED BY BROWN \& GROSS.

1859. 


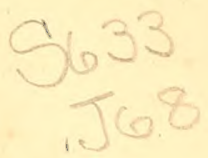

Entered, according to Act of Congress, in the year 1859, by BROWN \&-GROSS.

In the Clerk's Office of the District Court of Connecticut.

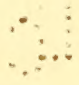

WILLIAMS \& WIIEY. 


\section{PREFACE.}

IN 1856 the writer attempted to turn his chemical knowledge to the use of Agriculture, by examining the commercial fertilizers then offered for sale in the markets of Connecticut and New York.

In a business having such prospects of extension as lay before the trade in manures, in a region where convenient markets largely counterbalance the disadvantages of poor and worn-out soils, it was to be anticipated that frauds would arise, especially since it is so difficult or even in many cases impossible, to judge accurately of the quality of a fertilizer from its external characters.

Chemistry which has done so much for all the practical arts during the last 50 years, and which has made possible the extensive use of artificial fertilizers, fortunately offers the farmer complete protection against every attempt to defraud him by worthless mixtures, sold under high-sounding names and forged certificates; and although there is no scientific merit in analyzing manures, there is great practical use in saving the hardtoiling farmer from profitless and ruinous expenditures.

In the year just mentioned, the writer published in the Homestead a series of papers on the principal fertilizers then on sale in Connecticut. These articles excited much interest among the readers of that Journal, and at the Annual Meeting of the Connecticut State Agricultural Society, in Jan. 1857, the writer was invited to address that body upon "Frauds in Commercial Manures." It was then shown that gross deceit had actually been practised by parties soliciting the patronage of the farmers of this State, and the great facilities for perpetrating further frauds were made the subject of a lengthened exposition. At that time the writer was commissioned on behalf of the State Agricultural Society to make chemical analyses of all commercial manures offered for sale in the State, and to report upon them through the columns of the Homestead. At the annual meeting of the Society in 1858, he presented his First Annual Report as Chemist to the Society, comprising the analysis and valuation of forty-three samples of commercial manures, with an intro- 
duction giving some general considerations on the nature and use of manures, and followed by a preliminary notice of an extended investigation into the agricultural merits of Peat and Muck, which was undertaken at the suggestion of Henry A. Dyer, Esq., the able Secretary of the Society.

At the Executive Meeting of the State Society in 1859, a Second Annual Report was offered, which contained the completed investigation of Peat and Muck, together with analyses of such fertilizers as had been found in market during the previous year.

This volume embodies these two Reports, ${ }^{*}$ and consists of a series of disconnected essays, retaining nearly the form in which they were originally presented to the Society.

The analyses of commercial fertilizers have been duplicated in most instances, in order to ensure entire accuracy, and the statement of results has been accompanied with such explanations as appear adapted to facilitate their use.

The methods of analysis are indicated in appendices, so that those versed in such matters may judge of the reliability of the analytical examinations.

The writer has had the gratification of finding his labors appreciated, not only by the State Society, which continues to appropriate the fund requisite for their prosecution; but also by practical farmers, who point with satisfaction to instances in which they have been saved from loss by the contents of these pages.

By demonstrating the immediate practical and pecuniary advantage which the Agriculturist may derive from Chemisttry, the writer hopes to excite more interest in this noble science, among those whom it is especially adapted to benefit; being confident that it has but just begun to reveal its power, and if properly encouraged will in time become a most useful aid to the farmer in nearly every step of his yearly routine.

$$
\text { SAMUEL W. JǪHNSON, }
$$

Analytical Laboratory of Yale College, New Haven, Ct., Avg. 18, 1859.

* The first 58 pages are oceupied with the Reports made in the year 1857, (presented complete in January, 1558), and now revised, and are referred to in the table of contents on page 5 . The remainler of the book comprises investigations made in 1855 , and has a separate table of contents on paige 59. 


\section{ESSAYS ON MANURES. \\ 1857.}





\section{O NTENTS,}

\section{FOR ESSAYS IN 1857.}

1. What are manures? - . . . - .

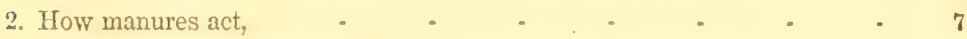

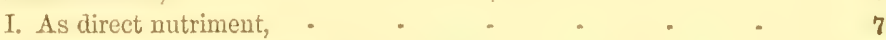

II. As solvents or absorbents, - $\quad$ - $\quad$ - 7

III. They may improve the physical characters of the soil, $\quad 8$

3. Exhaustion and renovation of the soil, - . . . . . 8

4. Comparative agricultural value of nanures, - _ _ . . . 8

5. What manures are most generally useful? _ _ . . 10

6. Uses of special or partial manures, - . _ _ _ . 10

7. Comparative commercial value of manures, _ _ _ . $\quad$ - 11

8. Valuation of manures-substances to be regarded as commercially im-

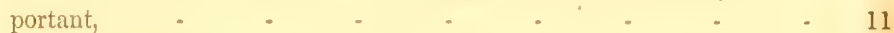

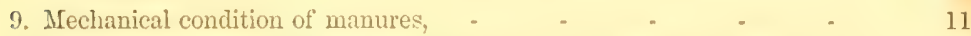

10. Chemical condition of manures-actual and potential ammonia-soluble and insoluble phosphoric acid, - _ _ - 11

11. Prices of the important ingredients of commercial fertilizers, - $\quad 13$

I. Insoluble phosphoric acid, - . . . . . 13

II. Soluble phosphoric acid. - . 13

III. Actual ammonia, - . $\quad$ - $\quad$ - $\quad 13$

IV. Potential ammonia, - . - . - . . 14

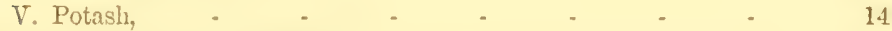

12. Potash may be usually neglected in valuing a manure, - . - . 14

13. Computing the approximate money value of concentrated fertilizers, 15

14. Estimating the value of cheap manures, - - _ - 16

Examitatiox of Commerchl Maxures.Guajo. - $\quad 16$

1. Peruvian Guano, - $\quad$ - $\quad$ - $\quad$ - $\quad$ - $\quad$ - $\quad$ - 16

2. Pacific Ocean Guano, - . - . - . 18

3. Ichaboe Guano, - . $\quad$. $\quad$. $\quad$. 19

5. Baker's Island or American Guano, - . . - 20 
ii.

Superphosphates, - . - .

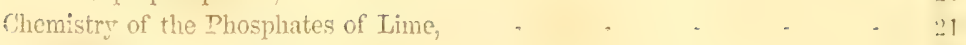

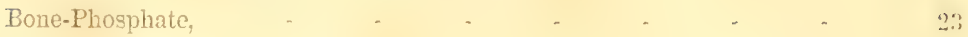

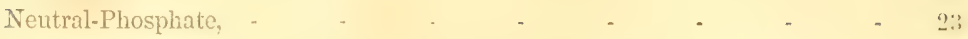

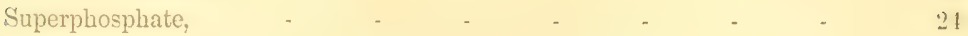

Standard of composition of commercial superphosphates, - _ _ _ 26;

Mape's Superphosphate, _ - $\quad$ - $\quad$ - $\quad$ - 25

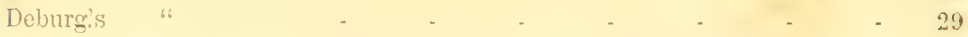

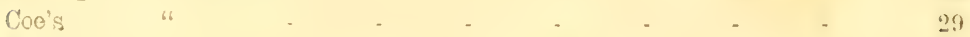

Coe \& Co's. "

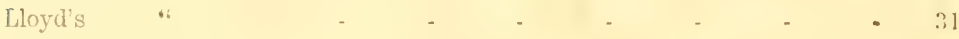

Rhorles' "

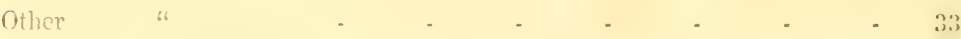

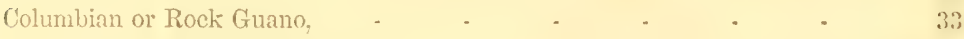

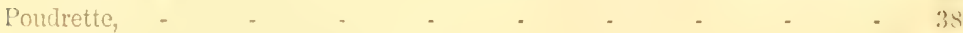

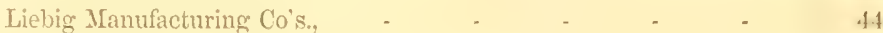

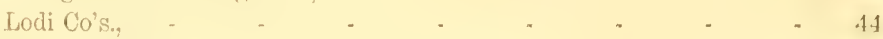

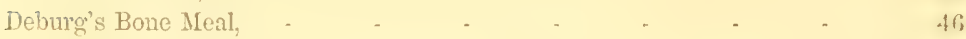

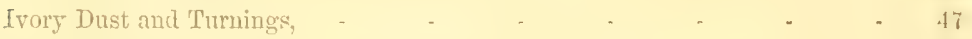

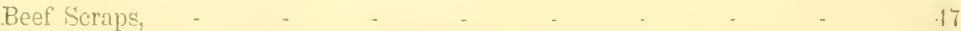

Cotton-seed Cake-its agricultural value, _ _ _ _ _ _ _ $\quad 47$

Peat and Muck-Preliminary Notice, _ _ _ _ _ _ _ 52

Appendix-Methods of Analysig, . . . . . . 5 i 


\section{INTRODUCTORY.}

\section{GENERAL CONSIDERATIONS ON MANURES.}

\section{What are manures.}

Manures are substances which are incorporated with the soil for the prurpose of supplying some deficiency in the latter. Huwever numerous and different may be the materials which assist the growth of plants, judging them by their origin, exterual elaracters and nanes, chemistry has in late years demonstrated that they all consist of only about a dozen forms of matter, which will be specified below.

2. How manures act.

Manures may act in three distinct ways.

I. They may enter the plant as direct nutriment. Carbonic acid, water, ammonia or nitric acid, sulphuric acid, phosphoric acid, silica, oxyd of iron, chlorine, lime, magnesia, potash and soda, are the elements of vegetable nutrition-the essential plant-fiont.

In a fertile soil all these materials are accessible to the plant. If one of them be absent, the soil is barren; if a substance that contains the missing body be applied to the soil, it makes the latter fertile.

II. Manures may act partly as solvents, or absorbents, and thus indirectly supply food to the plant, e. g., lime, gypsum, salts of ammonia, \&c.

Soils are infertile not only from the absence or deficiency of some one or more of the above-named forms of plant food, but also for other recasons. The food of the plant must be soluble in water, so as thus to be transmitted into the plant as rapidly as needed. Soils are often unproductive because the stores of plant-food they contain are locked up in insoluble forms. Lime, guano, the products of the decay of vegetable matters, often fertilize a field merely by their solvent action on the soil. Gypsum acts as an absorber or fixer of ammonia. 
III. Manures improve the physical character of the soil, i. e., malie it warmer, lighter or heavier, more or less retentive of moisture, \&c. Such are some manures that are often applied in large quantity, as lime, marl and muck.

A soil is often barren, not because it has no supplies of nutrim(-1it for the plant, neither for the reason that those supplies are in:mluble; but because the suil itself is so wet or dry, so tenacious and impenetrable, or so light and shifting, that vegetation fitils to find the physical conditions of its growth and perfection.

Almost all our ordinary fertilizers exercise to a greater or less degree all these effects. Thus lime, on a clay soil, may, 1st., mechanically destroy the coherence and tenacity of the clay, and give it the friability of a loam; $2 d$., chemically decompose the clir, making potash, sorli, ammonia, \&ce, soluble, and, 3d, be directly absorbed and appropriated by the plant.

3. Exhaustion of the soil by cropping, and renovation by weathering.

Under cultivation there is removed from the soil by each crop, a greater or less quantity of plant-food. The stores of mutriment in the soil thus continually become smaller and smaller.

$\mathrm{By}$ the action of the atmosphere (weathering, assisted by pulrerization of the soil (tillagt,) the insoluble mattcrs of the suil are gradually made soluble and available to vegetation.

There is thus constantly going on in the soil an exhausting, and as constantly, a renovating process. In most soils under orilinary cultivation, the exhaustion, or removal of plant-food, proceeds more rapidly than the supply by weathering. Such soils therefore tend to become unproductive. In a few cases, the solntion of the materials of the soil itself goes on so rapidly that there is always present in them an excess of all the matters requisite to nourish vegetation. These soils are inexhaustible.

To assist in maintaining the first class of soils in a state of productiveness, manures are employed.

4. Comparative agricultural value of different fertitizers.

It is obvious from the foregoing considerations that manures are required to exercise very different functions in diflerent cases, according to the character of the soil, as determined by its origin and by its previous treatment. The soil itself is constantly 
changing umler culture, so that what is useful on my neighbor's soil that has been tilled and cropped for twenty years, may be yuite valueless on mine which is just reclaimed from the forest. What benefits my soil this year may be of no perceptible advantage next year.

In how far manure is needed for the special purpose of supplying the soil with food for vegetation, it is often difficult to decide. If a new and good soil is repeatedly cropped until it ceases to yield remunerative retums, it may be that addition of some one substance, lime, or potash, or sulphuric acid, will restore its fertility. It more often happens that several bodies are deficient; but what is deficient can only be certainly learned by actual trial. In any special ease that substance is most valuable as a manure, (in so far as the direct nutrition of the plant is concerned,) which is most deficient in the soil in accessible form.

As regards the indirect action of manures, in virtue of their ahsorbent or solvent powers, and as regards their eflects in meliorating the texture and other physical characters of the suil, frictical men have established certain rules, founded on extended experience, which it is not needful to recapitulate here.

Thus much is certain: that one fertilizing agent has no absolute and invariable superiority over another, for all are erually indispensable. The superiorty that any one manure may be reputed to possess, depends upon circumstances. Circumstances are exceedingly various and continually changing. The reputation aud local value of manures is ectually various and changing.

In some regions, as in certain districts of Pennsylvania, lime is considered the best manure. In numerous localities, plaster (sulphuric acid and lime,) is chiefly depended upon. In some districts, superphosphate of line; in others, Peruvian guano is almost exclusively used.

Anong the substances essential to vegetation, there are some which almost never fail from the soil. Thus, oxyd of iron and silica are present in every soil. Lime and sulphuric acid may often be wanting. Potash and soda are not unfrequently deficient. Available ammonia and phosphoric acid are liliewise often liable to exhaustion.

Ammonia and phosphoric acid, which possess the highest 
commercial value among fertilizers, have been considered by some whose opinions are of weight in the agricultural world, to possess also a decidedly greater agricultural value than other manures. It is asserted that in the growth of certain crops, and in fict those crops which best remunerate the farmer, these substances are most rapidly exhausted from the soil. Now it is undoubtedly true that on the soils of certain districts, and in certain courses of cropping, the application of ammoniacal and phosphatic manures produces the most striking results; yet it is by no means proved, or even probable, that on the whole, all soils and all systems of cropping included, these bodies are oftener lacking, or oftener and more permanently useful, tham some of the other fertilizing substances.

\section{What manures are most often and most generally useful?}

While we can not accord to any simple manure, or to any single ingredient of a manure, a miversal fertilizing superiority, it is true that some manures are more useful than others, on ae. count of their compound nature. The more ingredients a manure can supply to vegetation the more useful it is. Stable manure is the universal and best fertilizer, because it contains everything which can feed the plant. Swamp muck, straw, and vegetable refuse generally, are of similar character. Fertilizers, like lime, plaster, salt, \&e., which contain but a few ingredients, can not in general be depended upon for continuously maintaining the fertility of the soil.

6. Uses of special or partial manures.

Special manures, i. e., manures which contain some one or few ingredients, are of use, very rarely as the farmer's chief reliance, but often as adjuncts to stable manure. Several special manures may often be so combined as to make an effectual substitute for stable manure. In high-farming, and in market gardening, and generally where circumstances admit of raising the most exhausting erops without fallow, laying down to grass, or rotation of any sort, special manures are most advantageously employed. In ordinary mixed furming they are useful in assisting to reclaim or improve poor lands; but in the best practice they pliy as yet a very subordinate part, unless peculiar rircumstances make them extraordinarily cheap. 


\section{Comparative commercial value of manures.}

The commercial value of a manure is measured by its price, and may be quite independent of its real agrieultural value, though it usually depends considerahly on its reputerlagricultural value. The scarcity of a substance, the cost of preparation and transportation, the demand for it on account of other than agricultural uses-all these considerations of course influence its price. It is commercially worth what the dealer can get for it, so much per bushel or ton.

8. Valuation of manures. - What substances are to be regarded as commercially important in costly manures.

In any fertilizer which is sold as high or higher than half a cent a pound, there are but three ingredients that deserve to be taken account of in estimating its value. These are ammonia, phosphoric acid, and potash. Every thing else that has a fertilizing value may be more cheaply obtained under its proper name. If the farmer needs sulphuric acid he purchases gypsum; if he needs soda, common salt supplies him. Every thing but these three substances may be procured so cheaply, that the farmer is cheated if he pays ten dollars per ton for a manure, unless it contains or yields one or all of these three substances in considerable proportion.

9. Mechanical condition of Manures.

Nothing is so important to the rapid and economical action of a manure as its existing in a finely pulverized or divided state. All costly fertilizers ought to exist chiefly as fine, nearly impalpable powders, and the coarser portions, if any, should be capable of passing through a sieve of say eight or ten holes to the linear inch. The same immediate benefits are derived from two bushels of bones rendered impalpably fine by treatment with oil-of-vitriol, ten bushels of bone-dust, and one hundred bushels of whole bones. Fineness facilitates distribution, and economizes capital.

10. Chemical condition of manures - State of solubitity, \&.c.-Ammonia, potential and actual-Phosphoric acid, soluble and insoluble.

The solubility of a manure is a serious question to be considered in its valuation. We are accustomed to speak of ammonia as existing in two states, viz: actual and potential. By aetual 
ammonia, we mean ready-formed ammonia; by potential ammonia, that which will result by decomposition or decay- " that which exists in possibility, not in act." Now the former is almost invariably soluble with ease in water, and is thus readily and immediately available to plants; while the latter must first become "actual" by decay, before it can assist in supporting vegetation.

In Peruvian guano, we have about half of the ammonia ready formed, and easily soluble in water, the remainder exists in the form of uric acid, which yields ammonia by decay in the soil, but may require weeks or months to complete the change. In leather shavings or woolen rags the ammonia is all potential, and as these bodies decay slowly, they are of less value than guano as sources of ammonia. Oil-cake, (linseed and cotton seed, contains much potential ammonia, and in a form that very speedily yields actual ammonia.

We do not know with what precise results the process of the decay of ammonia-yielding bodies is acemplished in the soil. Out of the soil such bodies do not give quite all their nitrogen in the form of ammonia: a portion escapes in the uncombined state, and thus becomes unavailable.

Phosphoric acid may occur in two different states of solubility; one reatily soluble, the other slowly and slightly soluble in water. The former we specify as soluble, the latter as insoluble phosphoric acid. In Peruvian guano we find 3.5 per eent. of soluble phosphoric acid, existing there as phosphates of anmonia and potash. The remaining 10 to 12 per cent. is insoluble, being combined with lime and magnesia. In most other manures, gewuine superphosphates excepted, the phosphoric acid is insoluble.

Among those phosphates which are here ranked as insoluble, there exist great differences in their availatbility, resulting from their mechanical condition. The ashes of bones, and the porous rock-guano when fincly ground, exert inmediate effect on crops, while the dense, glassy, or crystallized phosphorite of Hurdstown, N. J., and the fossil bones (so-ealled coprolite of Englind,) are almost or quite inert unless subjected to treatment with oilof-vitriol, (see page 31. ) 
11. The reasonable price of phosphoric acid, ammonia, and potash.

I. Insoluble phosphoric acid.-There are several substances now in market, which, as fertilizers, are valuable exclusively on account of their content of phosphoric acid; which, moreover, are at present the cheapest sourees of this substance that possess the degree of fineness proper to an active fertilizer. I'hese substances are the phosphatic guanos, (Columbian and American guano,) and the refuse bone-black of the sugar refineries. From them we can easily calculate the present lowest commercial value of phosphoric acid. If we divide the price per ton of Columbian guano, $\$ 35$, by the number of pounds of phosphoric acid in a ton, which, at 40 per cent., amounts to 800 pounds, then we have the price of one pound as nearly $4 \frac{1}{3}$ cents.

Refuse bone-black may be had for $\$ 30$ per ton; it usually contains 32 per cent. of phosphoric acid. The same division as above gives us $4 \frac{2}{3}$ cents as the cost of phosphoric acid per pound.

In this report I shall adopt the average of these figures, viz.: $4 \frac{7}{2}$ cents, as the reasonable price of insoluble phosphoric acid.

Phosphorie acid is much eheaper in crushed bones; but this material is not in a suitable state of division to serve as the basis of a firir estimate.

II. Soluble phosphoric acid.-This is nearly always the result of a manufacturing process. Professor Way, chemist to the Roral Acricultural Society of Finglund, estinates its worth at $10 \frac{1}{2}$ cents per pound. Dr. Voelker, of the Royal Agrieultural College of England, and Dr. Stoeckhardt, the distinguished Saxon Agricultural Chemist, reckon it at $12 \frac{1}{2}$ cents per pound. They have deduced these prices from that of the best commercial superphosphates. In this report the price will also be assumed at $12 \frac{1}{2}$ cents. This, I believe, is considerably more than it is really worth, but is probably the lowest rate at which it can now be purchased.

III. Actual ammonia.-The cheapest commercial source of this body is Peruvian guano. Although it contains several per cents. of potential ammonia, yet the latter is so readily converted into actual ammonia, that the whole effect of the manure is produced in one season, and therefore we may justly consider the whole as of equal value with actual ammonia. 


\section{4}

Good Peruvian guano contains:

2 per cent., or 40 pounds per ton of potash.

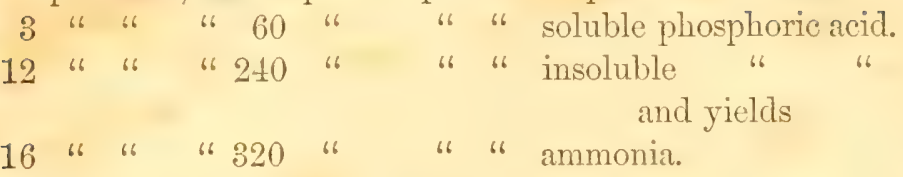

If we add together the values of the potash, (see next page,) and of the phosphoric acid, soluble and insoluble, and subtract the same from the price of guano we shall arrive at the worth of the ammonia-as follows:

$40 \times t=\$ 1.60 ; 60 \times 12 \frac{1}{2}=\$ 7.50 ;$ and $240 \times 4 \frac{1}{2}=\$ 10.80 ;$ total $\$ 19.90$.

$\$ 65.00-\$ 19.90=\$ 5.10$ the value of 320 pounds of ammonia. $\$ 45.10 \div 320=14$ cents nearly, the value of one pound.

This price, 14 cents per pound, will be employed in this report.

IV. Potential ammonia. The value of this varies so greatly, being, for example, as uric acid in guano, not inferior to actual ammonia, while in woolen rags it is not worth more than one half as much, that we ean fix no uniform price, but must decide what it shall be, in each special case, separately.

V. Potush. The value of potash is difficult to estimate, because it may vary exceedingly according to circumstances. Wood ashes are its chief sources; these are poor or rich in potash according to the kind of tree that yields them, and the soil on which it has grown. It may vary from five to twenty per cent. Stoeckhardt, who estimates the value of ammonia at twenty cents, makes potash worth four cents per pound. The price of potashes can not serve as a guide, for they are never used for agricultural purposes. Four cents is certainly ligh enough for this country if it is correct for Germany.

12. Potash may be usually neglected.

Most concentrated manures contain very little or no potash. In guano it rarely excceds three per cent. Superphosphate of lime can contain none of consequence. Potash can not be economically added to manufactured manures, because nearly pure potash, or even the raw material from which it is extracted, viz. : wowd-askes, has a higher commercial value for technical than for agricultural purposes. Besides, potash is not generully de dicient in soils, and therefore farmers do not wish to pray for it as an in. 
gredient of costly manures. It is only when a manure is profescolly sold as containing much potash, that this ingredient deserves to be taken account of in its valuation.

13. Computing the money-value of concentrated manures.

In what immediately precedes, is contained the data for calculating "frproximutierly the price that can be aftorded for a highpriced manure, if we have before us the results of a reliable analysis. The actual calculation is very easy, and has been illustrated already in deducing the value of ammonia from Peruvian guano. We give here a resume of the prices adopted in this report, viz. :

Potash, per pound, - - - - - 4 cents.

Insoluble phosphoric acid, per pound, - - $4 \frac{1}{2}$ "

Soluble " " 6 " - $12 \frac{1}{2}$ "

Actual, and some forms of potential ammonia, 14 "

As a further example of the calculation, here may follow the details of the valuation of a superphosphate of lime. Analysis gave the following percentages:

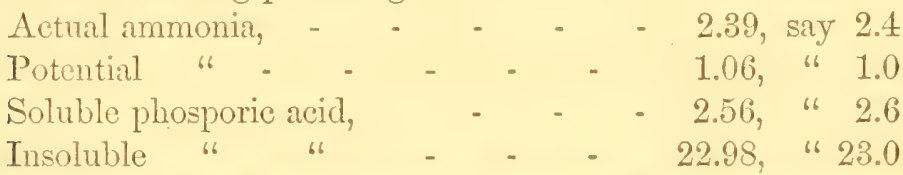

Multiplying the percentage of each ingredient by its estinated priee, and arling together the prochuets thus obtained, gives the value of one hundred pounds; this taken twenty times, gives us the worth of a ton of two thousand pounds.

In the case before us, the quantity of potential ammonia is so small that we may reckon it with the actual ammonia without materially influencing the result. Thus,

$2.4+1.0=3.4 ; 3.4 \times 14=.48$, value of ammonia in $100 \mathrm{lbs}$. $2.6 \times 12 \frac{1}{2}=.33$, value of soluble phos. acid in 100 pounds.

$23 \times .04 \frac{1}{2}=\$ 1.03$, value of insol. phosphoric acid in 100 lbs.

$\$ 1.81$, total value of 100 lbs. 20

$\$ 36.80$, value of one ton. 
It is not claimed that this method of valuation is more than rough and approximate. Usually the price demanded is more than that obtained by calculation. In case of the superphosphate just mentioned, the selling price is $\$ 45$. There is no doubt that it ought to be better for that money. The farmer must decide for himself whether he can get the same fertilizing materials more cheaply. If he cannot he may purchase such a superphosphate. For comparing the worth of different fertitizers this methor of computation is of great value, as will be seen further on, where will be found tables giving the calculated values of all the high-pried manures that have come into my hands officially, during the last two years.

It is but just to mention here, that this method of estimating the value of fertilizers was first proposed nine years ago by Dr. J. A. Stoechinart, Profussor of $\Lambda$ gricultural Chemistry in the Royal Academy of Agriculture and Forestry, at Tharaid, near Dresden, in Saxony, and has been adopted in principle by the chemists of the agricultural societies in Great Britain.

The estimates I made in 1856 were much lower than those now given. The price of manures lias advanced since that time, (Peruvian guanos ten clollars per ton,) and the prices I then proposed for phosphoric acid were too small. All the estimated values in this report are founded on the prices just given.

14. Estimation of the value of cheap manures.

The method of valuation above described is not applicalile to cheap manures, which contain but little ammonia or phosphoric acid. Their value often depends more upon the mechanical and chemical condition of their ingredients, than upon the quantity of any one. The few manufactured manures of this sort, may best be compared with some sinilar fertilizer of standard commercial value, viz.: stable manure, leached ashes, \&c. Under the head Poudrette, examples will be given.

\section{EXAMINATION OF COMMERCIAL MANURES.} GUANO.

1. Peruvian Guano.-The manner in which the importation 
and sale of this standard fertilizer has been hitherto conducted, is such as to afford a sufficient guarantee of its genuineness. But four samples have been amalyzed. All were good, as shown by the following results:

ANALYSES OF PERUVIAN GUANO.

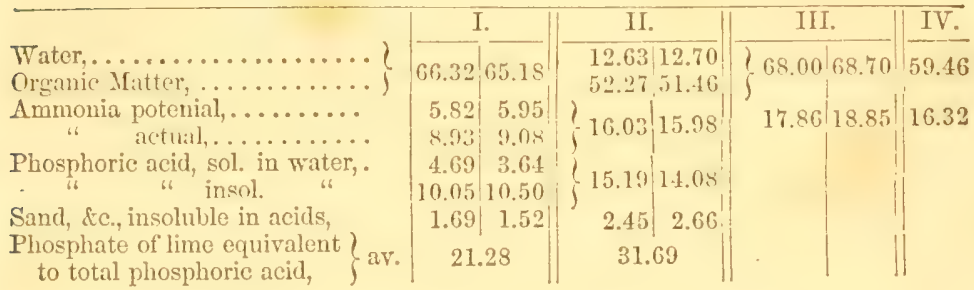

I. Came from the store of $\mathrm{Wm}$. Kellogg, Hartford, 1856.
II. " "
"Wm. B. Johnson, New Haven, 1857.
III. " " "
"Backus \& Barstow, Norwich, 1857.
IV. " "
" C. Leonard, Norwalk, 1857.

A Peruvian guano is genuine and good, when it contains 15 per cent. of ammonia, and the same amount of phosphoric acil. The first analyses were made more complete than is necessary for judging of the quality of this manure. It is sufficient, as in the last two analyses, to ascertain the amount of loss, (water and organic matter,) by burning, and the amount of ammonia.

I believe the fact that gramo may rapilly depreciate in quality by keeping, is not sufficiently thought of. In a note by Dr. Frocker, in a recent German $\Lambda$ grienltural paper, it is stated that the loss in guano may amount to one-fifth or even one-fourth of the whole ammonia originally present, during a single winter, especially when access of moist air is allowed. If guano is kept dry and away from the air the loss is trifling. The ammonia of a genuine guamo, although to a considerable extent " existing in possibility not in act," passes so readily into actual ammonia that it must be reckoned as such. The phosphoric acid also, in a Peruvian guano, is all in a readily soluble state, and it is not fitir to make so great a distinction between the portions soluble and insoluble in water, as would be right in case of a manure which has been reduced to powder by mechanical means. 


\section{Pacific Ocean Guano.}

ANALYSES.

\begin{tabular}{|c|c|c|c|c|}
\hline \multirow{3}{*}{ 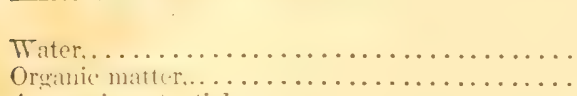 } & \multicolumn{2}{|c|}{ I. } & \multicolumn{2}{|c|}{ II. } \\
\hline & & & 21.70 & 21.44 \\
\hline & & 36.10 & 32.35 & 32.33 \\
\hline 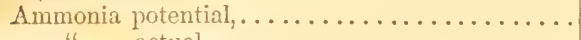 & .75 & & 71 & .58 \\
\hline " actual, $\ldots \ldots \ldots \ldots \ldots \ldots \ldots \ldots \ldots \ldots$ & 1.96 & 1.84 & & \\
\hline Phosphoric acid, soluble in water, ............ & 2.27 & $\begin{array}{r}2.77 \\
20.91\end{array}$ & $(23.27$ & 24.60 \\
\hline $\begin{array}{l}\text { Sand, } f e, \text { insuluble in acid,.................... } \\
\text { Phosphate of lime equivalent to total phosphoric }\end{array}$ & 2.75 & 2.10 & .511 & .57 \\
\hline acid, arerage, $\ldots \ldots \ldots \ldots \ldots \ldots \ldots . . . .$. & 53 & & 51. & \\
\hline 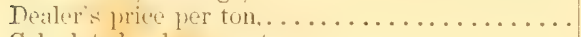 & $\$ 50$ & & & \\
\hline Caleulated value per ton,................. & $\$ 34$ & & & \\
\hline
\end{tabular}

I. From a sample sent by the importers to a dealer in Hartford, 1856.

II. From a sample sent by the dealers in New York to the agricultural store of Wm. B. Johnson, talien from the bags by this gentleman in my presence.

The sample 1. when sent into this State was advertised as nearly if not quite equal to Peruvian guano. In support of this statement the following certificate was given: "I have analyzed a sample of guano for Willet of Co., and find it to contain the following:

Phosphate of lime,

Carbonate " "

Urate of Ammonia,

Phosphate " \&c., $\}$

20.54

Chloride of Sodium, " Potassium,

Sulphate of Soda, sc.,

Undecomposed organic matter, feathers, \&e.,

Silicious matter,

Water and loss,

$$
\begin{array}{r}
5.10 \\
12.00 \\
\hline 100.00
\end{array}
$$

JAmes Chilton, M. D., Chemist."

New York, October 4th, 1854.

The above analy sis has a very elaborate appearance, but does not instruct us as to the value of the sample analyzed by Dr. 
Chilton. In fact, it is eminently adapted to deceive; it gives the impression that the substance in question eontains 20.5 per cent. of ammonia salts, yet without actually asserting that it contains even 1 per cent. of ammonia. Calculation shows that so fir from being "nearly if not quite equal to Peruvian guano," it is not worth so mue:h by $\$ 31$ per ton, and that $\$ 16$ wats charged for it above its real value.

The second sample analyzed last summer, is still poorer. In calculating its value, I have admitted it to contain the same amount of soluble phosphoric acid that was found in I. This ingredient was not determined and is probably less than thus admitted.

3. Ichaboe Guano. I quote the analysis and history of this manure from my investigations marle in 15,50 , in order to show what sort of impositions have vanished from the State of Connecticut since a chemical scrutiny has been exercised over our fertilizers. Ten rears ago a rery good guimo was obtained from the Ichaboe islands, containing 7 per cent. of ammonia, and 15 per cent. of phosphoric acid; worth therefore now, about $\$ 35$ per ton. In 1851 the deposits were exhausted. In 1856 it was announced that there was a new arrival of this superior guano, and it was offered in New York at $\$ 10$ per ton. An authentic sample was procured at the store of the agent, A. Longett, in New York City, and subjected to analysis.

It had a very unpromising appearance, and contained some feathers, together with nuch coarse sumel and gravel. Several pounds were rubbed in a mortar to break down any soft lumps, and then were shaken on a sieve of sixteen holes to the linear inch.

89.1 per cent. passed the sieve.

$9.4 \quad$ " coarse sand and gravel.

1.5 " feathers remained.

\section{0}

This fine portion was analyzed as usual. The results were calculated on the whole, inchuding the 9.4 per cent. of sand and gravel, under the item "sand and insoluble matters," and the feathers unler "organic matter." To the potential ammonia 
found in the fine guano, was added 0.2 per cent. as the greatest amount that could be yielded by the feathers.

\section{Analysis of Ichaboe Guano.}

Water and organic matter,

$17.43 \quad 18.52$

Ammonia potential,

$1.37 \quad 1.41$

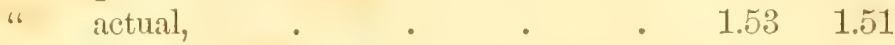

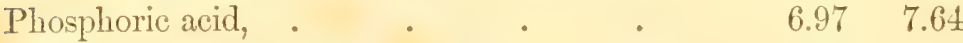

Sand and matter insoluble in acid, . $\quad 65.72 \quad 63.87$

Phosphate of lime equivalent to total phosphoric acid, average,

Dealer's price,

$\$ 40$.

Calculated value, $\$ 15$.

This is the only manure I have examined that contained $6 J$ per cent. of sand and gravel.

4. Baker's Istand or American Guano.-The specimen of this guano furnished me by Mr. Secretary Dyer, is of excellent mechanical condition, and gave results essentially agreening with those of Dr. Higgins and Dr. Gale, viz:

Water, organic and vegetable matters, $\quad \begin{array}{lll}11.97 & 11.70\end{array}$ Insoluble matters, sand, . $\quad$. $\quad$. $\quad .10 \quad .17$ Phosphoric acid, . $\quad$. $\quad$. $\quad$ o $\quad 38.16 \quad 38.63$ Ammonia, . . . . . . . $\quad .68$

Phosphate of lime equivalent to phos. acid, $\quad 83.36$ Calculated value, $\quad \$ 34.50$

It thus appears that the above is an excellent quality of phosphatic guano. So fincly divided is the phospluate of lime that it must be dissolved with sufficient rapidity, in any moderately retentive soil, and if it ean be had at \$35 per ton, I shoukl not hesitate to use it in preference to any superphosphate or other phosphatic manure now in our market. It can not, however, produce the remarkable effects of Peruvian guano, or of other ammoniacal manures, whose efficacy depends greatly on their ammonia.*

* Analyses made during the present year demonstrate that what is now sold in this State as American Guano, is a very inferior article containing but 7.9 per cent. of hosphoric acid, and chiefly consisting of sulphate of lime.

S. W. J., 1859. 


\section{SUPERPHOSPHATES.}

The mannfacture of manures hearing the general designation of superplensplute of Lime, first begun in this comntry about five years ago, and has rapidly extended. As was to be expected, they have proved highly useful in very numerous instanectim and when well prepared are to be looked to as the best means of supplying phosphoric acid to crops. There is, howerer, no other fertilizer which so easily admits of artulteration or fratul, as this, and none whose real value is so difficult to determine. Simple inspection or any other means short of a thorough and costly analysis, fumishes not the slightert clue to its genumeness and excellence.

There is so much confusion with regard to the riflerent phosphates of lime, arising mainly from the great variety of names that have been applied to them, that perhaps it will be a survice to many of the rearlers of this report, to set forth the chemistry of this subject in a few words. For this purpose I copy from my published articles.

\section{Chemistry of the Phosphates of Lime.}

The reader will please bear in mind, that plosphlote of line is in chemical language a salt: which means-in a chemical sense be it remembered-a compound of two classes of bodies, the one called acids, the other bases.

These bodies follow the universal natural laws of combination in definite proportions, and the numbers expressing these proportions, are termed equivalents.

We can best illustrate this with a boly like sulphate of lime, (plaster of Paris, gypsum,) which is a salt consisting of hut one acid, and one base, and but one equivalent of each.

The acid is sulphuric acid, its equivalent is 40

The base is lime, its equivalent is 28

The salt is sulphate of lime, its equivalent is 68

The ahore becomes intelligible when it is consilered that in cvery specimen of pure gypsum that has ever been cxitnincel, the lime and sulphurie acid are present in exactly the propor- 
tions indieated by the numbers 40 and 28 , and it has been proved a hundred times, that when lime and sulphuric acid are brought together in such circumstances that they can unite, they always do unite in the above proportions. This is what is meant by the law of definite proportions.

The word equivalent simply means that 28 parts by weight, grains, pounds, \&c., of lime, are equal to, or go as fur, in making a salt, as 40 grains, pounds, \&c., of sulphuric acid.

Unlike sulphuric acid, (one equivalent of which usually combines with but one equivalent of a base,) one equivalent of phosphoric acid usually unites with three equiralents of base; and these three equivalents may be all of one base, or two of one base and one of another, or, finally, may be all of different bases. What is most remarkable is, that water may act as a base; but it is not customary to allow the water to figure in the name of the compound; and in this way, the three phosphates that contain lime and water as the basic ingredients, are all called phosphates of lime. They are distinguished from each other by a varicty of prefixes, unfortmately numerons, and none of which are strietly in accordance with the general principles that regulate chemical name-making.

The constitution of these three phosphates of lime may be represented as follows:

The first is phosphoric acid (72), lime (28), lime (28), lime (28).

The second is phosphoric acid (72), lime (28), lime (28), water (9.)

The third is phosphoric acid (72), lime (28), water (9), water (9.)

The equivalents are given with each ingredient, and by adding then together we find the equivalent of each phosplate.

The 1st, 72 of acid, and 84 of base. is 156 .

The $2 d, 72$ " " and 65 " " is 137 .

The $3 d_{1} 72$ " " and 46 " " is 118 .

What is the use of these equivalents? may be asked. In 156 parts (ozs. or lbs.) of the 1st are 75 parts, (ozs. or lbs.) of phosphoric acid: in 137 parts of the $2 d$, and in 118 parts of the $3 d$, is the same quantity. A simple operation of "rule of three," will reduce these quantities to percents, and thus we may more readily compare their composition. 
Percent composition of the phosphates of lime.

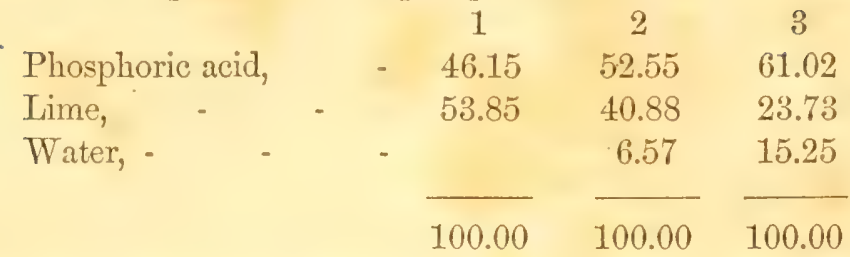

With regard to the names of these phosphates, I have already hinted that much confusion exists.

To No. 1 have been applied the names, neutral, basic, ordinary, tri-, and bone-phosphate. To No. 2, bi-, di-, and neutral phosphate. To No. 3, mono-, bi-, acid, and superphosphate.

No. 1, we may designate as bone-phosphate of lime, because it is the chief earthy ingredient of bones, or at any rate it remains when bones are burned, and constitutes the larger share of boneashes. It is almost absolutely insoluble in pure water; but dissolves perceptibly in water containing in solution salts of anmonia, or common salt, or carbonic acid. It is also the principal ingredient of the so-called mineral phosphates,--of Apotite, that oceurs abundiuntly in the iron mines of northern New York, of the Eupyrchroite of Crown Point, and the Phusphorite of Estramadura in Spain, and of IIurdstown, New Jersey. In the fossil bones, the so-called Coprotitis of certain districts in Fingland, and in the phosphatic nodules of the silurian rocks of Canada, a rariable quantity of bone-phosphate of lime is contained. The phosphoric acid of all the genuine guanos exists mostly in combination with lime as bone-phosphate.

No. 2, most commonly called the neutral phosphate of lime, deserves notice as oceurring mixed with bone phosphate in the Columbian guano, and in the sinilar phosphatic guanos recently imported by the Philadelphia Guano Company. It will be noticed further on.

The agrieultural value of phosphoric acid, and of the phosphates of lime is sufficiently understood. To them, bones matinly owe their efficacy as a fertilizer. It is well known that, although bones are highly useful when applied to the soil in a coarsely-broken state, they are fir more valuable if redueed to small fragment, or better still, if ground to dust. This is be- 
cause nothing can enter the plant in a solid form. All that a crop absorbs through its roots must be dissolved in the water of the soil. The bone-phow hate of lime is only slightly soluble in water, and is of course very slowly presented to the plant. The more finely it is divided or pulverized, the more surfice it exposes to the action of water and the more rapidly it dissolves. By grincling it is only possible to reduce bones to a gritty dust, fine ferhaps to the maided eye, but still coarse, when seen under the Inicrosenpe. Chemistry furnishes a cheap means of extending the division to an astonishing degree, and enables us to make bone-inanure perfect both in its mechanical and chemical qualities.

This brings us to No. 3, or superphosphate of lime, which is the characteristic ingredient of the genuine commercial article known by that name, in which, however, it is largely mixed with other substances. Its peculiarity is, ready solubility in water. It may be prepared from either No. 1, or No., 2, by arting to these phosphoric acid, or by removing line, in presence of water. In practice lime is removed.

If to 156 parts (one equivalent) of bone phosphate of lime, we add 80 parts (two equivalents) of sulphuric acid,* with suffieient water to artmit of an intimate and perfect mixture, then the 80 parts of sulphuric acid talie 56 parts (two equivalents) of lime and form sulphate of lime, while the phosplioric acid retains 28 parts (one equivalent) of lime, and 18 parts (two equivalents) of water replace the lime removed by the sulphuric acid, s) that there results 136 parts of sulphate of lime, and 118 parts of superphosphate.

The manuficture of good superphosphate of lime, consists essentially in sulujecting some form of bone-phospluate of limeit may be fresh or burned bones, mineral-phosphates or phosIhatic guanos--to the action of' sulphuric acid. 'The product of such treatment contains sulphate of lime, superphosphate of lime, and still a greater or less share of undecomposed bone-phosphate, together with some free snlphuric acid, because the materials can not be brought into such thorough contact as to cnsure complete action.

* Oil of Vitriol is a compound of about 75 per cent. of sulphuric acid, with 25 per cent. of water. 
The rualer can easily perform a simple experiment that illustrates the change which superphosphate of lime, or any soluhle phosphate, always molergoes when brought into the soil. Stir a spoonful of superphosphate in a tumbler of water; let it settle and then pour off the clear liquid into another tumbler, (if no superphosphate is at hand, use instead of the liquid just mentioned, strong vinegar in which some bits of bones have stood for a few days.) Now stir a few lumps of saleratus or soda, in water, and pour it gradually into the first liquid. Immediately a white cloud, or precipritate, as the chemist calls it, is formed; at the same time the liquid will foam like soda water, from the escape of carbonic acid gas.

This white cloud is precipitated bone-phosphate of lime, and does not esutially differ from the original bone-phosphate, except that it inconceivably finer than can be obtained by any mechanical means. The particles of the finest bone-dust will not average smaller than one hundredth of an inch, while those of this precipitated phosphate are not more than one twenty-thouandth of an inch in diameter.*

Since the particles of the precipitated phosphate are so very much smaller than those of the finest bone-dust, we can understand that their action as a manure would be correspondingly more rapid.

In fiut, the applieation of superphosphate to the soil, is always spectily followerl by the formation of this precipitated phosphate; the iron, lime, potash, \&c., of the soil, having the same effect as that produced by the salir ratus or soda in the above experiments.

The artrantage of dissolving, or rather acting upon bone's with sulphuric acil, is then, not to furnish the plant with a new fool; but to present an old dish in a new shape, more readily accessible to the plant. In addition to the advantage of sub-division thus presented, another not less important is secured; viz: distribution. This may be illustrated as follows: If one part of a quantity of superphosphate be mixed with chalk, lime, or ashes before use, while another portion is directly applied, in both cases precipitated phosphate will be furnished to the soil. The

\footnotetext{
* Prof. OgDes N. ROod, of the Troy University, has had the kindness to meas. ure them under the microscope at my request.
} 
sub-division will be equal, but the distritution will be unlike. In the first ense, the ready-formed phosphate is very imperfectly mixed with the soil, by the mechanical operations of tillage. In the latter instance, if the superphosplate be scattered on the surface, it is unaffected until a rain falls upon it. Then the superphosphate dissolves, and trickles or soaks down into the soil, meeting here with a particle of lime or potash, and depositing a particle of bone-phosphate, traveling on a little way, and depositing another, and so filling the whole soil to a eertain depth with the precious fertilizer.

It seems then that it is important not only that the superphosphate be made, but that it remain such, until strewn on the soil.

I would suggest that the simplest, and for agricultural purposes, the most accurate way of decignating the phosphuates of lime, and all other phosphates, is to divide them into two classes, soluble and insoluble, and always to base calculations on the phosphoric acid they contain, because it, and not lime or water, is the valuable ingredient of them all. Accordingly, in all my analyses, I have invariably stated separately the amount of phosphoric acid soluble in water and the quantity insoluble in that vehicle of vegetable nutriment.

For the sake of comparison with the common standards, the quantity of bone phosphate equivalent or corresponding to the phosphoric acid, has been inclutel in the analytical tables. The amount of bone phosphate of lime is obtained by multiplying: the phosphoric acid by 13 and dividing the product by 6 .

What ought to be accepted as the standard of composition in a commercial superpliosphate?

The answer to this question is: as good an article as can be manufactured on the large scale.

There are two classes of good superphosphates. One is represented by the following analysis made by me in 1852, on what then was Mapes' improved superphosphate:

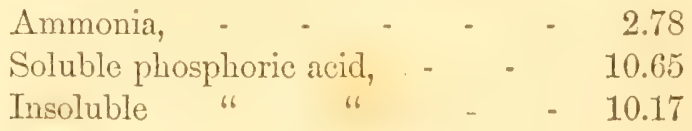




\section{7}

Here we have 21 per cent. of phosphoric acid, one-half of which is soluble in water. The proportion of soluble phosphoric acil is sufficiently large for a quick and cnergetic action, while the still insoluble phosphorie acid renders its effect more lasting. The 3 per cent. of ammonia is a constituent, which makes the manure more generally uscful than it would be otherwise. Such a manure is worth as follows:

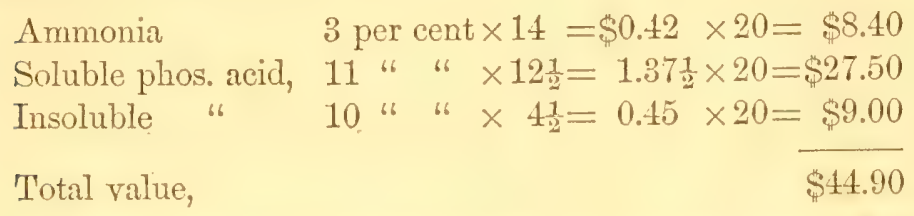

This sanple is the only one of its class that has hitherto fillen into my hands.

'The ofher kinct is, strictly speaking, a superphospluate, con. taining but little insoluble phosphoric acid, am $n$ ammonia. It is precisely what it is called, and is intencled to be an adjunet to other fertilizers. The following statenent of composition and worth - the average of four best English samples, accorting to Prof. Way's analyses-gives an idea of this manure :

Soluble phosphoric acid, 13.23, worth per ton,
Insoluble
" 3.07 ,
66
$\$ 2.80$

$\$ 33.20$

\section{Total value, - $\quad$. $\quad$ - $\quad$ - $\quad$ - $\quad$ - $\$ 36.00$}

The only specimen of such a superphosphate that I have analyzed, is that made by B. M. Rhodes \& Co., of Baltimore, Maryland.

Besides these two classes of superphosphates, there is another, which indeed includes many good manures, lut they hardly deserve to be called superphosphates, as they contain but two or three per cent. of soluble phosphoric acid. They are, however, called superphosphates, but we cannot admit that they are any thing better than second-rate articles.

In stating the composition and value of the superphospluates I have examined, I shall class together those coming from the same manufacturer, or otherwise such as most nearly agree in composition. This plan will cnable us to trace the improvement of 
deterioration in the manufacture, when numerous samples have been examined, and, otherwise, will facilitate comparison.

\section{Mapes' Superphosphate-Newark, New Jersey.}

The best superphosphate that has ever come under my examination, was the one that is first given in the table below. The sample analyzed in 1856 had but half the value of the first; and in 1857 the three specimens analyzed are worth but one-third as much. It is clear that this is a brand not to be depended upon, and the material that lias come into Comecticut the past year is hardly worth a long transportation.

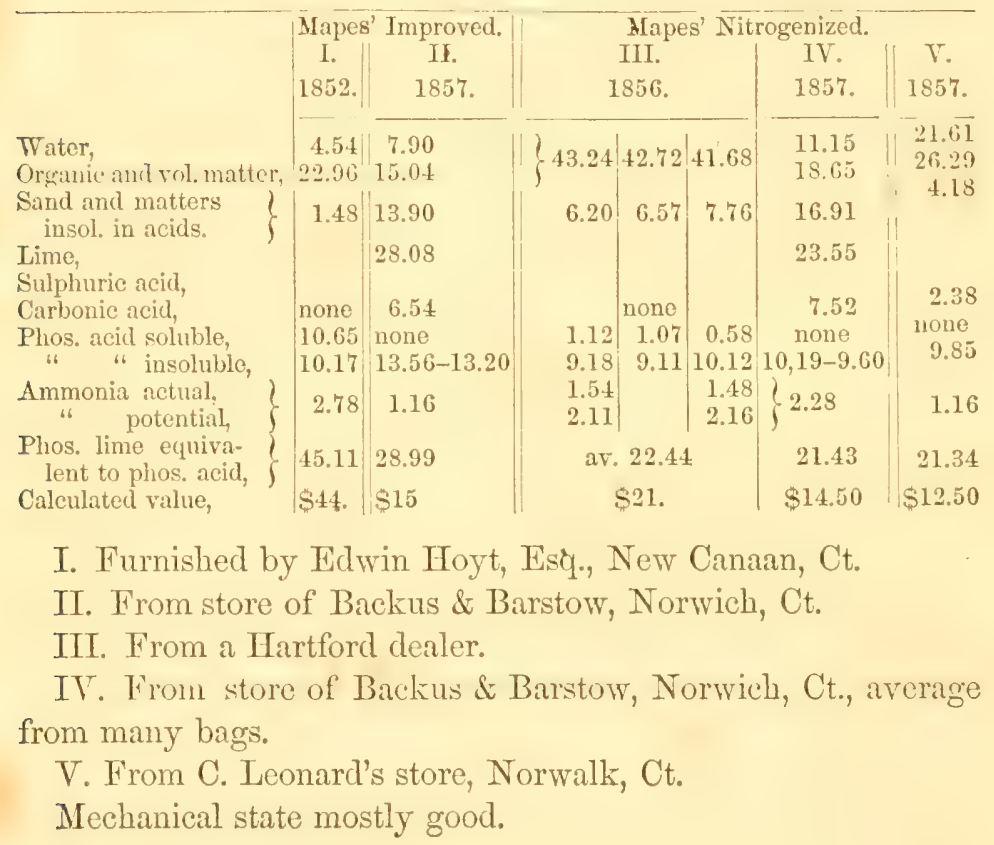


Deburg's Superphosphate-Tilliamsburg, Brooklyn, L. I.

The sample analyzed in 1856 was of a very fair quality. The last year it is seen, however, that there is a serious filling off.

Water, organic and volatile matters, Sand and matters insoluble in acids, Phosphoric acil soluble in water,

Ammonia actual,

"6 potential,

Phosphate of lime equiv. to phosphorie acid,

Calculated value,

\begin{tabular}{|c|c|c|}
\hline Deburg & perphosp & \\
\hline $\begin{array}{c}\text { I. } \\
1852 .\end{array}$ & $\begin{array}{l}\text { II. } \\
1856 .\end{array}$ & $\begin{array}{c}\text { III. } \\
1857 .\end{array}$ \\
\hline $27.65 \mid 26.24$ & $24.57 \times 21.23$ & 25.20 \\
\hline $8.45 \quad 8.80$ & \begin{tabular}{|l|l|}
6.89 & 7.37
\end{tabular} & \\
\hline 5.96 & $\begin{array}{ll}2.56 & 2.46\end{array}$ & 51 \\
\hline $14.37 \quad 15.78$ & $\begin{array}{l}22.98 \\
22.53\end{array}$ & 17.61 \\
\hline 1.38 & \begin{tabular}{l|l|}
2.39 & 2.25 \\
\end{tabular} & 1.44 \\
\hline & $1.06 / 1.2 t$ & \\
\hline av. 45.56 & 54.74 & 39.26 \\
\hline$\$ 32$. & $\$ 36.25$ & $\$ 21.50$ \\
\hline
\end{tabular}

I. From the agricultural store, New Haven, Ct.

II. From the factory-taken from a heap in my presence.

III. Fron Messirs Bakus \& Barstow, Norwich-simple made up by taking a spoonful from each bag of a large lot.

Mechanical condition, good.

Coe's Superphosphate-Middletown, Ct.

This fertilizer, manufactured in Connecticut, has been subjected to pretty severe scrutiny, and has maintained a goorl degree of uniformity in composition. 'I'he variations are perhaps not greater than are necessarily incidental to the manuficture. 


$$
\begin{aligned}
& 30
\end{aligned}
$$

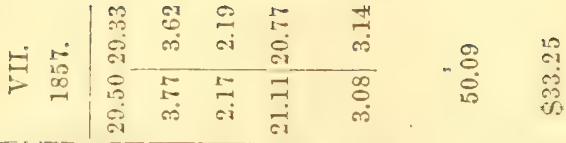

$$
\begin{aligned}
& \begin{array}{r}
-5 \\
5
\end{array}
\end{aligned}
$$

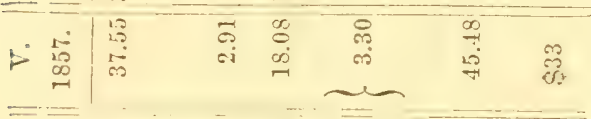

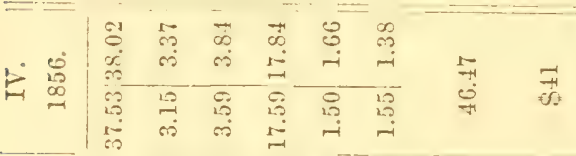

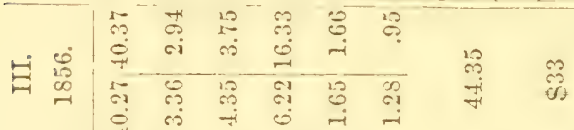

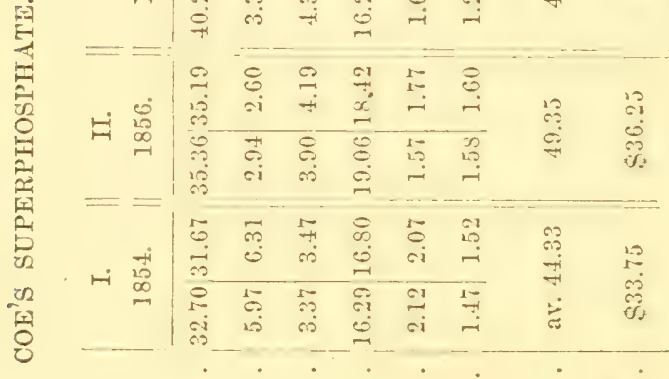

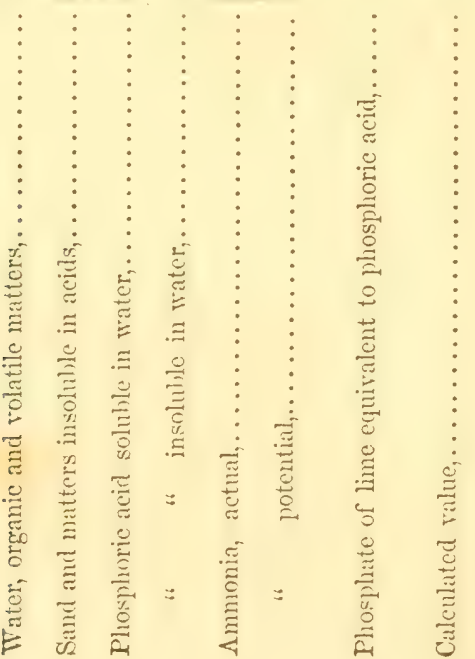


I., II., III., IV. From the agricultural stores of New Haven and Hartford.

V. From store of Backus and Barstow, Norwich, Ct.

VI. and VII. From Henry Hull, Esq., Naugatuck, Ct.

Mechanical condition uniformly good.

Coe \& Company's Superphosphate-Boston, Mass.

This manure, furnished by Ienry Hull, Esq., of Naugatuck, Ct., is of a grayish white color, and is in good mechanical condition. Its analysis resulted as follows:

Water, organic and volatile matters, - $\quad 26.70 \quad 26.19$

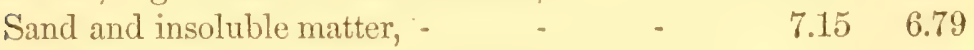

Soluble phosphoric acid, - $\quad$ - n none

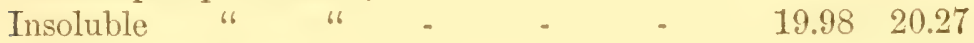

Potential ammonia, - $\quad$ - $\quad$ - $\quad$ - 3.06

Phosphate of lime equivalent to phos. acid, av., $\quad 43.59$

Calculated value, $\$ 26.50$.

This manure is wrongly named.* It is a good bone-manure at $\$ 30$ per ton.

\section{L'loyd's Superphosphate-Providence, R. I.}

This fertilizer I believe enjoys a good reputation as comprared with other similar manures. Its texture is fine. It is apparently made from unburned bones. Its composition is as follows:

Water, organic aud volatile matters - $\quad$ - $\quad 42.15 \quad 42.48$

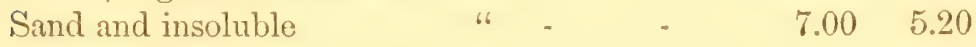

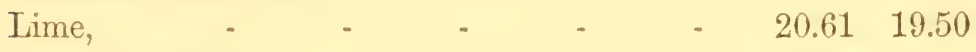

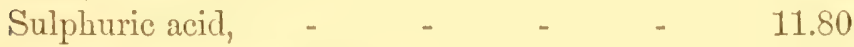

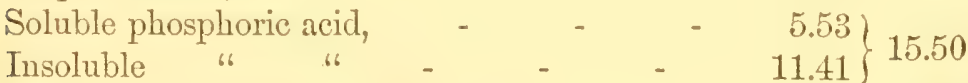

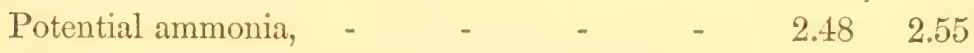

Phosphate of lime, equivalent to phos. acid, av., 35.14

Calculated value, \$31.

The proportion of soluble phosphoric acid is considerably above the average. The total amount is however small.

\footnotetext{
* I have since learned that this sample was mis-labelled. Messrs. Coe \& Co. sell it as "Steamed Bone."

S. W. J.
} 


\section{Rhodes' Superphosphate-Baltimore, Md.}

In my address before the State Agricultural Society a year ago, I made mention of Rhodes' superphosphate to illustrate a common fiult in the analysis of commercial manures, viz: calculating or inferring a result from insufficient grounds, instead of actually deciling the matter experimentally. An analysis of this manure was quoted from the proprietor's cireular, wherein the total amount of phosphoric acid is estimated, and from the quantity of sulphuric acid present is infered the proportion of soluble phosphoric acid. I stated that doubtless a fuller analysis would demonstrate that the amount of the soluble phosphoric acid was considerably smaller than represented.

The sample with which I have been furnished by Mr. Dyer gave the following results in three analyses:

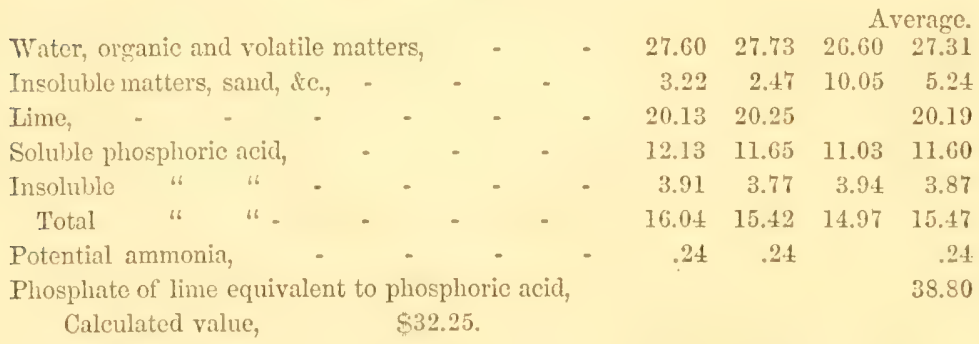

The variation in the analytical results is due to the difficulty of averaging the manure. When rubbed in a mortar it becomes slightly pasty and can not be very thoroughly intermixed.

The mechunical condition of this superphorphate is uncxeeptionable.

In a new edition of their circular, Messrs. Rhodes \& Co. publish analyeses and report made by Drs. Higgins and Bickell, aceording to which this superphospluate contained, in four samples respectively, the following amounts of phosphoric acid:

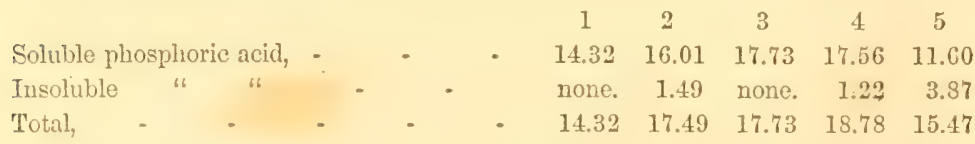

4 Is the statement made in their circular which I read last year before this Society. 5 Is the average result of $n$ y own ac- 
tual reterminations. It is seen that the statement in my ardiess is confirmed, in case of the sample I analyzed. At the same time. the difference is not seriously great.

In the anilyses of Mesirs. IIiggins and Bickell, several per cent of soda are given. I have not taken the trouble to estimate this ingredient, which has no signifieance in case of an expensive fertilizer.

Other Superphosphates.

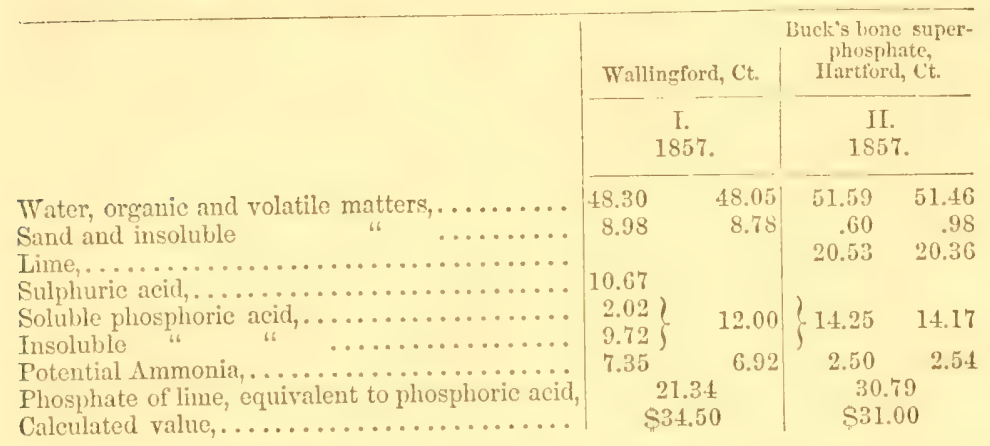

I. This was furnished me by Mr. Parmelee of New Haven. It contains much potential ammonia in the form of gelatine, but the material is so poorly plyerized, consisting of coarsoly-crushed bones, that its action must be slow. A large reduction must therefore be made from the calculated price.

II. Is in good form. The sample furnished was small, so that I was unable to determine the soluble phosphoric acid.

\section{COLUMIBIAN OR ROCK GUANO.}

This substance, which has also been called a native superphlosphate of lime, is reported to come from certain islands in the Caribhean Sea. It oecurs in hard stony masses, which rary much in structure, color and composition. The rock that is richest in phosphoric acid is concretionary in structure. Externally its color is gray or white, internally brown or black. 'This rock, thongh quite tough under the hammer, may be rearlily reduced to a fine powder, having a yellowish or brownish-gray color, and in this form it now appears in the market. It has been supposed 
that this gnano is formed from the excrements of gulls, pelicans, and cormorants, which are the sole inhabitants of the islands where it is found. 'These islands are a hundred or more in number, and it is said that the guano exists there in enomous quantities. The rock guano consists essentially of phosphates, but is more or less intermixed with other mineral matters. It contrins but a trifling amount of ammonia, or of ammonia-yielding substances.

The composition is seen from the following table: 


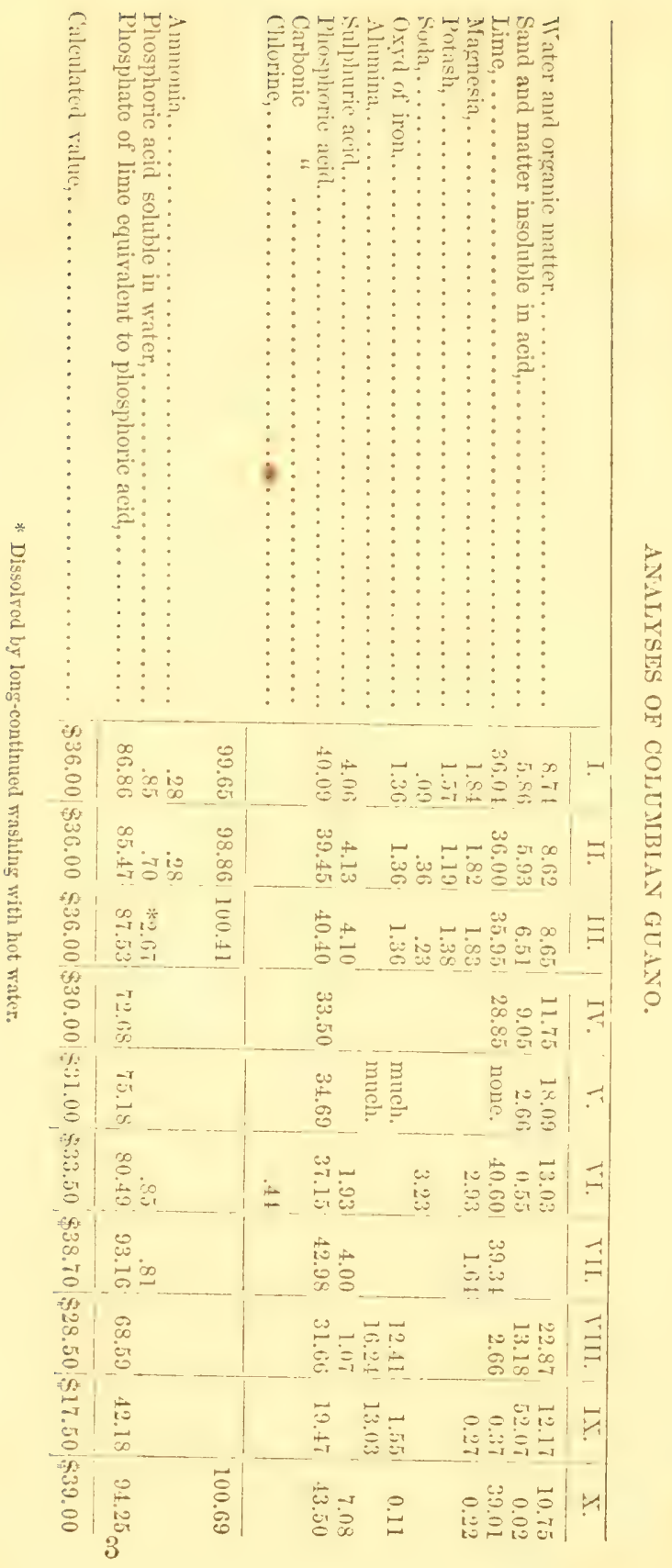


I. and II., gromel guano, sent to editors of Homestend, by the proprietors of the guano.

III., unground guano, sent to editors of Homestead, by the proprietors of the guano.

IV., from a gentleman-a purchaser-near Philadelphia, Pennsylvania.

V., from the store of C. Leonard, Norwalk.

The above five analyses were made under my direction.

VI., VII., VIII. and IX., are quoted from a paper by Wm. F. Taylor, of Philadelphia, in the Proceedings of the Phitudelyhice Academy of Natural sciences, March, 1857. The specimens were rock-samples, furnished by Dr. D. Luther, President of the Philadelphia Guano Company.

X., ground commercial sample; analysis by Dr.s. IIiggins \& Bickell.

Richness in phosphoric acid.-This, the only important ingredient, ranges in the majority of the above analyses at about forty per cent. In analyses V., IV., and VIII., it falls 5, 6, and 8 per cent. lower. In case of IX., we have but 20 per cent. of phosphoric acid. Analysis VIII. and IX., were made on a material quite different in external appearance from the rock furnishing the other samples. The Philatelphia Guano Company sent me specimens of these inferior kinds a year or more ago. They appear to be, and actually are, largely intermixed with sand, though when pulrerised they can seareely be distinguished by the eye from the best sorts. I had begun analyses of the specimens put into my possession, hut their completion was rendered unnecessary by the appearance of Mr. Taylor s extended investigation. 'I'hey contivin little or no line, and the phosphoric acid is combined with oxyd of iron or alumina.

The best quatities of Columbian guano form the richest known source of large quantities of phosphoric acid, if, indeed, there are large quantities of the best quality. But the above analyses show that even the commercial article foum in the agricultural stores, varies considerably in value, while some of the rock samples are worth but half as much as the hest qualities; and, therefore, bone-black, or bone-ash, is equal in this respect to the average of the best samples hitherto analyzed. 
Sotutility of the phosphoric acid.- The circulars of the Philadelphia Guano Company give an analysis of this guano, by Dr. Chilton of New York, according to which it contains $13.1 \pm$ per cent. of soluble phosphate of lime. J. C. Booth reports therein, that Columbian guano contains 6.05 per cent. of free phosplioric acid, or 32.27 per cent. of soluble phosphate of lime. Dr. David Stewat, chemist to the State A in an analysis he furnishes, makes it to contain 5.23 per cent. of soluble phosphoric acid. Dr. A. A. Hayes of Boston, in his analyses, states that it contains 11.4 per cent. of phosphoric acid more than is requisite to form bone-phosphate of lime. IIe says it is in fact a kind of natural bi-phosphate of lime. J. C. Booth,

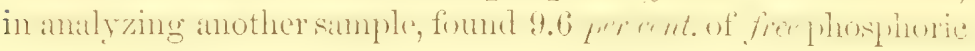
acid. On the strength of these statements, the Columbian guano has been called a native superphospliate of time. It is easy to understand how some of the gentlenen above-named have committed the inadvertency of asserting that the substance in ques. tion contains free phosphoric acid, or superphosphate of lime. The error is more to be attributed to the looseness of language than to any other cause.

The fact is, that some of these specimens of Columbian guano contain, in addition to the ordinary bone-phosphate of lime, the composition of which is-

phosphorie acid, lime, lime, lime-

more or less of the generally called neutral phospluate, which is-

phosphoric acid, lime, lime, water.

There is in it, however, no superphosphate of lime, which isphosphoric acid, lime, water, water.*

This neutral phospleate is slightly soluble in water, and is slowly decomposed by boiling water. Thus, in analyses I., II., VI. and VII., about 0.8 per cent. of phosporic acid was dissolved; and in III., by long continued washing with hot water, 2.67 per cent was made soluble. This neutral phosphate is decomposech by carbonic acid, and hence is doubtless readily available to vegetation.

* See that part of this report relative to superphosphate of lime. 
$A *$ concerns the ralne of those varicties which consist chiefly of phosphates of iron, and alumina, V., VIII. and IX., I am unable $t$ s state whether or not they are capable of readify yielding their phosphoric acid to regetation. As artificially prepared, thes phosphates are totally insoluble in jure water, and are not easily decomposable. In fact, nearly all the knowledge we have of the compounds, leads to the idea that they are mandapted to feet the growing plant. Some writers have not hesitated to dechare them quite ralueless for agricultural purposes. The only satisfuctory evidence, however, must be brought from direct trials with them in the soil, for bodies are soluble there, which ordinarily are accepted as the types of insolubility.

The Prixe SAlu Horsture, of Germany, who has devoted much time and means, to studies having a direct bearing on agriculture, found, indeed, that phosphate of iron is actually assimilated by vegetation; but we do not yet know whether it may be appropriated with such ease as to adapt it for a fertilizer.

I had hoped to institute some experiments with a view to determine this point, but have not found the opportunity.*

\section{POUDRETTE.}

Since chemistry has explained in such a beautiful manner the action of manures, and made evident what enormous quantities of fertilizing material are daily lost to agriculture, the question of connomizing the effete matters which accumulate in large towns, has excited deep interest.

The subject is not merely one of agricultural importance, but has evtensive bearings upon the health of densely populated countries. Those substances which most easily pass into putrefaction, and then become in the highest degree disagreeable and danc vons to the inhabitants of eities, possess, as fertilizers, the greatest value to the farmer.

Not many years since it was common to find large cities filled with filth, which harl acemmulated during generations, with no other means of removal than the natural agencies of decay, or

* Inrestigations that have recently come to my knowledge, prove that the phosphates of irou and alumina are available as food to plants.

S. W. J., 1859 . 
rains might fumisl. Not a few of the fearful plicgues thist in former centuries have ravaged the capitals of the old worlil, trate their origin most unequirocally, to the disgusting negligence in these matters, then prevalent.

It is therefore fortunate for a people, when the refuse of the town, instead of poisoning the atmosithere and generating terrible pestilences, can be transported to the fields of the country, and under the wonderful transmutations of acriculture be converted into healthful food.

Numerous efforts have been made with a view to produce a good manure from the night-soil of cities, but so far as I can learn, with very limited success, if the quality of the product hitherto bromert into market is a proper criterion for juclenent.

Practice and science concur in attributing to human excrements, very high fertilizing properties. It is well-know? that the richness of manure depends upon the richness of the food that supports the animal producing the manure. It is equally wellknown that, on the whole, no animal is so well fed as man.

Notwithstanding these fucts the inanures that have been prepared from night-soil, and brought into commerce under the names Poudrette, Ta-Feu, \&c., are not remarkable for their value. It is true that good manures are made, but they are by no means so concentrated as reasonably to command a high price, or warrant much outlay for their transportation.

Some of the causes that conspire to this result, become evident from the following considerations:

The night-soil as usually collected lias already lost the ehief part of its original value. Unless special arrangements are made to prevent the escape of urine from the vaults of privies, the greater part of it soaks away directly into the aljoining ground and is lost. Now the value of the urine voided by an adult man during one year, for example, is much greater than that of the corresponding solid excrements. It contains, according to Stoeckhardt, (Chem. Field Lectures, page 72):

Double the quantity of phosphorie acid.

Four times as much nitrogen.

Six times as much alkalies.

Not only is the urine itself lost to a considerable degree, but 
in the usual construction of privies it falls upon the solid excrements and washes away a considerable share of their soluble and active matters, so that the contents of a vault, even though quite fresh, are of very inferior value.

Again, the vaults are only emptied at considcrable intervals, between which, especially in warm weather, a rapid putrefaction of their contents takes place, by which a good share of the nitrogen that remains after the urine has leached out the mass, escapes into the air in, the shape of ammonia compounds, and is lost. After the night-soil has passed these two stages of deterioration, it is usually no longer suitable for the preparation of a concentrated manure, even supposing it free from foreign matters.

But again, considerable quantities of worthless matter, coalashes, sc., find their way into the vaults, which are, indeed, often an omnium gatherum for all sorts of refuse. Often the slops of the kitchen run into them, and the rains flow through them on their way to the deeper earth, washing in sand and dirt, and washing out the valuable ingredients.

From these facts, it is seen that the raw material used in making poudrette and tafeu, must be of variable, and for the most part, of inferior value.

T'he process of manufacturing ought to consist merely in converting the night-soil into a shape convenient for transportation, and if possible concentrating the valuable ingredients. The 1.ianure is mate of the lus ymelity by treating the night-soil with sulphuric acid and then rapidly drying by artifieial heat. The acid prevents the loss of ammonia, while the drying removes the worthless water, and brings the mass into a suitable state for handling. The manure is manufactured most cheaply by mixing it with some drying or absorbent material, as peat, or swamp muck, or the charcoal of the same, and drying by exposure to the air. The first method is expensive and raises the cost of the product far above its value, unless the raw material is of unusually good quality. The second process dilutes the right-woil with matter's which are indeed very useful, but must be sold very cheaply.

Acereding to Nesbit's eareful calculation, fresh human exere- 
ments, solit and liquir tomether, when tried completely, yielt a material laving the following per eentage compusition in romel numbers:

Ammonia, (a considerable share not actual but

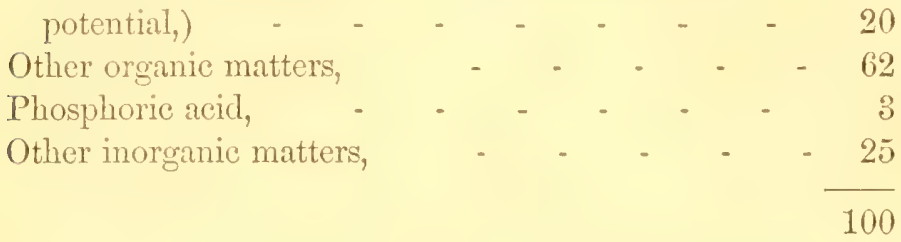

The value of this, estimated by the prices adopted in the present report, is $\$ 60$, and it therefore approaches Peruvian guano in commercial worth.

How effectually the causes I have enumerated deteriorate the value of night-soil before it is converted into a portable manure, is seen by the following analyses: 


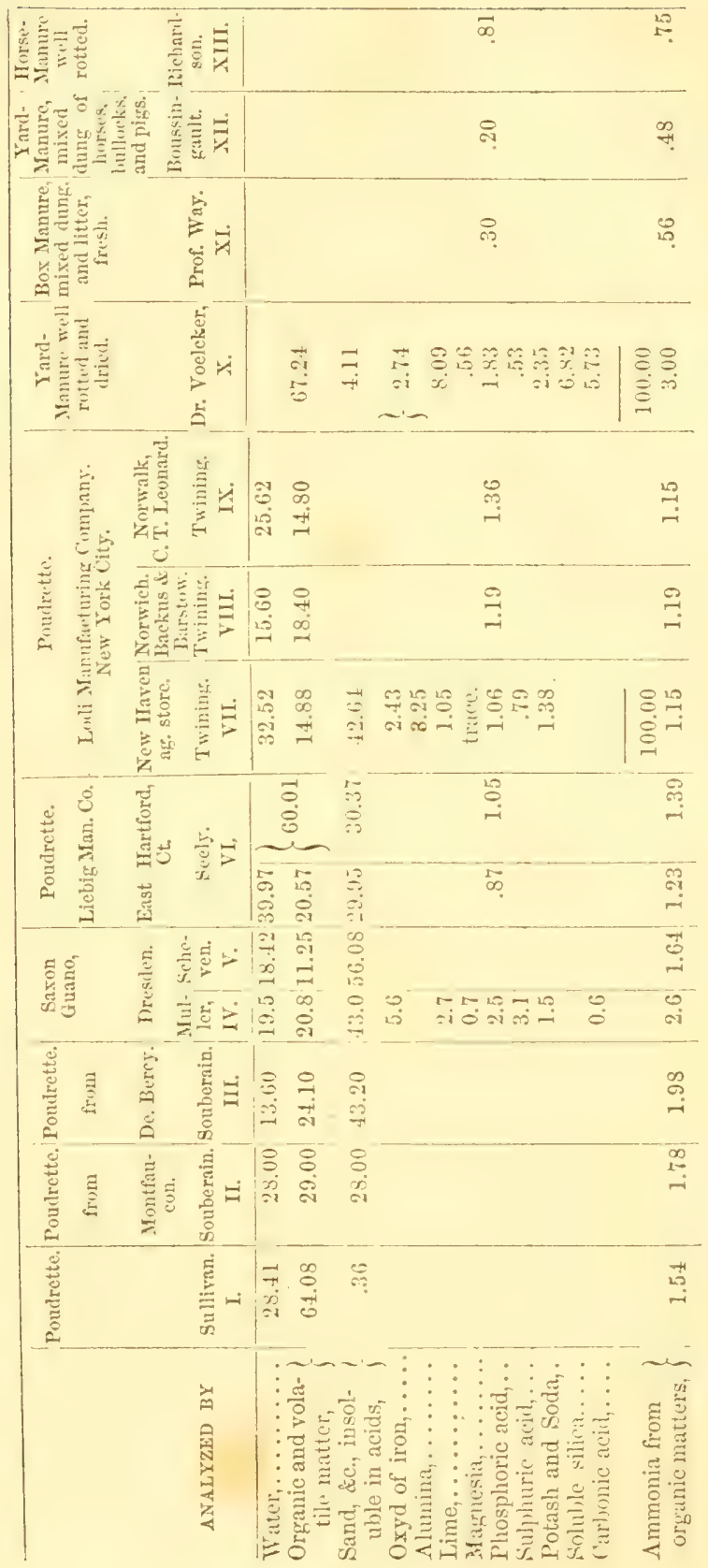


The analyses I.-V. are quoted from foreign journals. Analyses VI.-IX. were made in the Yale Laboratory. I. represents the composition of a mixture of two parts of turf-coal, with one part of night soil, and shows how poor an article is procured when it is known what is the process of making. It will be seen that although no dirt or sund wasmixed with the night soil, yet the amount of fertilizing matter is very small. The further details of the original analysis show that besides the ingredients stated above, there was but 5.3 per cent. of valuable matter in the poudrette, and this was mostly sulphate of lime.

II. and III. are analyses of poudrette made in France, the country where this manufiuture originated, and from whose language the name is derived. There is every reason to suppose that these specimens were prepared in the best manner; blood and butchers' oftal were employed in the latter.

IV. and $V$. show the composition of a poudrette made at Dresden in Saxony, the addition to which of some sulphate of ammonia, is claimed by Dr. Abendroth, the chemist who superintends its manufacture, to entitle it to the name of a guano. It does not differ materially in value from the French poudrette. I have before me a pamplilet setting forth the prineiples that, it is profesed, guide the production of this manure, and have full faith that the business is managed as well as can be. The price of the article is about $\$ 1.00$ per ewt. Dr. Mueller, chemist to the Agricultural Experiment Station at Chemnity, in Fixony, the author of 'one of the above analyses, remarks concerning it, as follows: "In an experimental trial made last year (1855) at the Chemnitz Agricultural Experiment Station, with the purpose of testing the effect of various manures, the suine comernent of money being invested in each application, it resulted that the Saxon guano had the least effect of all. This led me to make the accompanying analysis. A glance at the figures is enough, without any actual trial, to show that no great effect can be expected from such a manure. From the quantity of valuable matters present, six cut. of this might be considered equivalent to one cut. of Peruvian guano; but when the form is taken into account-nearly one-half of the ammonia being inert, and the phosphoric acid existing as almost insoluble phosphate of iron- 
its value must be estimated lower. The other ingredients are of less importance, and, at any rate, may be procured more cheaply from other sources."

VI. represents the composition of a poudrette manufactured by the so-called Liebig Manufacturing Co., at East Hartford, Ct. It does not claim to be a concentrated fertilizer, its price being but $\$ 1.50$ per barrel when sold in quantity. It is not just then to cotimate its ralue from the ammonia ant phosphorie areirl alome, for the cheaper a manure is, the more must its less valuable ingredients figure in estimating its worth.

These have not been separately estimated, for the reason that no calculation of any permanent value, could be founded on one analysis of a material that is so likely to vary in these ingredients, especially where it is sold by bulk. This being a kind of manure that is applied in large quantity, and the ingredients being in proportions more nearly approaching the demands of the growing plant, than is the case with concentrated fertilizers, whose true function is to make up special deficiencies in the soil, we must appeal to practice for precise information as to its worth. Again, it has but a local value, for being bulky, it can not repay much expense in transportation, and therefore should not be jurlert ly the general principles that commend or commemn a superphosphate or guano; but by the particular wants of the soil in the neighborhood where it is sold, and the local circumstances that there affect the price of other cheap fertilizers.

VII., VIII. and IX. are analyses of the Lodi Co's. Poudrette, prepared from the night soil of New York city. The extravagant and pristent claims that have been set un in fivor of this manure, led to a complete investigation of its merits. To insure a fair examination, general analyses were made on three samples, and one of them was submitted to a full and minute analysis. The simmples dithered much in their degree of dryness. TII. fresh from New York, was quite moist, almost wet. VIII. was moist, but still powdery. IX. was dry to the feel.

In all these commercial poudrettes we observe a very large proportion of valueless water and sand, viz: 60 to 75 per cent.

The quantity of organic matters averages at about 20 per cent. This yields but 1.2 per cent of ammonia. There remains 
but 4.5 per cent. of other fertilizing substances. The amalyses, $\mathrm{X}$--XIII. enable us to compare these poudrettes with common stable or yard manure. Analysis $\mathrm{X}$. represents the composition of dried yard manure. Fresh yard manure contains from 65 to 75 per cent. of water, so that we must take but one-third to onefourth of the numbers there given. We see then that the best of these poudrettes does not excced dried yard manure in value, or is worth but three to four times as much as its weight of common yard manure, if we judge alone from chemical composition.

But the question of manurial value is by no means a purely chemical one. As already insisted upon, the form as well as the kind and quality of matter, must be duly considered. In a concentrated fertilizer the assumption that the ingredients are in a state to be readily available to the plant, is the indispensable basis of calculations founded on composition. In discussing the value of cheap manures, this matter becomes of paramount importance. In these respects the Liebig Manufacturing Co's. Poudrette is unexceptionable. It is free from coarse refuse, and having undergone fermentation, it would seem able to produce an immediate and rapid effect. It can be applied with seeds by a drill, does not impregnate the soil with the germs of noxious weeds, and has other obvious advantages over barn-yard or sta. ble manure. From a chemical point of view we may assume it to be worth as much as three times its weight of stable manure. Farmers must decide for themselves whether it is economical for their use. For some it will not be; for many others who command city prices for their produce, and are obliged to transport all their manure some miles, it can hardly fail to be highly valuable. Its modest price is certainly in its favor, and I am credibly informed that it is in good repute among those who have used it.

The Lodi Co's. Poudrette can not be recommended. The organic matter of the Fisit IIartford Pomlrette is a fermenterl peat or muck, is highly divided and absorbent of moisture and ammonia. The Lodi poudrette contains nearly as much organic matter, but it mostly consists of sticks and the dust of hard coal. In fact all manner of eity refuse, old nails, apple-seeds, \&c., \&c., are found in it. It is coarse and lumpy in texture. Its selling 
price is $\$ 1.50$ per 1)bl. of about $200 \mathrm{lbs}$. So long as the firmer can procure 400 lbs. of good stable manure for $\$ 1.50$, so long it is cheaper than this poudrette.

In this connection the question occurs-can not the night soil of cities be profitalily secured for agricultural purposes without losing any of its original value. Undoubtedly it can be, and it is a subject worthy of the most careful consideration of the parties concerned in such an indertaking, viz: those on whose premises it is inevitably produced, those who may find profitable employment in making it portable, and finally, those who are in perpetual need of just such a material for inereasing the yield of their farms.

Nesbit has estimated the total amount of dry matter annually excreted by an adult, well but not highly fed, at 90 lbs., containing 16.55 llis. of ammonia, and 2.55 of phosphoric acil, the former at 14 cents per $\mathrm{lb} .=\$ 2.36$; the latter at $4 \frac{1}{2} \mathrm{cts} .=12 \mathrm{cts}$. Both amount. to $\$ 2.48$. If this estimate be correct, a city of 30,000 inhatitants, like New Ifaren, furmishes yearly 875,000 worth of the most valuable fertilizing material, which now is not only lost, but is a nuisance. Could a little prejudice be overcome, undoubtedly the whole of this might be economized in a most profitable manner. The raw material, if collected fresh, is rich enough to warrant the outlay of considerable money in preparing it for use.

DEBURG'S BONE MEAL.

This substance sent me by Messrs. Backus \& Barstow, of Norwich, had the appearance of bone-ash or the residue of burnt bones, and proved to be such on analysis.

Water, - $\quad$ - $\quad$ - $\quad$ - $\quad$ - $\quad$ - $\quad$ - 3.04

Organic and volatile matters, mostly chareoal, - $\quad 2.07$

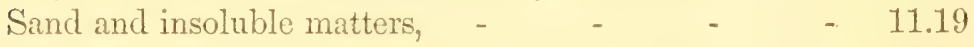

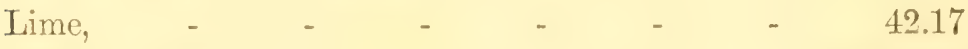

Phosphoric acid, $\quad$ - $\quad$ - $\quad$ - $\quad$ - $\quad 34.06-35.42$

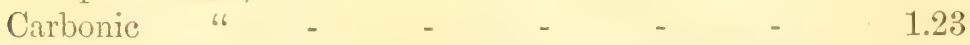

Magnesia, sulphuric acid, with undetermined matters, $\quad 4.88$ 
Bone Meal is a term that has long been in use in England, to signify finely ground bones, and it is a departure from good usage to apply the name to bone-ash. This is a good phosphatic fertilizer, and comes very near in composition to the average samples of Columbitm grumo. The calculated ratue is s.31.75.

IVORY DUST AND TURNINGS.

The examination of these substances from the comb factory at Meriden, has led to the following analytical results:

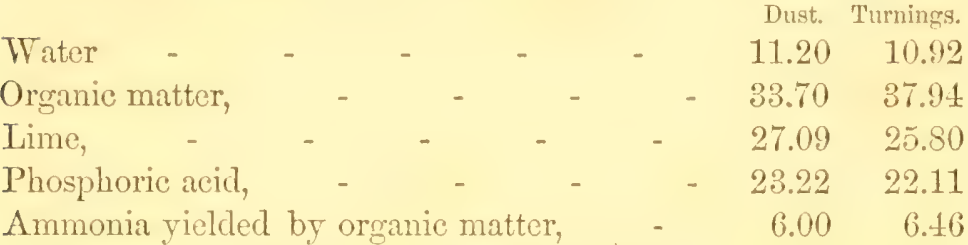

The above is nearly the composition of the bones of domestic animals, and it is obvious that this material must be a valuable fertilizer, though the quantity that can be procured is small.

BEEF SCRAPS.

This material is a residue of the soap-boiling processes. It occurs in the form of cakes, which having been very strongly pressed, are so hard as to withstand any attempts at pulverization. In composition it is almost pure muscular fibre or cellular tissue. It contains 97.42 per cent. of organic matter, and yields 13 per cent. of ammonia on decay. It must be exceedingly valuable to manufacturers as a source of ammonia, but from its hardness can not be directly useful, except it is reduced by some solvent, or is softened by soaking with water. I understand it now commands a gool price from the manufiteturers of superphosphates.

ON THE COMPOSITION ANT AGRICULTURAL VALUE OF COTTONSEED CAKE.

Recently a process has been patented for removing the hulls from cotton-seed, so that this material may be expressed for its oil. This new industry is now prosecuted in Providence, R. I., and so enormous are the quantities of cotton-seed that hitherto have been nearly useless refuse, which may thus be profitably 
ceonomized, that this mannficture will duthtless be a permanent and extended one. The important agricultural uses to which the cake remaining after the expresssion of flax, rape and other oily seerls, have been applied, makes it inpurtant to study what are the properties of the cotton-seed calse. I have examined specinnes from the Providence mills, and find that its composition is not inferior to that of the best flax-seed cake, and in some points its agricultural value surpasses that of any other kind of oil-cake of which I have knowledge; as will appear from the following statement of its composition compared with that of linseed cake.

\begin{tabular}{|c|c|c|c|c|c|}
\hline & I. & II. & III. & IV. & V. \\
\hline 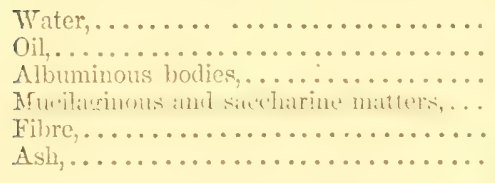 & $\begin{array}{r}6.82 \\
16.47 \\
44.41 \\
12.7 .1 \\
11.76 \\
7.80\end{array}$ & \}$_{8.96}^{48.82}$ & $\begin{array}{r}11.19 \\
9.08 \\
25.16 \\
48.93 \\
5.64\end{array}$ & $\begin{array}{r}9.23 \\
12.96 \\
28.28 \\
31.22 \\
9.00 \\
6.21\end{array}$ & $\begin{array}{r}16 . \overline{91} \\
10.69 \\
411.11 \\
27.16 \\
5.04\end{array}$ \\
\hline 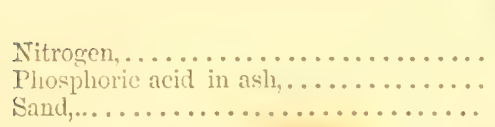 & $\begin{array}{r}100.00 \\
7.05 \\
2.36 \\
.94\end{array}$ & $\begin{array}{l}7.75 \\
2.45\end{array}$ & $\begin{array}{r}100.00 \\
3.95 \\
1.32\end{array}$ & $\left|\begin{array}{r}100.00 \\
4.47\end{array}\right|$ & 100.00 \\
\hline
\end{tabular}

No. 1 . is the cake from Providence.

No. II. gives some of the results of an analysis made by Dr. C. T. Jackson, on cake prepared by himself from hulled cottonsevel. (Paterit (oflice Report for 185\%), agricultural part.)

No. III., analysis of Dr. Anderson on cotton-cake, made at Edimburgl, Scotland.

No.IV., average composition of eight samples of American linseed cake. (Journal of Highland and Ag. Soc. of Scotland, July, 1855, p. 51.)

No. V., Meadow Hay, Saxony, Dr. Wolff.

The two points of interest before us are, the nutritive and manurial value of this cake. With reference to both, chemistry and practical results agree in their conclusions. The great value of linseed eake, as an adjunct to hay for fat cattle and milch cows, hitis long been reengnized; and is undeniably traceable in the main, to three ingredients of the seeds of the oil-yielding 
plants. The value of food depends rpon the quantity of matters it contains which may be appropriated by the animal which consumes the food. Now, it is proved that the fat of animals is derivable from the starch, gum and sugar, and more directly and easily from the oil of the food. 'These four substances, are, then, the fat-formers. The muscles, nerves and tendons of animals, the fibrine of their blood, and the curd of their milk, are almost identical in composition, and strongly similar in many of their properties, with matters found in all vegetables, but chiefly in such as form the most concentrated food. These llood- (and muscle-) formers are characterized by containing about $15 \mathrm{z}$ per cent. of nitrogen; and hence are called nitrorgenous substances. Since albumin (white of egrg) is the type of these bodies, they are also often designated as the albuminous bodies.

The bony frame-work of the animal owes its solidity to phosphate of lime, and this substance must be fumished by the food.

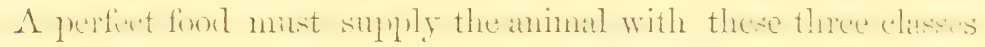
of bodies, and in proper proportions. What proportions are the proper ones, we have at present no means of knowing with accuracy. The ordinary kinds of food for cattle, contain a large quantity of vegetable fibre or woody matter, which is more or

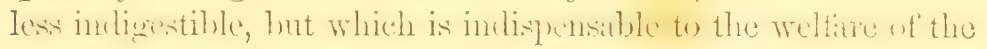
herbivorous animals, as their digestive organs are adapted to a bulky and rough food. (See analysis V.) The addition of a small quantity of a food rich in oil and albuminous substances, to the ordinary kinds of feed, has been found highly advantageous in practice. Neither hay alone, nor concentrated food alone, gives the best results. $A$ certain combination of the two presents the most advantages.

For fittruing animals, and for increasing the yidel and guality of milk, linseed cake has long been held in high estimation. This is to be expected from its composition. The muscle of flesh and the curd of milk are increased in quantity, because the albuminous substances of the linseed constitute an abundant and ready source of them; the fat of the animal and the butter of the milk are increased by the presence in the food of so much oil and mucilaginous matters.

A year ur two since, Mr. M'Lagan of Scotland, reported in the 
Journal of the Mighland Society, some trials on the value, as food, of linseed cake, cotton-seed cake, and bean meal. Analysis III. represents the composition of the cotton cake; IV. that of the linseed cake. The bean meal has 25 per cent. of albuminous matters, but $1 \frac{1}{2}$ per cent of oil, and correspondingly more of the bodies that have the same nutrient function as the mucilaginous and saccharine matters. Six animals of nearly erual size and quality were fed during three months in Winter, with all the turnips and straw they would eat, and in arlition, two of them received daily, four pounds of linseed cake, two, four pounds of cotton-seed cake, and two, four pounds of bean meal. The animals thrived as well on the cotton-seed cake as on the other kinds of food-as shown by their appearance, and by their weight when slaughtered.

When linseed cake is fed in too large quantity it purges the animal. The quality of beef is excellent when the daily dose of oil-cake does not exceed six pounds for an animal of 700 pounds. Cases are on record when more than this quantity has spoiled the beef, giving it a taste like tallow.

Probably like results would follow excessive feeding with cotton-seed cake. In the best cotton districts of India, the cottonseed bears a high value as food for fat cattle. I know of no experiments with it on milch cows, but it is to be expected that here also it will have the same effects as linseed cake.

A Bavarian farmer has recently announced that heifers. fed for three months before calving with a little linseed cake in addition to their other foller, acquire a larger developinent of the milk vessels, and yield more milk afterward, than similar animals fid as usual. If this be a fact, cotton-seed cake must have an equally good effect.

Some of those who have used cotton-seed cake have found difficulty in inducing cattle to eat it. By giving it at first in small doses, mixed with other palatable fovel, they soon leam to eat it with relish.

On comparing the analyses II. and I., with the average composition of linseed cake, IV., it will be seen that the cotton-seed cake is much richer in oil and albuminous matters than the linseed cake. A correspondingly less quantity will therefore be 
required. Three pounds of this entton-seed cake are equivilent to four of linseed cake of average quality.

The value of the article in question as a manure, is obviously very considerable. The dung of cattle, etc., fed upon it, will be greatly richer hoth in nitrogen and phombates, tham that of animals fer on hay alone. Where stock is kept, probably the best manner of using this cake as a fertilizer, is to feed it to the cattle, and carefully apply the manure they furnish. In this way, whatever is not economized as fat or flesh, will be available as manure.

In England and on the continent of Europe, linseed-and rapecake have been used directly as a dressing for the soil, and with results fully equal to what is indicated by their composition. These kinds of cake decompose readily, and their effect is usually finished in one season. 500 or 600 pounds per acre is considered a good application; more is liable to be injurious. It is found that when applied with the seed, these kinds of cake prevent gemination to a consilerable degree; but if applin a weok or so previous to sowing, this detriment is not encountered.

The cotton-secd is often employed in the Southern States, with good effects, as a manure for Indian corn, \&e. I do not know whether like rape and linseed cake, it destroys the secl. For manuring purposes it is about one-third richer than linseed cake. Its effects are mostly due to the nitrogen it contains, and therefore are similar to those of guano. It is best used in conjunction with other fertilizers. I should judge that a mixture of 400 pounds of this cotton-seed cake with 50 bushels of leached wood-ashes per acre, would make an excellent application for most crops. It is highly important that the cake be miformly distributed, and thoroughly inermixed with the soil.

This cotton-sced cake is doubtless an excellent material for composts, owing to its ready decomposability.

Its commercial value as a mantre, if calculated from the prices

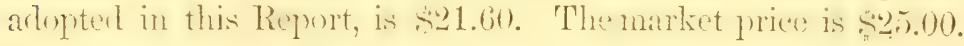
Therefore, next to Peruvian guano, this is a substance which, if its composition proves uniform, is most nearly worth what it costs.

Note. In maling the analyses which are included in this 4 
Report, I have heen greatly assisterl hy the following gentlemen, students in the Yale Analytical Laboratory, viz: Messrs. A. D. Willson, A. P. Rockwell, M. Wation, and G. F. Barker. I am especially inclebted also to my slibilful profeswional assistants, Messis. Henry M. Seely and Edward II. Twining, who have each made numerous analyses.

\section{PEAT AND MUCK-PRELIMINARY NO'TICE.}

The investigation of the Peats and Mucks sent in to me from various parts of the State, last summer, has been funsecuted as far as has been possible. Seventeen specimens hare leen submitted to analysis, and in them have been made the following determinations, viz:

\section{Water.}

Organic matter.

Ash.

Portion soluble in water.

" insoluble in water.

" soluble in carbonate of soda.

" insoluble in " 6 " 6

Total nitrogen or potential ammonia.

In twro cases, complete analyses of the ash have been carried out. In all of them, the ash has been more or less analyzed, where the quantity of it has allowed.

This lathor has ocenpien my alble assistant, Eitwart II. Twining, nearly the whole of four months. Some of the analytical proceses consumed a great deal of time, and the conseguence is, that now, when I must present my report, many interesting points remain uninvestigated. I therefore prefer not to enter into the details of the results already obtained, but to reserve this most important suloject for further and more extencterl sturlies, if such be the pleasure of the Society. The analytical results as far as finished, serve to indicate the direction in which new researches may be undertaken with most pronise of usefulness.

I may mention in brief, some of the more important facts that hise transpired in this research. Tery great differenees exist 
betreen different specimens. Some are but slightly alranced in the peaty decomposition, and yield but a few per cent. of matter soluble in alkalies; others consist almost entircly of soluble peaty substance, the so-called humic, nlmic and gevo acils. An important question, yet very undeciled, so far as my knowlelge extends, is, how do these differenees staml comecterl with the readiness of decomposition which is essential to the fertilizing applications of peat? This is a branch of inquiry that deserves to be studied experimentally, both in the laboratory and on the farm. ILereafter I shall attemint to offer some suggestions for a practical study of this sulject, which may lead to a better knowledge of the best methots of compostine, se. Some of the peats examinerl, have discolved in water to the extent of only three-fourths of a per cent. Others have yielded to water, five, six, and one as much as twelve per cent., viz: five per cent. of mineral, and seven per cent. of vegetable matter. The precise nature of the matters thus dissolved has not been accurately studied in any one case. It is shown, however, that the character of the portion soluble in water varies very widely; for example, in the specinen pielding twelve jur eent. it is chiefly compounds of the peaty acids with oxyd of iron, that are extracted by water. In other cases much lime and little iron is dissolved. These particulars deserve the most minute sturly, becanse the matters soluble in water are those which are immediately serviceable to vegetation. Very likely some of thes: peats maly be at first injurions from the cuantitice of solnble salts of iron they contain.

That part of the investigation relating to the estimation of nitrogen, has furnishel the most interesting results. Nospecimen of peat that I have examined, though all have been merely air-dried, and contain from ten to thirty per cent. of water, has yielilut less than one per cent. of potential ammonia, while the arerage yield is two pere echt., and one specinen gave thre and one-hilf per cent, which is onc-fifth as much as is formu in the best Peruvian guano.

Mr. Daniel Buck, of Porunnock, has long employed peat as fucl, and some time ago brought to the notice of Messis. Dyer and Thell the fact that the peat he employs, cxhales a strong 
odor of ammonia when burning. This observation has been made in my laboratory with other samples.

In the two specimens of peat-ashes, one furnished by Mr. Buck, and coming from the peat just mentioned, the other by Mr. Stanwoul, of Colebrook, were found, besides large quantities of carbonate of lime, considerable sulphate of lime and magnesia, also nearly one per cent. of phosphoric acil and the same amount of alkalies.

The gentlemen who have furnished these peats, namely: Mesurs. T'. S. Gold, Nithan ITart, Titus L. IIart of West Cornwall, Lewis M. Norton of Goshen, Messrs. Pond and Miles of Milford, Messts. Russell Peck of Berlin, B. F. Northrop of Griswold, J. II. Stanwood of Colebrook, S. Loveland of North Granby, Daniel Buck of Poquonock, Adams White, Philip Scarborough, Perrin Scarborough, and the Messrs. Dyer of Brooklyn, have communicated to me a large amount of valuable imformation respecting the character and value of the deposits, which would be most anprempriately enbodied in a future report, should I be permitted to complete this investigation.

Practical men have already abundantly proved that many peats are of exceeding agricultural value. T'his is no discovery of mine, or of those who have already subjected these substances to a chemical examination. Mr. Daniel Buck of Poquonock, has used his peat without any preparation, as a top-dressing on grank. and has experienced the most decieled results from its use in this simple manner. He estimates his raw peat as equal to cow-dung in fertilizing value.

What may be expected from a thorough chemical investigation of these deposits is this: We shall be able to decide which are valuable, and which are indifferent for fertilizing purposes. We shall exeite thronghout the State and the whole country, in fact, in interest in these deposits, that will lead to their extended and systematic use. We shall thus acquire a full practical knowlerlge of their merits, and of the best methods for converting them into grain and flesh and milk.

Unquestionably, the greatest service we can render to our farming interests is to develop our internal resources. The imortation of foreign fertilizers is enriching foreign merchants, 
and withrl rawing cash from the pockets of om farmers. Their use is extremely liable to run to excess, and makes our acticulture unstearly and improvident. Tre need, not only to live and make money from our soils, but to constantly improve the soil, and thus extend our agricultural capital. The enlightened ecomony of the enormous masses of muck and peat which Comecticut enntains, which probably exceed in extent those of any other State, can not fail to exereise the most beneficent influence on our material prosperity. Wo shall thus at once fertilize those fields that are alleady arable, and reclaim from waste a large area of land that is now all but useless.

I doubt not that the peat beds of our State are destined to be of immense value for other thim merely agricultural purpuses. As fuel, they have already been employed to some extent. In Europe a vast deal of ingenuity has been bestowed upon the means of preparing peat-fuel, so as to arlapt it to transpurtation and advantageous use. In Bristol of this State, the Copper Company have for some time employed a furnace in connection with their steam engine, which reecives the peat as it comes iripping wet from the swamp, and consumes it with the greatest economy, even the water it contains being made to contribute to its heating effect.

In Germany, a method has been invented for converting the porous, bullyy, and friable peat, into dense hard cakes, or bricks, which eontain little of the coarse impuritics of the peat, and may be transported without loss or pulverization, and burn with a great degree of frecolom. All this is aceomplished without any fressure, by simply diffusing the peat in water, allowing the latter to settle, and drying the deposit.

Again, in Ireland and Germany, peat is consumed in large quantities in an entirely new industry, which has originated and grown to a good deal of vigor within the last five to six years. The peat is distilled, either over a free fire, or by over-heated stean, and a large number of useful products are thus obtained, quite analogous to those now prepared to some extent in this country from bituminous coals.

As an example of the kind and quantity of these products, the following statement may be adduced: 
From a turf or peat exeavated in Hanover, Germany, and worked in the air-dry state, were obtained:

2 per cent. of a clear, colorless, light-turf-oil or photogene.

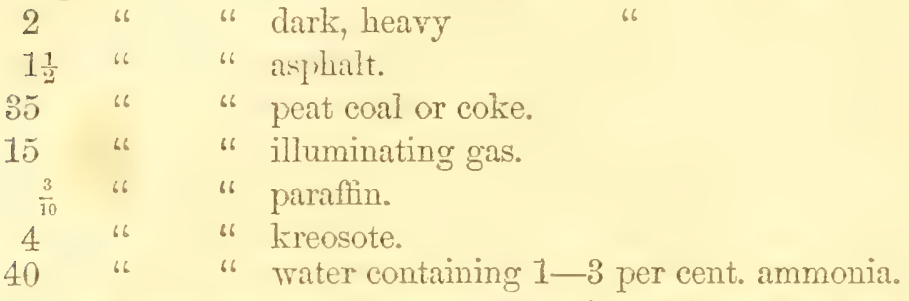

These prolucts are all susceptible of useful applications for pmposes of illumination, lubrication, heating, preservation of wood, manufacture of lamp-black, varnish, and even of perfumery.

If I slould be authorized to continne my labors, I shall commmicate to the Soretety a hill aceonst of all these rarions technical applications of preat, in so fir as they jronise to be of serrice to the inclustrial interests of this State.

I have taken measures to provide myself with means of infinmation on all these topres, as furnished by the sesentific and rechnical joumals and publications of Great Britain, Germany and France. I also wish to examine personally, the more important of our peat-lecks, so as to ixe able to compare their physical with their chemical charieters, and thus to establish rules hy which practical nen may be gutided in the economy of the difterent varieties. 


\section{APPENDIX.-METhons OF ANALYSIS.}

The general methou of analysis for guanos, superphosphates, \&c., whose commercial value lies almost exclusively in ammonia and phosphoric acid, is as follows:

1. Of the well averaged and pulverized sample, a quantity of 2 grams is weighed off and dried at a temperature of 212 deg. until it ceases to lose weight; the loss is water. If loss of ammonia is feared, a lnown quantity of oxalic acid is alded before drying.

2. The dried residue of 1 , is gradually heated to low redness in a poredain cup, and maintained at snch a heat, until all organic matter is burned off. The loss is organic and volatile matter. Usually the substance is directly heated to rechess without separately estimating the water.

3. The residue of 2 , is pulverized if need be, and digested for some tine with molerately eonecntrater hychochloric acil. The diluted solution is filtered off and washed, the residue weighed as sand and insoluble matters.

4. The solution 3 , is brought to the bulk of three or four liquirl onnees, mixed with rather nore than its volume of strong alcohol and enough sulphuric acid to unite with all the lime which in therehy completely separated as sulphate. The liquid is filtered ofl', the sulphate of lime is washed with dilute alcohol, dried and weighed; from it is calculated the amount of lime.

5. The solution 4, is evaporated until the alcohol is removed, then withont filtration, to it is arded an excess of a liquirl made by diswlying in 2 quarts of water, 30 grams of sulpluate of magnesia, 11 grams of chlorid of ammonium, $37 \frac{1}{2}$ grams of tartaric acil, and to grams of carbonate of ammonia, (see W. Mayer, in Liebig's Amalen, Tol. 101, p. 168, ) and finally exeess of ammonia. After five to six hours, the precipitate of ammoniaphosphate of magnesia, usually mixed with some brown organic matters, is collected in a filter and whished three or four times with ammonia water; it is then dissolved from the filter by dilute hydrochloric acid, and again thrown down by ammonia, 


\section{8}

after addition of a little tartaric acid. It is now pure, and is finally washed and weighed as usual for the estimation of phosphoric acid.

6. 1 gram of the manure is burned in the usual way, with soda lime. The resulting ammonia is collected in 20 culbic centimeters of a fifth-solution of oxalic acid, (12.6 grams of pure oxalie acid to a liter of water, and estimated by titrition with a dilute potash solution.

7. The soluble phosphoric acid of a manure is estimated by washing 2 grams of it with several ounces of water and treating the solution as in 4 and 5 .

8. To determine actual ammonia, one or two grams are mixed in a flask, with a pint of water; a piece of caustic potash is added, and three-feurths of the water slowly distilled ofl through a Liebig's condenser into a standard oxalic acid. The ammonia is then estimated by titrition.

In complete ash-analysis of manures, or in examining organic bodies, e. g., cotton-seed cake, the usual and approved methods are employed. 


$$
\begin{gathered}
\text { ESSAIS ON MANURES. } \\
1858 .
\end{gathered}
$$





\section{CONTENTS,}

\section{FOR ESSAYS IN 1858}

I'STE

Pijit Axd Much.- Essay on tietr Nature and Agricultural Uses.

1. What is Pent? - $\quad$ - $\quad$ - $\quad$ - $\quad$ - $\quad$ - 61

2. Conditious of its formation, _ _ _ _ _ _ _

3. Diflerent kinds, - $\quad$ - $\quad$ - $\quad$ - $\quad$ - $\quad$ - $\quad$ - $\quad$ - 69

4. Chemical composition, _ _ _ _ _ _ _ _ _

a. Organic or combustible part, - _ _ _ _ _ _ - 64

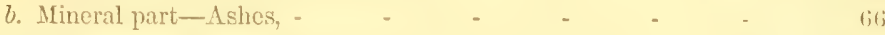

c. Nitroger or potential ammonia, - _ _ _ _ _ $\quad 66$

5. Characters that adapt Pent for agrieultural use, - _ _ -

A. Physical or amending characters, - _ _ - $\quad$ - 67

I. Alsorbent powver for water, as liquid and vapor, - _ _ $\quad 6.5$

II. " " "ammonia, - - - - $\quad$ - 199

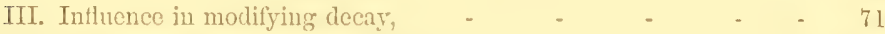

IV. Influence in disintegrating the soil, _ _ _ _ _ - $\quad$ - $: 2$

$\mathrm{V}$. Influence on the temperature of soils. $\quad$ - _ _ _ _

B. Fertilizing characters, - - - - -

I. Fertilizing eflects of the organic matters, including nitrogen, it

1st. Organic matters as clirect food to plants, - _ _ _ it

2d. Organic matters as indirect food to plants, - - $\quad$ -

3d. Peculiarities in the decay of Peat, - _ _ _ - 7 ;

II. Fertilizing effects of ths ashes of Peat, - _ _ - i

III. Comparison of Peat with stable manure, _ _ _ _ _ $\quad$ si

6. Characters of Peat that are detrimental, or that need correction, _ $\quad 82$

1st. Possible bad effects on heary soil, _ _ _ _ _ $\quad$ - 82

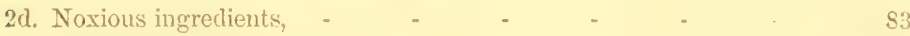

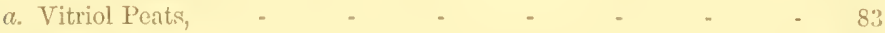

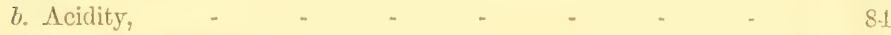

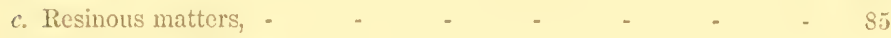

3d. Deficient ingredients, $\quad$ - $\quad$ - $\quad$ - $\quad$ - 85

7. Preparation of Peat for agricultural use, - . $\quad . \quad 85$

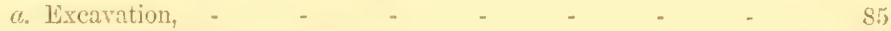

b. Exposure, or seasoning, - - - - - - si

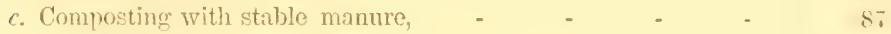

" sight soil, - . - . - .

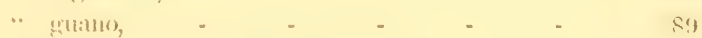

" tish, and other animal matterse, - - 56

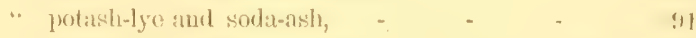

"wood-ashes, matl, lime, salt and lime mixture, de, 51

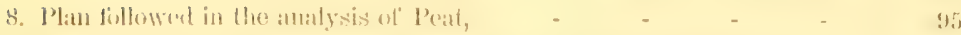

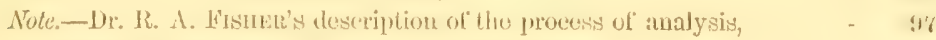

9. The value of analyses and of practical information, - of

Cireular of inquiry; _ a . . . . . 
10. Results of analyses, and answers to circular:-

No. 1, from Lewis M. Norton, Goshen,

No. 2

No. 3 ,

No. 4, “ Messrs. Pond \& Miles, Milford,

Ni. 5, "* " "

No. 6, ". Samuel Camp, Plainville,

No. 7, “ Russell U. Pock, Berliu

No. 8, “ Rev. B. F. Northrop, Griswold,

To. 9, “ John H. Stanwood, Colebrook,

No. 10, : N. Hart, Jx., West Cornwall,

No. 11, “ A. L. Loreland, North Granby,

C't. - 101

No, 12, “ Daniel Buck, Jr., Poquonock,

No. $1: 3$

$$
\text { " } 6
$$

To. 1.1. "Philip Scarborough, Brooklyu,

No. 15. " Adams white,

No. 16. " Paris Dyer;

No. 17.

Perrin Scarborough,

Nก. 1ঙ. ". Geo K. Virgin, Collinsville,

No. 19.

$$
66
$$

":

No. 20. "6

No. 21.

Solomon Mead, New Haven,

No. 22."

Edwin Hoyt, New Canaau,

In. 23.

$$
66
$$

No. 21.

No. 25.

A. M. Haling, Rockville,

No. 26 .

N1). 27.

"،

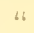

No. 28. " Albert Day, Brooklyn,

No. 29. " Chauncey Goodyear, N. Haven,

N๋. 30. " Rev. W Wm. Clift, Stonington,

No.:3. " Hemry Keeler, South Salem, N.

No. 32. "John Adams, Salisbury,

No. 33. Appendix-Salt marsh mud from Rev. $1 \mathrm{Fm}$. Clift, Stonington, 1 is

No. 3. Shell marl from Joln Adams, Salisbury, Ct., - _ - $15: ;$

No. 35. Marsh raud from Solomon Mead, New Haveu, Ct., - 153

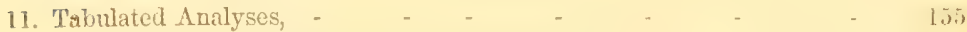

Commercial Ferthlzers-SCale of Prices. - - - -

Fish manure, Quinnipiac Company's, - - - -

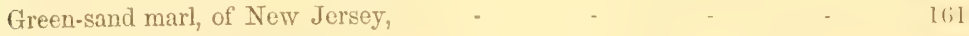

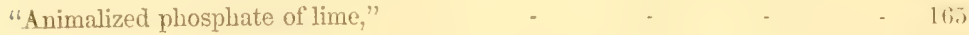

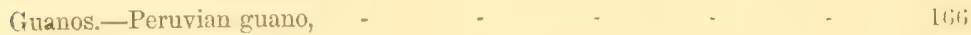

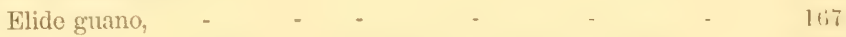

Superphosphates of lime.-Pike \& Co's: Coe \& Co's: Greeue \& Preston's: Coe's, 1tis

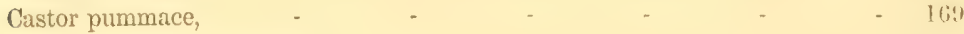

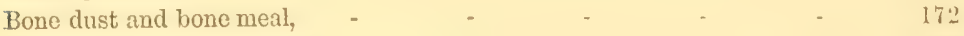

Appendis-Sombrero Guano, + * * * + . $\quad$ - 175 


\section{PEAT AND MUCK.}

\section{ESSAY ON THEIR NATURE AND AGRICLLTURAL LSES.}

\section{What is Peat?}

By the general term Peat we molerstant the veretable soil of salt-marshes, beaver-meadows, bogs and swamps.

It comsists of regetable matters resulting from the decay of many generations of aquatic or marsh plants, as mosess, sedeces, coarse grase's, and a great variety of shrubby plants, mixed with more or less mineral sulstances, partly derived from these plints, and partly washed in from the surrounding lands.

2. The conditions under which Peat is formed.

The production of Peat from fillen and decaying plants, depends upon the presence of so much water as to cover or saturate the vegetable matters, and thereby himler the full acess of air. Saturation with water also has the effect to maintain the decaying matters at a low temperature, and by these two ("atisis in combination, the process of decay is made to proceed with great slowness, and the final prokucts of such slow decaly, are compunds that themselves resist deeay, and hence they ateumulate.

In New England there appears to be nothing like the extensive mmers that abomel in Ireland, Scotland, the north of England, North Germany, Molland, and the elerated platins of Bararia, which are mostly level or gently sloping tractsof' comtry covered with peat or turf to a depth often of 20 fiet. In this country it is only in low places, where streams lecome olstructed ank form swamps, or in bays and inlets on salt water, where the el) and flow of the tide keeps the suil constintly wet, that our peat-beds occur. 
In the countries above named the weather is more uniform than here, especially are the summers cooler, and rain fills are more frequent. Such is the greater humility of the atmosphere that some sprecies of mosses, - the so-called sphagnums, - which have a ronderful avidity for moisture, (hence used for packing plants which require to be kept moist on journeys, are able to keep fresh and in growth during the entire summer. These mosses decay below and throw out new vegetation above, and thus produce a bog wherever the earth is springy. It is in this way that in those countries, the moors and peat-bogs actually grow, increasing in depth and area, from year to year, and raise themselves above the level of the surrounding country.

There the reclamation of a moor is usually an expensive operation, for which not only much draining, but actual cutting ont and burning of the compact peat is necessary.

The warmth of our summers and the dryness of our atmosphere prevent the accumulation of peat above the highest level of the standing water of our marshes, and so soon as the marthe's are well drained, the peat ceases to form, and in most cases the swamp may be easily converted into good meadow land.

Springy hill-sicles, which in cooler, moister climates would become moors, here dry up in summer to such an extent that no peat can be formed upon them.

\section{The different kinds of Peat.}

Tery great differences in the characters of the deposits in our peat beds are olservable. These differenees are partly of color, some peats being gray, others rel, others again black, the majority when dry possess a brown-red or snuff color. They also vary remarkably in weight and consisteney. Some are compact, destitute of fibres or other traces of the regetation from which they have been derived, and on drying shrink greatly and yield tough dense masses which hum readily, and are employed as fuel. Others again are light and porous, and remain so on drying; these contain much intemixed vegetable matter that is but little advanced in the peaty decomposition. Some peats are almost entirely free from ninemal matters, and on burning leare but a few per cent. of ash, others contain consideruble quantities 
of lime or iron, in chemieal combination, or of samel and clay that have been washed in from the hills adjoining the swamps.

The peat of some swamps is mostly derived from mosses, that of others from grasses, some contain much decayed wood and leaves, others again are free from these.

In the same swamp we usually observe more or less of all these difterences. We find the surfice peat is light and full of partly decayed vegetation, while below the deposits are nore compact. We commonly can trace distinct strata or layers of peat, which are often very unlike each other in aprearance and quality, and in some cases the light and compact layers alternate so that the former are found below the latter.

The light and porous kinds of peat appear in general to be formed in shallow swamps or on the surface of bogs, where there is considerable access of air to the decaying matters, while the compacter peats are found at a depth, and scem to have been formed beneath the low-water mink, in more complete exclusiun of the atmosphere.

The nature of the vegetation that flourishes in a bog; no doubt has some effect on the character of the peat. The peats chiefly derived from mosses that have grown in the full sunlight, have

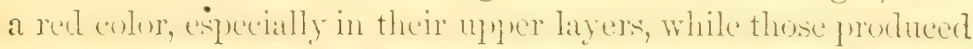
principally from grasses are often grayish in appearance, or are full of silvery fibres-the skeletons of the blades of grasses and sedges.

The accidental admixtures of soil often greatly affect the appearance and value of a peat, but on the whole it would appear that its quality is most influenced by the nature and degree of decomposition it has been subjected to.

The term muck is chiefly used among us to designate what is more correctly called peat. In proper usage, muck is a general term for manure of any sort, and if applied to peat should be qualified as swamp-muck.

Sonne intelligent firmer's call the surface layers of their swamps, which are loose and light in texture, swamp-mack, and to the bottom layers, which are more compact and often serviceable as fuel, they apply the term peat. This distinction is not very definite, but is convenient in many cases, and will be employed 
in this Peport as fur as practicable; although accorting to usage it is often necessary to use the words peat and muck synonymously.

\section{The Chemical Composition of Peat.}

Pure peat is derived from the decay of woody-fibre, which constitutes the organic basis of nearly all plants, and is essenlially the sane thing whether found in true wool or in grasses and mosses.

Like the regetation from which it is formed, it is for the most part combustille, and if free from accirlental admixtures of earthy matters, leaves but a few per cent. of ash when bưrned.

(a) The organic or combustible part of peat varies exceedingly in composition. It is in fact an indefinite mixture of several or perhaps of many bodies whose precise nature is little linown. These bodies have received the collective names humus and geine. In order to understand the general characters of Humus, as we shall designate the organic matters of peat, it is necessary to remind ourselves of the nature of the processes of decay, by which it is produced.

In a chemical sense, decay is strongly similar to combustion or burning. It is in fact a burning at low temperatures, a combusting gong on so slowly that there is no accumnlation of heat, and no exhibition of light. To go back one step further, both these processes are cases of oxydation. A piece of wood whether consumed in the fire, or allowed to decay in the soil, is finally lrowe to the same result. Its organic portion is disipgated in the form of invisible gases, its mineral matters remain behind as ashes or earth. It is the vital principle of the atmosphereoxygen gas, which is consumed in these changes, and which if it be supplied in sufficient quantity, bums, i. e., mintes with the carbon and the hydrogen of the wood, and converts them into carbonic acid and water.

When wood instead of being burned with full access of air is heated in close ressels or in conl-pits, with imperfect suply of oxyen, then its most casily combustihle prarts-those portions which give flane-are humt ofl, and charcoal is left-a substance that burns without flame. 
When wood or vergetable matters generally, instear of leing pernitted to moulder away in the free atmosphere, with just enough moisture and suficient warnth to promote complete decay, are liept muler water and thus nearly shut ofl" from the action of oxygen, * a sinilar buming out of the more combustible (oxyclable) matters of the wood takes place, and peat results, a substance, which like charcoal, lums without or with little flame, is highly inctestructible, and is richer in carbon than the wood from which it was formed.

In the formation of peat this removal of the more combustible parts of the wood cannot go on nearly to the degree it does in the preparation of charcoal, on accumet of the lower temperature, and the fir smaller sulply of air. With the changes in temperature, and with the vilrialble acess of air, are comnecterl the diflerences in the nature and relative quantity of the ingredients of peat. The larger share of the organic matters that may be separated from peat, possesses acid characters.

If peat be agitated, or better, boiled a short time with water, it is partly disolved. 'I'he quantity taken up by water valries from 1 to 17 per cent, and of this a variable portion is organie acids. The extract or solution in water has generally an annher or pale brown color, like the water of swamps or of forest streans, and the acids it contains are two in nmonber, and have received the names crenic and apocrenic acids.

In the water extract these acids are in general partly uncombined and fartly miterl to various lases, as lime, matgresia, oxyd of iron and alumina.

The great mass of the peat remaining after the treatnent with water, consists of one or several acids which are soluble in solutions of an allati, and math thus be removed from the remaining ingrextients. To exhibit these acids, the so-callerl humir: acicls,we boil the peat with a solution of carbonate of soda; a dark brown liquil is shortly obtained which contains the humic acids united with soda.

If now, any strong acil as sulphuric acid, is arderl in cxcess to the solution of humate of socta, the suda is tatien by the sul-

* Not entirely, for water dissolves a certain quantity of oxygen which supports the respiration of fishes. 
phuric acid, and the humic acids are separated, and sulsile as a black or brown sediment.

In most peats, after the extraction with water and carbonate of socka, there still remains a black resiche which is insoluble in alkalies and has been termed hunine. This suljstance is usually mixed with more or less undecomposed regretable matter or fibre, from which we know no means of separating it. It is not an acid, clse it would combine with alkalies. Its composition, however, does not differ much from that of the humic acils just mentioned.

Besides the bodies above named, a small amount of resinous matters exists in some, perhaps in all peats; occasionally too, a bituminous or pitchy matter has been found in them, hut these substanes are doubtless of no arrieultural significance whatever.

Such is a concise sketch of the organic or combustible ingredients of peat, and it is of suffeient fullness and aceuratey for our present purpose.*

(b) The mineral part of peat which remains as ashes when the organic matters are burned away is variable in quantity and composition. Usually a quantity of sand or soil is found in it, and not unfrequently constitutes its larger portion. Some peats leave on burning much carbonate of lime, the ash of others again is mostly oxyt of iron; silicic, sulphuric and phosphoric acids, magnesia, potash, sorla, almnina and chlorine, also occur in small quantities in the ash of all peats.

In some rare instances peats are found which are so impregnated with soluble sulphates of iron and alumina as to yield these salts to water in large yuantity, and sulphate of iron (green vitriol.) has actually been manufuctured from such peats, which have in consequence been characterized as vitriol peats.

(c) The nitrogen or potential ammonia of peats is an important ingredient, which is never absent, though its quantity varies from 1 to 5 per cent.

* The varieties of humic and ulmic acids, of humine and ulmine, described by Mulder and Herrmann are not noticed here, for the reasons that these chemists disarree as to their properties and existence, and they are of no agricultural importince. 
5. After this general statement of the composition of peat, we may proceed to notice: The characters that adapt it for agr $i$ cultural uses.

These characters are conreniently diseussed under two heads, viz:

(A.) Those which render it useful in improving the texture and other physical characters of the soil, and indirectly contribute to the nourishment of crops,-characters which constitute it an amendment to use the language of French agricultural writers; and,

(B.) Those which make it a direct fertilizer.

(A.) Considered as an amendment, the value of peat depends upon

I. Its remartable power of absorbing and retaining water, both as a liquid and as vapor:

II. Its power of absorbing ammonia:

III. Its action in modifying the decay of organic (animal and vegetable) bodies:

IV. Its effect in promoting the disintegration and solution of mineral matter's, (the stony matters of the soit): and

$V$. Its influence on the temperature of the soit.

The agricultural importance of these properties of peat is best illustrated by considering the faults of a certain class of soils.

Throughout Connecticut are found abundant examples of light, leachy, hungry soils, which consist of coarse sand or fine gravel; are surface-dry in a few hours after the heaviest rains, and in the summer drouths, are as dry as an ash-heap to a depth of several or many feet.

These soils are casy to work, are ready for the plow early in the spring, and if well manured give moderate crops in wet seasons. In a dry summer, however, they yield poorly, and at the best they require constant and very heavy manuring to keep them in heart.

Crops fail on these soils from two causes, viz. : want of moisture and want of food. Cultivated plants demand as an indispensable condition of their growth and perfection, to be hept within certain linits of wetness. Buckwheat will flourish best on dry soils, while cramberries and rice grow in swamps. The crops 
that are most profitable to us, wheat, oats, ete, require a medium degree of moisture, and in all cases it is desirable that the soil be equally protected from excess of water and from drouth. Soils must be thus situated either naturally, or as the result of improvement, before any steadily good results can be obtained in their cultivation.

In wet seasous these light soils are tolerably productive if well manured. It is then plain that if we could add any thing to them which would retain the moisture of dews and rains in spite of the summer-heats, our crops would be uniformly fair, provided the supply of manure be kept up.

But why is it that light soils need more manure than loamy or heavy lands? We answer-hecause, in the first place, the mains which quickly descend through the open soil, wash down out of the reach of vegetation the soluble fertilizing matters, and in the second place, from the porosity of the soil the air has too great access, so that the vegetable and animal matters of manures decay too rapidly, their volatile portions, ammonia and carbonic acid, cseape into the atmosphere, and are in measure lost to the crops. From these combined causes we find that a heavy dressing of well-rotted stable manure almost, if not quite entirely, disappears from such soils in one season, so that another year the field requires a renewed application; while on loany soils the same amount of manure would have lasted several years, and produced each year a better effect.

We want then to anend light srils by incorporating with them something that prevents the rains from leaching through them too rapidly, and, that at the sane time, renders them less open to the air, or absorbs and retains for the use of crops the volatile products of the decay of manures.

Now for these purposes vegetable matter of some sort, is the best and almost the only amendment that can be economically employed. In many cases a good peat or muck is the best form of this material, that lies at the farmer's command.

I. Its absorbent power for liquid water is well known to every farmer who has thrown it up in a pile to season for use. It holds the water like a sponge, and after exposure for a whole summer is still distinctly moist to the feel. 
Its whorbunt power for verpor of water is so great that more than once it has lappened in Gernamy, that barns or close sherls filled with dried peat, such as is used for fuel, have been burst hy the swelling of the peat in dimp weather, occasioned by the absorption of moisture from the air. This power is further shown by the fact that when peat has been kept all summer long in a dry room, thinly sureal out to the air, and has become like dry snuff to the fecl, it still contains 10, 20, 30, and in some of the specimens I have examined, even 40 per cent. of water. To dry a peat thoronghly, it recuires to be exposed for some time to the temperature of boiling water. It is thus plain that no summer heats can dry up a soil which has had a good dressing of this material, for on the one haml, it soaks up and holds the rains that fitl upon it, and on the other, it absorts the vapor of water out of the atmosphere whenever it is moist, as at night and in cloudy weather.

II. Absorbent power for ammonia.

All soils that descrve to be called fertile, have the property of absorfing and retaining anmonia and the volatile matters which escape from formenting mammes, but light and coarse suils may be deficient in this power. Ilere again in respecet to its atsorptive power for ammonia, peat comes to our aid.

TVe may easily show hy clirect experiment that peat absorbs and combines with ammonia.

I took for example a weighed quantity of the peat No. 29 from the New Inven Bearer Pond, the specimen fumished me by Chauncey Gondyear Esil., and poured upon it a known quantity of clijutesolution of ammonia, and agitated the two together for 18 hours. I then distilled ofl' at a boiling heat the mabsorbed ammonia and determined its quantity. 'This anount subtracted from that of the ammonia originally employed, gave the quantity of ammonia absorbed and retained by the peat at the temperature of boiling water.

The peat retained ammonia to the anount of .95 of one per cent.

I made another trial with carbonate of ammonia, adding excess of solution of this salt to a quantity of peat, and exposing it to the heat of boiling water, until no smell of ammonia was 
perceptible. The entire ammonia in the peat was then determined, and it was found that the dry peat which originally gave 2.4 per"cent. of ammonia (potential,) now gave 3.7 per cent. The absorbed quantity was thus 1.3 per cent.

This last experiment most nearly represents the true power of absorption, because in fermenting manures ammonia mostly occurs in the form of carbonate, and this is more largely retained than free ammonia, on aceount of its power of decomposing the humate of lime, forming with it carbonate of lime and humate of ammonia.

The absorbent power of peat for ammonia is beantifully shown by the analyses of three specimens sent me by Edwin Iloyt, Escl., of New Canan. The first of these (No. 22,) is the swamp muck he employs. It contains in the dry state but .58 per cent. of ammonia (potential.) The second sample (No. 23,) is the sane muck that hats lain moder the flooring of the borse stables, and has been in this way partially saturated with urine. It contains 1.15 per cent. of ammonia. The third sample is, finally, the sane muck composted with white-fish. It contains 1.31 per cent. of ammonia.

The quintities of ammonia thus alborbed, both in the laboratory and field experiments is small-from .7 to 1.3 per cent. The alsurytion is without dould almost entirely che to the organic matter of the peats, and in all the specimens on which these trials were marle, the per centage of inorganic matter is large. The results therefore become a better expression of the power of peret in general to absorb ammonia, if we reckon them on the organic matter alone. Calculated in this way, the organic matter of the Beaver Pond peat (which constitutes but 68 per cent. of the dry peat) absorbs 1.4 per cent. of free ammonia and 1.9 per cent. of ammonia out of the carbonate of ammonia. In the sane mamer we find that the organic matter of Hoyt's muck has absorbed 2.35 per cent. of ammonia.

We ofserve that the peat which is, naturally, richest in ammonia, absorbs less, relatively, than that which is poor in this substance.

When we consider how small an ingredient of most manures ammonia is, viz.: less than one per cent. in case of stable ma- 
nure, and how little of it in the shane of grano for instance is usually applied to crops-not more than 40 to $60 \mathrm{lbs}$. to the acre. (The msual dresings with gruano are from 250 to 400 1hs. per acre, and ammonia averages but 15 per cent. of the guann) we at once perceive that an absorptive porrer of two or even one per cent. is adequate for every agricultural purpose.

III. The influence of prat in modifying the decay of oryanic matters deserves notice.

Peat itself in its native bed or more properly the water which impregnates it and is charged with its soluhle principles has a remarkable anti-septic or preservative power. Many instances are on record of the bodies of animals heing found in a quite fresh and well-preserved state in peat hoge, but when leat is removed from the swamp, and so far dried as to be convenient for agricultural use, it does not aplear to exert this preservative quality to the same degree or even in the same kind.

Buried in a peat bog or immersed in peat water, animal matters are absolutely prevented from decay, or decay only with extreme slowness; but if covered with peat that is no longer quite saturated with water, their decay is indeed checked in rapirlity, and the noisome ortors evolved from putrifying animal substances are not pereciver, still decay does go on, and in warm weather, no very long time is needed to complete the process.

The effect of peat in modifying decay is analogous to that of charcoal, and is probably connected with its extreme porsity. If a piece of flesh be exposed to the air churing summer weather it shortly putrifies and acouires an intolemalile orlor. If it he now repeatedly rubbed with charcoal dust, and hept in it for some time, the taint which only resides on the surface, may be completely removed, and the sweetness of the meat restored, or if the fresh meat be surrounded with a layer of chatcoal poweler of a certain thickness, it will pass the hottest weather without manifesting the ustual odor of putrefying bodies.

It does however waste away, and in time, completely disappears. It decays, but does not putrefy, it exhales, not the disgusting gases which reveal the neighlorhorl of carrion, but the pungent odur of hartshom. The gases which escape are the 
same that would result if the flesh were perfectly burnt up in a full supply of air, viz.: vapor of water, carbonic acid and ammonia.

If we attend carefully to the nature of decay thus modified by chareoal dust, we find that it is complete, rapid but regular, and unaccompanied by unhealthful or disagrecalle exhalations.

Peat has all the effects of charcoal with this advantage, that it permanently retains the anmonia formed in decay, which contrary to the generally received opinion charcoal does not.

From its absorptive power for water, it maintains a lower temperature under the sun's heat than dry charcoal or at light soil, and this circumstance protracts and regulates the process of decay in a highly beneficial mamer, so that if a muck-elressed soil receive an application of stable manure, fish, or guano,-in the first place, the ammonia and other volitile matters camot be formed so rapidly as in the mulressed soil, because the soil is moister and decay is thereby hindered,- - and in the second place, when formed they cannot eseape from the soil, but are fixed in it by the peculiar absorptive power of the vegetable acids of muck.

These properties of peat will be again recurred to, when we come to discuss its uses in composting.

\section{Peat promotes the disintegration of the soit.}

Every soil is a storehouse of food for erops; but the stores it contains are only partly available for immediate use. In fict, by fit the larger share is locked up, as it were, in insoluble combinations, and by a very slow and gradual change does it hecome accessible to the plant. This change is chiefly brought about by the united action of water and carbonic acid gas, or rather of water holding this gas in solution. Nearly all the rocks and minerals out of which fertile soils are formed,-which therefore contain those inorganic matters that are essential to vegetable growth, - though very slowly acted on by pure water, are decomposed and dissolved to a much greater extent, to an extent, indeed, commensurate with the wants of vegetation, by water charged with carbonic acid gas.

The only abundant source of carbonic acid in the soit, is decaying vegetable matter. 
ITungry, leachy soils, from their deficiency of vegetable matter and of moisture do not adequately yield their own native resomeres to the supprort of crops, because the conditions for converting their fixed into floating capital are wanting. Such soils dressed with peat or green manured, at onee acquire the power of retaining water, and keep that water overcharged with carbonic acid, thus not only the extraneous manures which the famer applies atre fully econonized; but the soil" becone's more proluctive from its own stores of fertility which now begin to be unlocked and available.

It is probable, nay almost certain, that the acids of peat, exert a purerfinl fecomposing, and ultimately solvent effect on the minerals of the soil; but on this point we have no precise information, and must therefore be content merely to allute to the probalility, which is sustained by the fact that the acids crenic, apocenic and humie, though often partly uncombined, are never wholly so, but usually occur united in part to various bases, viz. : lime, magnesia, ammonia, potash, alumina and oxyd of iron.

V. The influence of pert on the temperature of light soils dressed with it may often be of considerable practical importance. A light dry soil is sulject to great variations of temperature, and rapinly follows the changes of the atmosphere from cold to hot, and from hot to cold. In the summer noon a sandy soil becomes so warm as to be hardly endurable to the feel, and again it is on such soils that the earliest frosts take effect. If a soil thus subject to extremes of temperature have a dressing of peat, it will on the one hand not become so warm in the hot diy, and on the other ham it will not erol so rapilly, nor so much in the night; its temperiture will be rendered more uniform, and on the whole more conducive to the welfare of vegetation. This regulative effect on temperature is partly due to the stores of water held by peat. In a hot day this water is constantly evaporating, and this, as all know is a corling process. At night the peat absorbs vapor of water from the air, and condenses it within its pores, this condensation is again accompanied with the evolution of heat. 


\section{1}

It appears to be a general, though not invariable fact that dark colored srits, other things being equal, are constantly the warmest, or at any rate maintain the temperature most fitvorable to vegetation. It has been repeatedly observed that on lightcoloret soils plants mature more rapilly if the soil be thinly covererl with a coating of some black substance. Thus Lampadius, Profersor in the School of Mines at Friberg a town situated in a mountainous part of Saxony, found that he conld ripen melons, even in the coolest summers, by strewing a coating of coal-dust an inch deep over the surface of the soil. In some of the vineyards of the Rhine, the powder of a black slate is employed to hasten the ripening of the grape.

Girardin, an eminent French agriculturist in a series of experinents on the cultivation of potates found that the time of their ripening varied eight to fourteen days, according to the character of the soil. He found, on the 25th of August, in a very dark soil made so by the presence of much humus or decaying vegetable matter, twenty-six varieties ripe; in sandy soil but twenty, in clay nineteen, and in a white lime soil only sixteen.

It cannot be doubted then, that the effect of dressing a light sandy or gravelly soil with peat, or otherwise enriching it in vegetable matter, is to render it warmer, in the sense in which that word is usually applied to soils. The upward range of the thermometer may not be increased, but the uniform warmth so salutary to our most valued crops is thereby secured.

(B.) The ingredients and qualities of peat which make it $a$ direct fertitizer next come under discussion. We shall notice:

I. The organic matters, incluting nitrogen or ammonia.

II. The inorganic or mineral ingredients; and

III. Institute a comparison between peat and stable manure.

In division $I$. we have to consider:

1st. The organic matters as clirect food to plants.

Twenty years ago, when Chemistry and Tegetal)le-Physiology began to be applied to A grienlture, the opinion was fimmly held among scientific men, that the organic parts of humus-by which we understand decayed regetable matter, such as is found to a greater or less extent in all gooul soils, and abounds in many 
fertile ones, such as constitutes the leaf-mould of forests, such as is proluced in the fermenting of stahle manure, and that firms the principlal part of swamp-muck and peat,-are the true nomrishment of vegetation, at any rate of the higher orders of plants, those which supply food to man and to domestic animals.

In 1810, Liebig, in his celebrated and admirable treatise on the " $\Lambda_{1}$ plications of Chemistry to Agriculture and Physiology," gave as his opinion that these organic bodies do not nourish vegetation except by the products of their decaly. Ile asecrted that they cannot enter the plant directly, but that the water, carbmic acid and anmonia ressulting from their decay, are the sulstances actually imbibed by plants, and from these alone is built up the organic or combustible part of vegetation.

To this day there is a division of opinion among scientific men on this subject, some ariopting the views of Lieling other's adhering essentially to the old doctrines. Many experiments and trials have been made with a view to settling this question, but such are the difficulties of a direct solution that scarcely definite results either way have been obtained.

On the one hand, Liebig and those who adopt his doctrines, have denonstrated that these organic matter's are not at all essential to the growth of agrieultural plants, and hate shown that they can constitute but a small part of the actual food of vegetation taken in the aggregate.

On the other hand, there is no satisfactory evidence that the soluble organic matters of the suil and of peat, are not actually apluropriated by, and, so far as they go, are not directly serviceable as food to plants.

Be this as it inay, practice has abundantly demonstrited the ralue of humus as an ingredient of the soil, and if not directly, yet inclirectly, it fumishes the material out of which plints build up their parts.

2d. The organic matters of peat as indirect food to plants. Very nearly one-lialf by weight of our common crols when perfectly dry, consists of carbon. The substance which supplies this element to plants is the gas, carbonic acid. Plants derive this gats mostly from the atmosphere absorbing it by nucans of their leaves. But the free atmosphere, at only a little space 
above the soil, contains but 1-25,000th of its bulk of this gas, whereas plants flomrish in air containing a larger quantity, and in fact their other wants being supplied, they grow better as the quantity is increased to $1-12$ th the bulk of the air. These considerations make sufficiently obvious how important it is that the soil have in itself a constant and abundant source of carbonic acid gas. As before said, organic matter in a state of decay, is the single matcrial which the farmer can incorporate with his soil in orker to make it a supply of this most indispensable form of plant-food.

The nitionfen of crops, an ingredient that characterizes those vegetalle sulstances which have the highest ralue as food for man, is naturally supplied to plints in the form of ammonia, and we are sufficiently aware of the great fertilizing value of this substance and of its commereial worth, in the shape of guano, \&e., Ee., for agricultural purposes, a worth depending upon the fact of its comparative scarcity.

It has long been known that peat contains a considerable quantity of nitrogen, and the average amount in the 38 specimens I have subnitted to analysis, including peats and swamp mucks of all grades of quality, is equivalent to $1 \frac{8}{4}$ per cent. of ammonia on the air-tried substance, or more than twiee as much as exists in the best stable or yard manure. In several peats the anomit is as ligh as 3 per cent., and in one case 3.1 per cent. were found.

There is a difference of opinion among chemists as to the state in which this nitrogen exists in peat and humus. Some assume it to be ammonia held in a peculiar state of combination with the hmmic and other acils, so that the ordinary means fail to separate it, and this is the most commonly received view. Certain it is that we cannot get nuch actual ammonia from a peat by a treatment which will displace this body perfectly from a guano or other ordinary manure. In two trials but about 1 per cent. was obtained.

In orker then to estimate the availability of the nitrogen of peat, we must fall back ou general principles, and practical experience.

We know from the exact demonstrations of chemical science 
that when organic bodies decay their elements enter into new and more stable combinations and that their nitrogen appears in the form of ammonia. If bodies very rich in nitrogen underge a rapir putrefutive decay, a purtion of the nitrugen separates as such and escapes combination, it is probable however that highly porous substances containing hut a few perent. of nitrogen, yield all or nearly all their nitrogen in the shape of ammonia, or, what has the sane agricultural significance, in that of nitric acid.

'The conclusion then is entirely warranter that the nitrogen of peat becomes almost completely avatilathle, as the prat decalys in the soil. This conclusion is stipported by the fact attested by practical men, that certain varieties of swamp-muck are equal to stalle numure in their fertilizing effects, although inferior to the latter in respect to the ruantity of substances msmally held to be autive fertilizers which they contain, anmonia (nitrogen) alone excepted.

3d. The decay of peat itself offers some peculiarities that are worthy of notice in this comnection. It is more gradual and regular in decay than the vegetable matters of stahle dung, or than that furnished by turning meler sod or green (wen)s. It is thus a more stearly and lasting benefit, expecially in light soils, ont of which ordinary regetable manures disappear too rapidly. The decay of peat aplears to proceed throngh a regular series of steps. In the suil, especially in contact with soluble alkaline bodies as ammonia and lime, there is a progressive conversiun of the insoluble or less soluble into soluble compounds. 'Thus the inert matters that resist the immediate solvent power of allialies, ahsorb oxygen from the air and form the humic acid soluble in alliaties; the humic acits also undergo an analogons change, and pass into crenic acid, and this body is converted into apocrenic acid. The two latter are soluble in water, and, in the porous wisl, they are rapidly brought to the end-result of decay, viz.: water, carbonic acid and ammonia.

Great differences must be observed, however, in the rapidity with which these changes take place. Doubtless they go on most slowly in case of the black compact peats, and perhaps many of the lighter and more porous samples of swamp-much I 
have examined would decay nearly as fast as unaltered vegetable matter.

It might appear from the above statement that the effect of exposing peat to the air as is done when it is incorporated with the soil, would be to increase relatively the amount of soluble organic matters; but the fact in, that they are actually diminished and so becanse the oxydation and consequent removal of these soluble matters (crenic and apocrenic acids) procecd more rapidly than they can be produced from the less solutble humic acid of the peat.

II. With regard to the inorganic matters of peat consiclered as food to plants, it is obvious that leaving out of the account for the present, some exceptional eases, they are useful as fir as they go.

In the ashes of peats, we almost always find small quanties of sulplate of lime, magnesia and phospluoric acid. Potash and soda too, are often present though never to any considerable anount. Carlomate and sulphate of lime are large ingredients of the ashes of abont one-hall the peats I have examined. The ashes of the other half are largely mixcel with sand and soil, but in nost cases also contain considerable sulphate and often carbonate of lime and magnesia.

In one swamp-muck, No. 4, from Messrs. Pond and Miles, Milford, there was found but two per cent. of ash, at least one half of which was sand, and the remainder sulphate of lime, (gy)sum). Tn other samples 20, 30, 50 and even 60 per cent. remained after burning off the organic matter. In these cases the ash is chiefly sand. The amount of ash found in those peats which were most free from sand ranges from 4 to 9 per cent. Probably the average per centage of true ash, viz. : that derived from the organic matters themselves not including sand and aceidental ingredients, is not far from 5 per cent.

I regret that time has not allowed me to make more complete craminations of the ashes of all the peats that have come under analysis. What I have been able to do is with two exceptions simply to ascertain the presence, and in a rough way the comparative abundance of lime, magnesia, iron, sulphuric and earbonic acils. I am not entirely satisfled with the accuracy of 
the inferenees which I have heen obliged to draw from the necessarily superficial ash-examinations. But to carry out full culumtitative analyses of the ashes of $3 \pm$ peats and muches, is an innmense amount of labor, and could not be hoped to prove practically remmerative; because it must be with the analysen of peats as it is with that of soils, they may be useful to estahlish a general fict, but cannot be relied upon implicitly in inclividual cases unless they are strongly marked and peculiar.

I give here a statement of the composition of the ash of two peats, the only ones I have had time to examine fully. They doubtless give a fair irlea of the inorganic ingrerlients of the majority of the peats submitted to trial, siml not being talien into account.

Analysis of Peat ashes.

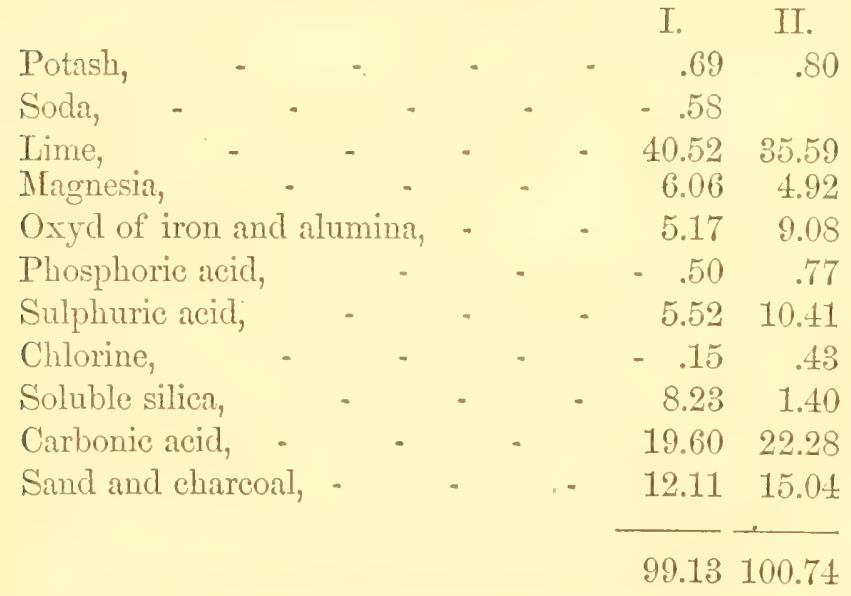

I. Was furnished me by Mr. Daniel Buck, Jr., of Poqnonock, and comes from a peat, (No.12,) which he employs as finel. For the elaborate analysis I an indelited to Mr. Geo. F. Barker of Charleston, Mass, a graduate of the Tale Scientifie Schuxl.

II. (from peat No. 9,) was sent me by Mr. J. H. Stanwood of Colebronk. MLr. O. C. Sparrow of Colchester, Ct., a graduate of the Yale Scientific School, executed the analysis. 
The furtilizing constituents of both these ashes consist almost entirely of carbonate and sulphate of lime, and carbonate of magnesid. Phosphoric acid and potash are present, but in small quantity. Nevertheless, as will be shown presently, the ingredients of these ashes must be considered as largely contributing to the fertilizing effect of the peats from which they were derived.

In a few instances, there is an almost entire want of useful ash ingredients, for example, in Virgin's mucks, Nos. 18, 19 and 20; and Ifoyt's muck, No. 22. In these simples, besides saud and oxyd of iron, there are ouly very minute quantities of lime and magnesia to be found.

\section{Comparison of Peat with Stable Manure.}

The frtilizing value of peat is best unkerstood by comparing it with smne standard manure. Stuble manure is obviously that fertilizer whose effects are most universally observed and ap. preciated, and by setting analyses of the two side by side, we may see at a glance, what are the excellencies and what the deficiencies of peat. In order rightly to estimate the worth of those ingredients which occur in but small per centage in peat, we must remember that it like stable manure, may be, and usually should be applied in large doses, so that in fact the smallest mererlients come upon an acre in considerable quantity.

In making our comparison we will take the analysis of Peat No. 12, (Mrr. Buck's, and une executed by Dr. Toelcker of the Royal Agrieultural College of England, on wellf-ermenterl farm yard manure of best quality, from the mixed dung of horses, cows and sheep.

The peat is understood to be simply air dried, yet perhaps dryer than it would become if dug and left heaped over one summer; while the yard manure is moist from the heap, and of the usual average dryness. 
No. I, is the complete analysis of Peat; No. II, of well rotted stable manure:

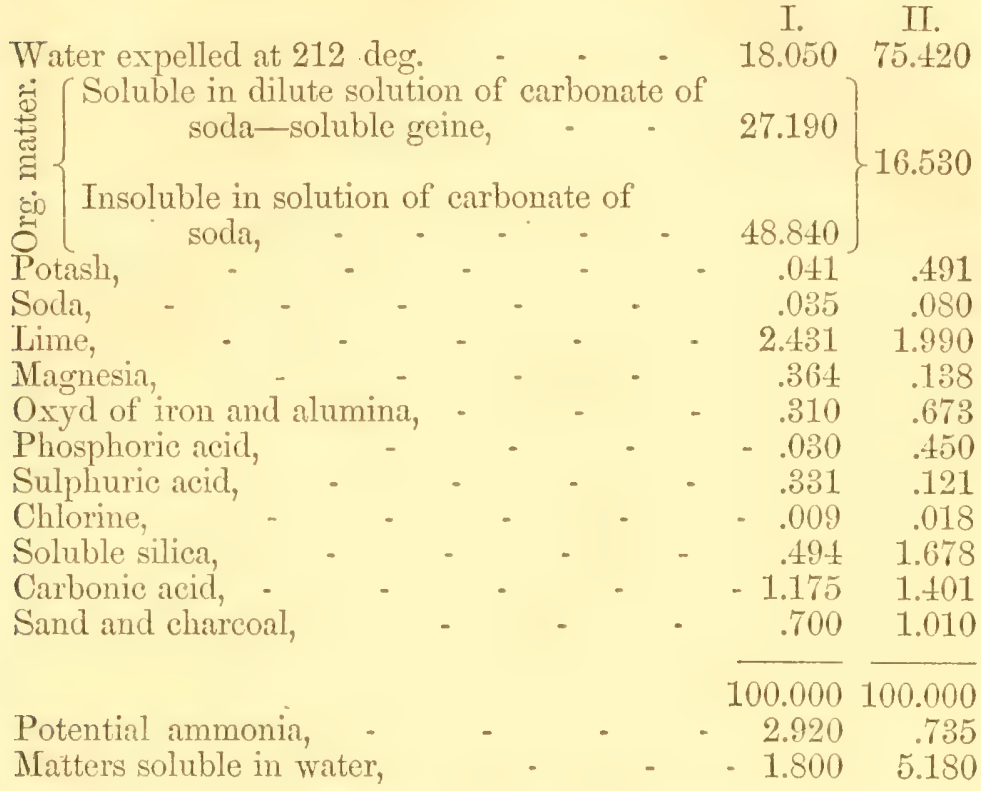

In stulying the above analyses we olserve 1st, that this peat contains five times as much organic matter, and four times as much potential ammonia as the yard-manure. $2 d$. It contains more lime, magnesia and sulphurie acid than yart-manure. $3 \mathrm{~d}$. It is deferint in potash and phosploric acid. We see thus that peat and yirl-manure are excellently adapted to go together; each supplies the deficiencies of the other.

We see also from this that peat requires the addition of phosflucter, (in the shape of hone-dust, or phosphatic guane, enel of potash, (as unleached wood ashes,) in order to make it precisely equal in composition to stable manure.

But there are some other questions to be discussed, for two manures may reveal to the chemist the same composition and yet be very unlike in their fertilizing effects, because their conditions are mlike, beeause they differ in their degrees of solubility or availability.

Now, as before insisted upon, it is true in general, that peat is 
much more slow of decomposition than yard-manure, and this fact which is an adrantage in an amendment is a diwarlvimtage in a fertilizer. Though there may be some peats, or rather muclis, which are energetic and rapid in their action, it secms that the most of them need to be applied in larger quantities than stithle manure in order to prodnce equal fertilizing effects.

Another matter that may be noticed here is the apparent contracliction between Chemistry, which says that peat is not equal to stable manure as a fertilizer, and practice, which in many cases affirms that it is equal to our standard manure.

In the first place, the chenical conclusion is a general one and does not apply to inclivichal peats, which in a few instances may be superior to yard-manure. If I mistake not, the practical judgment also is, that in general yard-manure is the best.

To go to the individual cases, $2 d$, a peat in which ammonia exists, to 3 or 4 times the amount found in stable or yard manure, may for a few seasons produce better results than the latter, nnerely on aceount of the presence of this one ingredient, it may in fact, for the soil and crop to which it is applied, be a better fertilizer thin yard namure, because the substance ammonia is most needed in that suil, and yet for the generality of soils, or in the long run, it may prove to be an inferior fertilizer.

Again, 3d, the melioration of the physical qualities of a soil, the anmhenent of its dryness and excessive porosity, by means of peat maty be more effective for agricultural purposes, than the application of tenfold as much fertilizing, i. e. plant-feerling materials; in the same way that the mere draining of an overmoist sill often malies it nore productive than do the heaviest manurings.

6. On the characters of Peat that are detrimental, or that may sometimes need correction before it is agriculturally useful.

1st. Bacl effects on heavy soils.

TTe have latid much stress on the amending qualities of peat, when applied to dry and leachy soils, which by its use are rendered nnore retentive of moisture and manure. Now these properties which it would seem are just adapted to renovate very light laml, under certain ciremstances may become diwarlvantagcous on heavier soils. On clays no application is needed to 
retain moisture. They are already too wet as a general thing. Unless a soil be open, some varieties of muck, (the denser peat. like kimls) are too slow in decay, and therefore do not yichl up their stores of plant-food with sufficient rapidity.

Put into the soil it lasts much longer than stubble, or green crops plowed in, ox than long manure. If buried too deeply, or put into a heavy soil, especially if in large quantity, it does not deciy, but remains wet, amel tends to make a bog of the field itself.

In soils that are rather heavy, it is therefore best to compost the muck with some rapidly fermenting manure. We thus get a compound which is fuicker thim muck, and slower than stathe monure, ete., and is therefore better adingted to the wants of the soil than either of these would be alone.

Here it will be seen that much depends on the character of the muck itself. If light, spongy, brown or gray in color, and casily drivel, it ma be usert alone with advantage on loany suls, whereas if dense, black, and coherent like some of the Irish peatr, a block of which when dry, will make a voyage across the Atlantic in the boiler of a steamship without losing its form-it would most likely be a poor amendment on a soil which has much tendency to becone compact, and therefore dows not readily free itself from excess of water.

A clay soil if thorough-drained and deeply plowed, may be ronderfully improved by even a heavy dressing of muck, as then, the water being let ofit, the muck can exert 10 detrincental action, but operates as effectually to loosen a too heavy soil as in case of sand it makes an over-porous soil compact or retentive. A clay may be made friable if well dratined by incorporating with it any sulstance as lime, sancl, long manure or muck which interpusine itself betwem, the clayey particles, prevents their adhering together.

2d. Noxious ingredients.

(a) Vitriol peat. Occasionally a peat is met with which is injurious if applied in the fresh state to crops, from its containing some sutstance which exerts a poisonous action on regetation. So fur as I can decide from my inquiries, the only detrinental ingredient that oceurs in peat is sulphate of protoxycl of iron, 
the same body that is popularly known under the names copperas and green-vitriol. This body is usually formed from sulphuret of iron, which is thus indirectly noxious.

I have found this substance ready-formed in large quantity in but one of the peats that I have examined, viz.: that sent me by Mr. Perrin Scarborough* of Brooklyn, Ct., (No. 17.) This remarkable peat dissolves in water to the extent of 15 per cent., and this soluble portion although containing some organie matter and sulphate of lime, consists in great part of green-vitriol.

Green-vitriol in minute closes is not hurtful, but rather beneficial to vegetation, but in larger quantity it is fatally destructive.

In the silt marsh mud sent me by the Rev. Wm. Clift of Stonincton, (No. 33,) there is likewise sulphate of protoxyd of iron in considerable quantity.

This noxious substance likewise oceurs in small amount in swamp muck (No. 22,) from E. Hoyt, Esq., New Canaan, and in hardly appreciable quantity in several others.

In a sample of the peat from the farm of Albert Day, Esq., Brooklyn, which is reputed detrimental, I have not been able to find any traces of this substance.

Besiles green-vitriol, it is possible that certain organie salts of protoryd of iron, may be deleterious, but there is not much evidence to support this idea.

(b) The acidity of Peats. Many writers have asserted that peat and muck possess a hurtful "acidity" which must be corrected before they can be usefully employed. It is indeed a fact that peat consists largely of acids, but, except perhaps in the vitriol peats, (those containing copperas,) they are so insoluble, or if soluthe, are so quickly modified by the absorption of oxygen, that they do not exhibit any "acility" that can be deleterious to vegetation. It is advised to neutralize this supposed acidity by lime or some other alkali before using peat as a fertilizer or amendment, and there is great use in such mixtures of peat with alkaline mitters, as we shall presently notice under the head of com-

* Erroneously said to be from Mr. Plilip Scarborongh, in an article in the IIomestead, Vol. 3, p. 540. 
posts, but $T$ know of no single fact, which warrants the iclea that the organic matters of any peat have any acidity that is hurtful to vegetation.

(c) Resinous matlers are mentioned by various writers as injurious ingredients of peat, but I find no evidence that this notion is well-formeded. The peat or muck formed from the decay of resinoms wood and leaves does not appear to be injurious, and the amount of resin in peat is exceedingly small.

3d. Deficient Ingredients. This topic has been alluded to alrearly, and we need only mention here that potash and phosphorie acid are in general the boties which must be atded to peat to milite a durably eflicient firtilizer. Sometimes, too, lime is wanting. 'To supply these ingredients; for potash, unl ached wood aslues or New Jersey Green Sand may be employed f for phospluric acid, bone-lust or phosphatic guano; for line, marl or leached ashes.

7. The Preparation of Peat for Agricultural Use.

(a) Excavation. As to the time and manner of getting out peat, the circumstances of each case must determine. I only venture here to offer a few hints on this subject, which belongs so exclusively to the farm. The month of August is generally the appropriate time for throwing up peat, as then the swanps are usually most free from water, aud most accessible to men and teans; but peat is often dug to best advantage in the winter, not only on account of the cheapmess of labor, and from there being less hurry with other matters on the farm at that season; but also beciuse the freezing and thawing of the peat that is thrown out, must probably atid to disintegrate it and prepare it for use.

A correspondent of the IIomestend, signing himself "Commentator," has given directions for gotting out peat that are well worth the attention of farmers. He says:

"The composting of muck and peat, with our stable and barnyard matnures, is surely clestined to becone one of the most im. portant items in farm managenent throughout all the older States at least. One of the difficulties which lie in the way, is the first removal of the muck from its low and generally watery bed; to ficilitite this, in many locations, it is less expensive to 
dry it before carting, by beginning an excavation at the border of the marsh in Autumn, sufficiently wicle for a cart path, throwing the muck out upon the surface on each side, and on a floor of boards or planks, to prevent it from absorting moisure from the wet ground beneath; this broad ditch to be carried a suffcient length and depth to obtain the requisite quantity of muck. Thus thrown out, the two piles are now in a convenient form to be covered with boards, which if properly done and liept covered till thesucceeding Autumn, the muck will be fonnt to be dry and light, and in some cases may be carted awray on the surface, or it may be best to let it remain a few months longer until the bottom of the ditch has become suffeiently frozen to bear a team, it can then be more easily loaded upon a sled or sleigh, and drawn to the yards and barn. In other localities, and where large quantities are wanted, and it lies deep, a sort of woolen railrual and inclined plane can be constructed by means of a plank track for the wheels of the cart to run upon, the team walking between these planks, and if the velicle is inclined to 'run off the track', it may usually be prevented by scantlings, say four inches thick, nailed upon one of the tracks on each side of the place where the wheel should run; two or more teams and carts may now be employed, returning into the excavation outside of this track. As the work progresses the track can be extended at both ends, and by continuing or increasing the inclination at the upper end a large and high. pile may be made, and if kept dry will answer for years for composting, and can be easily drawn to the barn at any time."

(b) Exposure or seasoning of peat. In most cases the chief or only use of exposing the thrown up peat to the action of the air and weather during several months or a whole year, is to rid it of the great amount of water which adheres to it, and thus to reduce its bulk and weight previous to cartage.

The general effect of exposure as proved further on by my analyses, is to reduce the amount of matter soluble in water, and cause peats to approach in this respect a fertile soil, so that insteud of eontaining 2.4 or even 6 per cent. of substances soluble in water, as at first, they are brought to contain but one-half these amounts or even less. This change, however, goes on so 
rapidly after peat is mingled with the soil, that previousexposure is rurly newsary, and most peats may be used perfictly fresh.

When a peat contains sulphate of iron, or, if such a case be possible, soluble organic salts of iron, to an injurious extent, these may be converted into other insoluble and innocuous bodies, lu a suflieient exprosure to the air. Sulphate of protoxyd of iron is thus changed into sulphate of peroxyd of iron, which is sainl to exert no hurtfin efleret on vegetation, while the soluble organic bodies of peat are oxydized and either converted into carbonic acid gas, carbonate of ammonia and water, or else made insoluble.

It is not probable, however, that merely throwing up a vitriol peat into heaps and exposing it thus imperfectly to the atmosphere, is sufficiont to correct its bad qualities. Such peats need the addition of some alkaline body, as ammonia, lime, or potash to render them salutary fertilizers.

(c) And this brings us to the sulject of composting with muct or peat, which appears to be the best means of taking full advantage of all the good qualities of muck, and of obviating or neutralizing the ill results that might follow the use of some raw mucks, cither from a peculiarity in their composition, (soluble organic compounds of iron, sulphate of protoxyd of iron,) or from too great indestructibility.

The ehemical changes (oxydation of iron and organic acids, which prepare the inert or even hurtful ingredients of peat to minister to the sulpert of vegetation, take place nosit rapilly in presence of an allatine body.

The alkili may be ammonie coming from the decomposition of animal matters, or time, potash or soda.

A great variety of matters may of course be employed for making or mixing with muck composts, but there are only a few which allow of extensive and economical use, and our notice will be confined to these.

First of all, the composting of muck with stable manure deserves attention. Its advantages may be summed up in two statements.

1st. It is an easy and perfect method of composting all manures, crin those kinds most liable to luss by formentation, as horse-dung; and, 
2 . It develops the inert fertilizing qualities of the muck itself.

Without attempting any explanation of the changes undergone by a muck and manure compost, further than to say that the fermentation which begins in the manure extends to and involves the muck, reducing the whole to nearly, if not exactly, the contition of well-rotted dung, and that in this process the muck effectually prevents the loss of ammonia,-I may appropriately give the practical experience of farmers who have proved in the most conclusive manner how profitable it is to devote a good deal of time and care to the preparation of this kind of compost.

\section{Preparation of Composts.}

To a given quantity of stable manure, two or three times as much weathered or seasonerl muck by bulk may be usut. The manure may either be removed from the stables, and daily mixed with the appropriate amount of muck, by shoveling the two together, at the heap, out of doors; or as some excellent farmers prefer, a trench, water tight, four inches deep and twenty inches wille, is constructed in the stable floor, immediately belint the cattle, and every morning a bushel-basketful of muck is put behind each animal. In this way the urine is perfectly absorbed by the muck, while the warmth of the freshly voided excrements so ficilitates the fermentative process, that, aceorling to MIr. F. ILolbrook, of Brattleboro, Tt., who I believe first mployed and described this method, much more muck can thus be well jrepared for use in the Spring, than by any of the ordinary modes of composting. When the dung and muck are remored from the stable, they should be well intermixed, and as fist as the compost is prepared, it should be put into a compact heap), and covered with a layer of muck several inches thick. It will then hardly require any shelter if used in the Spring.

On the farn of Mr. Pond, of Milford, Conn., I have seen a large pile of this compost, and have witnessed its effect as applied by that gentleman to a ficld of sixteen acres of fine gravelly or coarse sandy soil, which, from having a light color and excessive porosity, had become dark, unctuous, aud retentive of moisture, so that during the drouth of 1856 , the crops on 
this field were good and continual to flomrish, while on the contiguous land they were dried up and nearly ruined.

By reference to the Transactions of the Connecticnt State Agricultural Socicty for 1857 , it will beseen in the very interesting report of the committee on firms and reclitined lands, that on the firms which received the high premiuns, and the must honorable mention, composts of muck and stable maume are largely employed.

Messrs. Stephen Hoyt \& Sons of New Canaan, Mr. Samuld Prentice of Greenville, Mr. Philip Scarburough of Brooklyn, and Mr. Elisha Dickeman of Orange, near New IIaren, have used this compost with the most decided advantage, and doubtless all these gentlemen would concur in the opinion of many other excellent farmers, viz.: That a well made compost of two loads of muck and one of stable manure is equal to three loads of the manure itself.

This opinion is so well substantiated that we need not hesitate to pronounce it a fact, and if a fact, it is one which deserves to be painted in bold letters on every barn-door in Connecticut.

In the vicinity of cities, muck is often composted to great actrentuge rith might soil. The Lielig Manufacturing Conniany's Poudrette, mamufactured at East ILartforl, (for analysis of" which see my 1st Amual Report, 1'p. $t 1$ and 13 , ) is a carefully made preparation, of which these two matters are the chicf ingredients. In the neighborhood of New I Iaven large quantities of this kind of empost are anmally make, and the manuficture might he vastly extended with the utmost advantage to all partics concerned. Every farmer who can, would find it profitable, and not only so but pleasant and healthful, to comprost the priry and sink waste of his premises with muck. The outlay of a few dollars would provide such conveniences as are needful to accomplish this with ease, and instead of being afflicted with a nuisance, yielding an intolerable duantity of milasmatic suell ancl a few shoveifuls of effete waste, he might convert his mersang into an ohorless convenience, and make enough poudrettis to firtilize a large garden to the highest degree. (See Mr. Edwin Hoyt's account of its use for this purpose.)

Gucuo, so serviceable in its first applications to light soils, 
may be composted with muck to the greatest adrantege. Guano is an excellent material for bringing muck into good condition, and on the other hame the muck most effectually prevents any waste of the costly guano, and at the sume time, by furnishing the soil with its own ingredients, to a greater or less degree, prerents the exhanstion that often follows the use of guano alone. The quantity of muck shọull be pretty large compares to that of the guano, - a bushel of guano will compost six, eight, or probably ten of muck. Both should be quite fine, and should be well mixed, the misture should be moistened and litph covered with a layer of muck of several inches of thickness. This sort of compost would probably be sufliciently fermenterl in a week or two of warm weather, and should be made and kept under cover.

If no more than five or six parts of muck to one of guano are cinployed, the compost, aceorling to the experience of Simon Brown, Esq., of the Boston Culticutor, (Patent Oflice lieport for $15.5 \%$, will prove injurions if placed in the hill in contact with seed, but may be applied broadeast without danger.

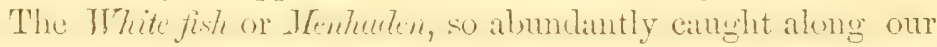
Sound coast during the summer months, or any variety of fish may be composted with muck, so as to make a powerful manure, with complete avoitance of the excessirely disagreable stenth which is proluced when these fish are put directly on the land. Messis. Stephen Ifoyt \& Sons of New Camaan, Conn., male this conpost on a large seale. They have employed 220,000 fish in one season, and use ten or twelve loads of muck to one of fish. $A$ layer of muck one foot or more in thichness is spreal upon the ground, and covered with a layer of fish, on this is put another layer of muck and another of fish, and so on till the pile is several feet high, finishing with a good layer of muck.

In the Summer when this work is usually attended to, the fermentation begins at once, so that no delay must be allowed after the fish are taken, in mixing the compost, and in a short time the operation is complete; the fish disappear, bones excepted, and by shoveling over, a uniform mass is obtained, almost free from odor, and retaining perfectly all the manurial valne of the fish. Lands well manured with this compost will keep in 
heart and improve, while, as is well lnown to our const firmers, - the use of fish alone is ruinous, in the end, on light soil.

For further particulars of the eomposts made by the Meciss. Hoyt, see analysis further on.

It is obvious that any other easily decomposing animal matters, as slaughter-house oflil, soly-builer's scrays, glue waste, etc., etc., may be composted in a similar manner, and that all these substances may be made together into one compost.

In case of the composts with guano, yard manure and other animal matters, ammonia is the alkali which promotes these changes, and it would appear that this substance, on some accounts, excels all others in its efficacy, but the other alkaline bodies, potesh and lime, are scarcely less active in this respect, and being at the same time, of themselves useful fertilizers, they may be employed with domble advantage in preparing muck composts.

Potash-lye and soda-ash have been recommended for composting with muck; but, although they are no doubt highly chlic:acious, they are quite too costly for extended use.

The other alkithe materials that may be cheaply employed,

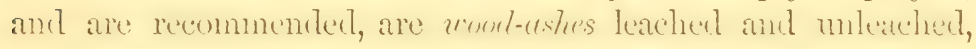
ashes of peat, manl, (consisting of carbonate of lime;) quick lime, gas lime, and what is called "salt and lime mixture."

With regard to the proportions to be used, no definite rules can be laid down; but we may safely follow those who have had experience in the matter. 'Thus, to a cord of muck, which is about 100 bushels, may be added of unleached wood ashes twelve bushels, or of leached wood ashes twenty bushels, or of peat ashes twenty bushels, or of marl or gat lime twenty hushels. T'en bushels of quick lime, slaked with water or salt-brine previous to use, is enough for a cord of muck.

Instead of using the above mentioned substances singly, any or all of them may be employed together.

The muck should be as fine and free from lumps as possible, and must be intinately mixed with the other ingredients by shoveling over. The mass is then thrown up into a compact heap, which may be four feet high. When the heap is formed, it is good to pour on as much water as the mass will absorb, (this 
may be omitted if the muck is already quite moist,) and finally the whole is covered over with a few inches of pure muck, so as to retain moisture and heat. If the heap is put up in the Spring, it may stand undisturbed for one or two months, when it is well to shovel it over and add water if it has become dry. It should then be huilt up again, covered with fresh muck, and allowed to stant as before until thoroughly decomposed. The time required for this purpose varies with the kind of muck, and the quality of the other material used. The weather and thoroughness of intermixture of the ingredients also materially affect the rapidity of decomposition. In all cases five or six montlus of summer wenther is a sufficient time to fit these composts for application to the soil.

The use of "sult and time mixture" is strongly recommended by so many writers, that a few more words may be levoted to its consideration.

In Dr. Dana's Mruck Manual, and in Johnston's Agricultural Chemistry, it is stated that common salt is decomposed by quick lime, with the production of carbonate of soda. Now although this change may occur in the soil or in presence of the organic matters of peat, yet there is no jurof that it does take place, and all the probabilities are opposed to such a change, so that from theoretical gromusts, there is no advantage to be anticipated from a mixture of salt and lime over the unmixed lime, as far as the action on peat or muck is concerned.

But the extraorlinary usefulness of the salt and lime mixture for composting has been so extensively and vigoronsly mintained, that many will be inclined to despise the ehenistry that doubts its benefits.

Therefore without entering into à chemical disenssion of its merits, we will be content here, to assert, that, if useful, its usefuluess is not as yet explained, or the explanations given are entirely unsatisfactory.

'That it is useful is testified to by good farmers' as follows. Says Mr. F. Ifolbrook of Vermont, (quoted from Patent Office Report for 1856, page 193.) "I had a heap of seventy-five half corrls of muck mixed with lime in the proportion of a half cord of muck to a bushel of lime. The muck was drawn to the field 
when wanted in August. A bushel of salt to six bushels of lime was dissolved in water enough to slake the lime down to a fine dry powder, the line being slaked no faster than wanted, and spread immerliately while warm, over the layers of mnek, which were about six inches thick; then a coating of lime and so on, until the heap reached the height of five feet, a convenient wirlth, and length enough to embrace the whole quantity of the muck. In about three weeks a powerful decomposition was apparent, and the heap was nicely overhanled, nothing more being done to it till it was loaded the next syring for spreading. The compost was spread on the plowed surfice of a dry sandy loam at the rate of about fifteen cords to the acre and harrowed in. The land was planted with corn, and the crop was more than sixty bushels to the acre."

Other writers assert that they "lave decomposed with this mixture spent tan, saw dust, corn stalks, swamp muck, leaves from the woods, indeed every variety of inert substance, and in much shorter time than it could be done by any other means."

It deserves to be aseertained by direct comparative expreriment, whether the lime slaked with a solution of salt, does really act with more power and rapidity than if slaked with water alone. If the "salt and lime mixture" possesses peculiar virtues, it is important to be known, and of not less consequenee is it to determine that its reputation is fictitious.

There appears to be no (lould that the soluble and nore active (canstic) forms of alkitine horlies exert powerful reconposing and solvent action on muck. It is asserted too that the insoluble and less active matter's of this kind, also have an effect though a less complete and rapid one. Thus, carbonate of lime in the rarinus forms of marl, leached ashes and peat ashes, (for in all these it is the chief and most "allialine" ingredient,) are recommended to compost with muck. But we are not informed what is the character of the changes they produce in muck or peat. From our chenical linowledge we should alnost decirle that in general they can haveno material effect, ancl yet it is very unsafe to judere in these things without actual and precise practical knowledge. 
The admixture of any earthy matter with peat will facilitate its decomposition in so far as it promotes the separation of the particles of the peat from each other, and the consequent access of air. This benefit may well amount to something when we add to peat one-fifth of its bulk of marl or leached ashes, but the question comes up: Do these insoluble mild alkalies exert any direct action? TVould not as much soil of any kind be cynilly efineacious by pronoting to an equal degree the contact of oxygen from the atmosphere?

It is possible that the carbonate of lime in presence of water and carbonic acid, whereby it becomes soluble to a slight extent, may act to liberate some ammonia from the soluble portions of the peat, and this ammonia may react on the remainder of the peat to produce the same effects as it does in the case of a compost made with animal matters. But speculations on this point thomgh easily mule, are of no value, except to suggest practical trials.

It often happens that opinions entertained by practical men, not only by farmers, but by mechanies and artisans as well, are founded on so unreliable a basis, are supported by trials so destitute of precision, that their accuracy may well be doubted, and from all the accounts I have met with it does not seem to be well established that composts made with carbonate of lime, are better than the muck and carbonate used separately. This, it is plain, is another question worthy of investigation.

If there is any advantage in composting muck with carbonate of lime, then nature has in some localities furnished actmirable facilities for making this kind of fertilizer: thus in Salisbury, Ct., on the farm of John Adam, Esq., occurs a peat swamp, at the button! of which, after excariting through four feet of peat, a layer of shell-marl, containing a large percentage of carbonate of lime, is found, which it is believed may be obtained in large quantities. (see analysis No. 34, in appendix.)

Such deposits are by no means uncommon, and whoever can demonstrate by a series of carefully conducted experiments, whether this marl is most cemomically anplied to the soil directly or in compost with muck, will confer no small fivor on Agriculture. 
It must not be forgotten that we have already insisted upon using leached wood ashes and carbonate of lime in conjunction with peat, in order to supply the deficiencies of the latter; and in the agricultural papers are numerous accounts of the effiency of such mixtures, but whether these bodies exert any good effect upon the peat itself, so that it is needful in general to take the trouble to make a compost, is it seems to me, a question not yet settled. In the case of vitriol peats, however, carbonate of lime is the cheapest and most appropriate means of destroying the noxious sulphate of protoxyd of iron, and correcting their deleterious quality. When carbonate of lime is brought in contact with sulphate of protoxyd of iron, the two bodies mutually decompose, with formation of sulphate of lime (gypsum) and carbonate of protoxyd of iron. The latter substance absorbs oxygen from the air with the utmost avidity, and passes into the peroxyd of iron, which is entirely inert.

S. I now proceed to discuss the ptan employed in the analysis of the Peats which I have examined.

The specimens came to me in all stages of dryness. Some freshly dug and wet, others after a long cxposure so that they were air-dry; some that were sent in the moist state, became

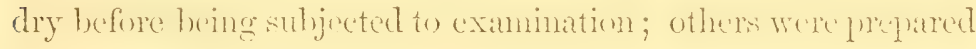
for analysis while still moist.

A sufficient quantity of each specimen was carefully pulverized, intermixed and put into a stoppered bottle and thus preserved for experiment.

The first point in the examination was to make a general analysis, viz.: to ascertain the amount of water, and the proportions of vegetable matter and of ash.

In the special analysis, it was sought to obtain some nearer insight into the condition of the organic matter. For this purpose I deemed it best to employ the usual method of treating with an alkali and determining the quantity soluble therein, which corresponds to the hunic (anel uhic) acid, and accortingly this operation hat been carriert out with no inconsiduable troulde. Unfortunately we do not now know whether these humic acids are possused of any surecial fertilizing or other preprerties, which cau confer interest on the linowledige of their quantity, nor can 
we ever leam their significance, if indeed they possess any, without numerous experiments directed immediately to this point. The only value, then, of these determinations, is that they give us some irleat of the degree to which the peaty decomposition is advanced.

In the earlier analyses 1 to 17 inclusive, the treatment with carbonate of soda was not carried far enough to dissolve the whole of the soluble organic acids. It was merely attemp,tel to make comparative determinations by treating all alike for the same time, and with the same quantity of alkali. I have little doubt that in some cases not more than one-half of the portion really soluble in carbonate of soda is given as such. In the later analyses, 18 to 33 , however, the treatment was continued until complete sepraration of the soluble organic acids was effected.

In no instance was any special examination of these soluble acids undertaken, since in the present state of our knowledge, this labor conld hardly be expected to yield any new results of agricultural importance.

By acting on a peat for a long time with a hot solution of carbonate of sorla, there is taken mp not merely a quantity of organic matter, but inorganic matters likewise enter solution. Silica, oxyd of iron and alumina are thus dissolved. In this process too, sulphite of lime is converted into carbonate of lime, but not dissolved.

The total anount of these solulle inorganic matters has been determined with approximate accuracy in analyses 18 to 33.

It was deemed of the highest importance to study the quantity anch character of the botics which pure water is able to dissolve from peats. In the watery extract of a peat we may expect to lind those substances which make it direetly useful as a fertilizer, ant also those which, like sulphate of iron, are noxious to vegetation. The general character of the matters soluble in water has been indicated already, and the analyses themselves give the special details.

With regard to the entire ash, and the amount of nitrogen, it is unnecessary here to remark upon the importance of investigating them, or to add to what has been written in the preeeding 
pares. The details of the process need in the analysis of pieat are griven in the accompanying note by my frienrl, Dr. Robert $A$. Fisher, to whose skillful assistance I am largely indebted for the analytical data of this Report, espereially for the analyses 18 to 33. I must also express my obligations to Mr. Eilwarl 11. Twining, assistant. in the Yale Analytical Laboratory, for the analyses 1 to 17 , executed by him in 1857 .

9. On the Use of Peat Analyses, and on the Value of Practical Information.

When I began this investigation, it was known that some peats or mucks were highly useful, while others haul proved detrimental, certain reasons too were known why they were good or bad in their effects, and in agricultural writings existed a great deal of statement that was partly true but more or less

* Note on tule Process of Axalysis.-The following is the general method employed in the analysis of peats and mucks: To prepare a sample for analysis, half a pound, more or less, of the substance to be examined, is pulverized and passed -through a wire sieve of 24 meshes to the inch. It is then thoroughly mired and bottled for use.

I. 2 grams of the above are dried (in a tared porcelain capsule, ) at the temperature of 212 degrees, until they no longer decrease in weight. The loss sustained

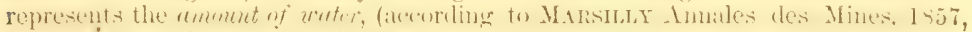
Xil., 4lit, peat loses carlon if driet at it temperature higher than 212 dentees.)

II. The capsule contaning the residne from I. is slowly heated to indipient rentness, and maintained at that temperature until the organic matter is entirely consumed. The loss gives the total amount of organic, the residue the total amount of inorganic matter.

NOTE-In peats containing snlphate of the protoxide of iron, the loss that occurs during ignition is partly due to the escape of sulphuric acid, which is set free by the recompsition of the above mentioned sult of iron. But the guantity is usually so small in comparison with the organic matter that it may be disregarded. The same may be said of the combined water in the clay that is mixed with some mucks, which is only expelled at a high temperature.

IIf. 3 grams of the sample are digested for half an hour, with 200 cubic centimeters (66.6 times their weight,) of beiling water, then remote from the wimn hath, and at the end of twenty-fomr lours, the clear lingud is decanted. This operation is twice repeated upon the residue; the three solutions are mixed, filtered, concentrated, and finally evaporated to dryness (in a tared platinum capsule, over a water bath. The residue, which must be diried at 212 degrees, until it ceases to lose weight, gives the total amount soluble in water. The dried residue is then heated to low redness, and maintained at that temperature until the organic matter is burned off. The loss represents the amount of organic matter soluble in water, the ash gives the quantity of soluble inorganic matter.

IV. I grani is digested for two hours, at a temperature just below the boiling point, with 100 cubic centimeters of a solution containing 5 per cent. crystallized carbonate of soda. It is then removed from the sand bath and allowed to settle. When the supernatant liquid has become perfectly transparent, it is carefully decanted. This operation is repeated until all the organic matter soluble in this menstruum is removed; which is accomplisled as soon as the carbonate of soda solution comes off colorless. The residue, which is to be washed with boiling water until the washings no longer affect test papers, is thrown upon a tared filter, and dried 
tinctured with uncertain speculation. It was to tearn whether other than the then linown causes of the excellence or worthlessness of peats existed, and to test the correctness of the current opinions, that this investigation was undertaken. By a comparative study of the characters of numerous specimens from all parts of Connecticut, it was houed to arrive at some definite and reliable seneral conclusions as to their value-to ascertain the range of their exeellence, and to establish safe rules for their use. I believe that this work has been satisfactorily accomplished. Berides these gencral results it was forseen that this investigation would assist in deciling a question much discussed of late, viz. : the ability of chemicil analysis to pronounce upon the precise value of any particular specimen.

I had at the outset no great faith that the chemist could tell by his analyses, if this peat be good or that bad, or: how much better one is than another. Now that 33 peats have been exannined, I helieve we are able in most cases to decicle ly andysis, with great prohability, whether my specimen is useful or hurtful; and if the former, whether it has a high or low degree of excellonce ; and yet, as will be seen further on, there are great difficulties in refining the precie linits where the gool peats

at 212 degrees. It is the total amount of organic and inorganic matter insoluble in cartonate of soda. The loss that it suffers unon ignition, indicates the amount of organic matter, the ash gives the inorganic matter.

Note.-The time required to insure perfect settling after digesting with carbonate of soda solution, varies, with difierent peats, from 24 hours to several days. With proper care, the results obtained are very satisfactory. Two analyses of No. 6, excented at different times, gave total insoluble in carbonate of soda. 1st annlysis 23.20 per cent, $2 d$ manalysis 23.45 per cent. ; which residues yielded respectively 14.30 and 14.15 per cent. of ash.

V. Tho quantity of organic matter insoluble in water but soluble in solution of carbonate of soda, is ascertained by deducting the joint weight of the amounts solnble in water, and insoluble in carbonate of soda, from the total amount of organic matter prescnt. The inorganic matter insolulle in water, but soluble in carbonate of socla, is determined by deducting the joint weight of the amounts of inorganic matter soluble in water, and insoluble in carbonate of soda, from the total inorganic matter.

VI. The amount of nitrogen is estimated by the combustion of 1 gram with soda-lime in an iron tube, collection of the ammonia in a standard fifth solution (12.6 grams to the liter,) of oxalic acid, and determination of the residual free acid by an equivalent solution of caustic potash.

This method in skifful hands uniformly gives such correct and corresponding results that it was deemed unnecessary to make duplicate analyses. In one case, however, Dr. Fisher execnted a second analysis which confirmed the numbers obtained by Mr. Twining a jear before.

S. W. J. 
pass into the bad. It is not to be expected that the amalysis of a peat or muck will ever suffice to fix its manurial value, as the analysis of a guano or superphosphate shows the worth of these fertilizers. From the nature of the ease, the muck analyses admit only a much looser and more general interpretation.

Whatever may be the merits of analyse's of peat and muck, it is certain that their value is to be only brought out in all perfection by the knowledge derived from actual trial on the furm. Пowever fir we may pursue our researches into the conditions of vegetable production, there will always remain unsettled points, and facts will be observed in practice which science can only imperfectly explain. Hence practice will always be in adrance of science in certain particulars, and must be invariably appealed to before any doctrine can be really established. If peat were now for the first time discovered and brought to the chemist, he could not, after the most minute analysis, jositively assert its usefulness, although he might find such strong probabilities that its action would be highly fertilizing, as to warrant immediate and careful trial. It is only when experience on the farm has proved its benefit, that he acquires satisfactory data for his decisions.

The chemist who will serve agriculture in the details of its operations, must not merely proced from his science out, towards practice; but he must often, and not less often, go in the other direction, for in the field there exist conclitions which can only be studied there, as they are wanting in the labowatory and in the study.

These considerations induced me to address a Circular to the parties who had sent in specimens, asking information on those points which appeared likely to be of greneral service, and would subserve the end of this inquiry. The circular was as follows, one slight amendation excepted:

\section{QUERIES.}

1. What is the length and brearth, and the number of acres in the swamp or marsh?

2. What is the average, and the greatest depth of the muck or peat? 
3. Is it drained or not, and if so, to what depth and how long has it been dry?

4. Is it a salt or fresh water marsh ?

5. Are the upper portions or layers dry luring the summer? If so, how long, and to what depth?

6. Have any crops been produced on the drained or dry portions? If so, what and how large crops? And what manures have proved useful on them?

7. What is the soil underlying, and at the edges of the swamp?

8. Does the swamp receive much wash from surrounding hills? If so, of what kinds of soil are they?

9. IIs the swamp (if fresh water, ) both inlet and outlet? Is the water hard or soft? How large are the streams? Are they subject to heary freshets in Spring and Autumn? Do they dry up in Summer?

10. If several samples are sent, are they from one place?

11. At the place where the sample or samples were taken, is there much variation in the quality or appearance of the muck at different depths? If so, specify these differences, and give the thickness of each layer?

12. What kind of trees or vegetation grows on the muck, and what kinds of timber or branches are found in it? Observe jarticularly if there be indications of much pine or other resinous timber.

13. Has the muck been employed fiesh from the swamp, withont any lengthened exposure to the weather, as a dressing for grass or other crops, and with what results?

14. Ias the long dug and exposed muck been applied to crops without other manures, and with what results compared to good stable manure?

15. Has the muck been composted or used as an absorbent? If so, with what materials, and to what advantage?

16. If composted, describe the manner of composting, giving the quantities employed.

17. If several mucks are sent, which do you consider best from actual experience? 
18. IIas the peat been used for fuel? If so, what is its quality for such use?

19. Please commmicate any other interesting facts with regard to the occurrence or uses of the muck or peat, which you may know.

\section{Results of analyses and answers to the Circular.}

Here follow the details of each analysis, accompanied by the information obligingly furnished by the grentlemen who sent in the mucks and peats. I have in some cases re-arranged, condensed, or otherwise edited the original auswers as anpeared necessary.

Brief comments are appented to some of the malyses, but it would swell the Report to an unwarrantable degree, to extend these renarks as might be wished, in each individual case.

No. 1.-Peat from Lewis M. Norton, Goshen. Came in form of dry, tough, heavy cakes, of a dark chocolate color. With exception of a few grass roots was well decomposed.

\section{Analysis.}

Organic matter, *soluble in carbonate of soda, $\quad 17.63$

$$
\text { " } \text { Total, insoluble in " " " " } 34.79
$$

+Inorganic matter,

Water,

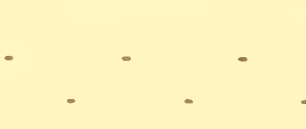

35.21

Soluble in water, $1.5 \pm$ per cent.

Nitrogen, $1.28=$ ammonia, 1.63 "

For answer to circular see No. 3.

No. 2.-Peat from Lewis M. Norton, Goshen. Lilie No. 1, but heavier.

* The proportions of organic matter in analyses 1-17 aro not strictly correct.

$\dagger$ Ash chiefly sand, contained but little carbonate of lime. 
Analysis.

Organic matter soluble in carbonate of soda, $\quad 60.02$ " insoluble in " " $\quad 11.65$

Total, $\quad 71.67$

*Inorganic matter, - $\quad$ - $\quad$ - $\quad$ - $\quad 8.00$

Water, - - - - $\quad$ - $\quad 20.33$

100.00

Nitrogen, $1.85=2.24$ ammonia.

For answer to Circular see No. 3.

No. 3.-Swamp muck from Lewis M. Norton, Goshen. Came in dry, very light colerent cakes, consisting largely of the flattened stems of swamp plants. Color light brown.

$$
\text { Analysis. }
$$

Organic matter soluble in carbonate of soda, 50.60

$$
\text { " insoluble in " " } 29.75
$$

Total,

80.35

+Tnorganic matter,
Water,
-

Soluble in water,

Nitrogen $1.90=2.31$ ammonia.

Anstiers to circular respecting Nos. 1, 2 and 3.

1. The swamp contains ahout 50 acres, was formerly a pond. Nearly all around it, at the height of about 6 feet alove the present surface may be seen the ancient high water mark.

2. The greatest depth exeavated is 10-11 feet. The greatest depth observed is 32 feet.

3. Six years ago it was undrained, but is now drained to the depth of $3-4$ feet.

4. The water is fresh.

5. The upper portions are dry enough for cultivation in summra and barely hard enough for plowing and taking off crops.

* The ash contains 37 per cent. of carbonate of lime.

+ Ash contains 33 per cent. of carbonate of lime. 
6. Trials have been made in raising corn, potatoes, buckwheat and grass. These experiments are comparatively recent, and the crops not very large, and in regard to corn and potatues it seems necesary that some manure be put in the hill. Carrots have done well; pumpkins have done well. Decompused manures only have been used. Potato topss grow large-the same of corn-but the tract being somewhat lower than the surrounding country is subject to early frosts.

7. Saml, and in some places clay (pure and goorl), gramite boulders are found at the edges on digging.

8. There are no high hills in the vicinity, and no wash.

9. The swamp has two or three inlets, and one outlet at the south-west. Suft water. Streams ordinarily small, but sulject to freshets or high water always with a large fall of rain. The streams are rarely if ever quite dry.

10-11. The three samples are from nearly the same place No. 1 is from the margin of the swamp; is mixed with sant and clay, and lies on the buttom-on which there is a bed of sind and clay, say 3-4 feet from the surface. It forms a stratum of $6-10$ inches in depth, is quite distinct from all above it, and is undoubtedly of the earlicst formation. Some three years ago specimens very similur were taken out at a depth of 10 feet and $5-6$ rods from the margin; I suppose that all below is of this kind.

No. 2 is from the surfure after removing the upper $3-1$ inches. It evidently has been somewhat decomposed by the action of the atmosphere-say 8 to 10 inches deep.

No. 3 is found between 1 and 2, though it should be stated that there is but little so light and poor as this sample.

12. The roots of large trees, spruce or pine, are foumd, but not near the outside. These roots, so far as observed, are abont 18 inches below the surface. No trunks of trees but many small alclers are found at about the same depth in a vertical position. These are all cut easily through with the shovel. I found one picee of alder, of the thickness of a man's wrist, lying horizontally at the depth of 8 feet. The bark in appearance resembled that of an alder just cut. (In a liater statement Mr. Norton remarks): As above described, and as since observed, the roots of many trees appear. They all secm to be of nearly the same depth 


\section{4}

below the surface (about 18 inches,) with goorl peat above and all around them. Some roots and trunks even of red ash are found near the outside. But at a remove of some 2 or 3 rods from the outside none such appear. Those of red ash are much rotten and seldom require the use of an axe. But farther in the swamp the roots only are found, and these are all of the resinous kind. We have had occasion to dig out many of these-strong (solid as new some of them,) and highly resinous. The indications are that these trees were say 1 to 2 feet in diameter-but unlike the ash, these trees never fell doun. They must have decayed stunding, as nothing appears to indicate the remains of a fallen tree.

13. It has not been considered as of much value when used fresh from the swamp.

14. There have been no careful experiments in its use after long exposure.

15. In compost, as an absorbent it has been extensively used, and with marked suceess, thrown into hog pens or put in barnyards.

16. Methor of composting: 2 parts muck with 1 part stable manure in a large heap-lone in the Spring before the fermentation of the manure and not stirred-carried upon the land the next Spring.

17. We have mostly used the grassy or surface muck-sometimes other-all good.

18. I have used peat for fuel (no mood of any consequence,) for some 4 or 5 years. No one else here has employed it. It is eut or dug with an instrument such as is used in Ireland. It answers for domestic purposes well, but it must be dry and liept dry. Ashes many and valuable only as manure-as they seem to contain no potash. In my kitchen stove I have a grate, and the ashes descend to a close brick vanlt below. Camy out a load at once-very convenient-peat cheaper than wood.

Lewis M. NORTON.

No. 4.-Swamp muck from Messrs. Pond \& Miles, Milford. Coherent but very light and porous in texture, full of roots and stems. Color chocolate brown-surface peat. 
Analysis.

Organic matter soluble in carbonate of soda, $\quad 65.15$

" " insoluble in " " $\quad$ " $\quad 11.95$

Total, $\quad 77.10$

*Inorganic matter, $\quad$ - $\quad$ - $\quad$ - $\quad$ - 3.23

Water, - - . . . . . . 19.67

Soluble in water, 1.63

100.00

Nitrogen, $1.20=1.46$ ammonia.

For answer to circular see No. 5 .

No. 5.-Swamp muck from Messrs. Pond \& Miles, Milford. Very light and loose in texture. Color, brownish rel. When dry easily separates into thin layers. Taken from a depth of 3 feet.

\section{Analysis.}

Organic matter soluble in water, - $\quad$ - $\quad 2.62$

" soluble in carbonate of soda, $\quad 65.13$

" insoluble in " $\quad$ " $\quad$ " $\quad 16.65$

Total, $\quad 84.40$

Inorganic matter soluble in water, - $\quad$ - 80

Insoluble in water, $\quad$ - $\quad$. $\quad 1.20$

†Total, 2.00

Water, - - - . - - - 13.60

100.00

Nitrogen, $0.95=1.15$ ammonia.

ANSWERS TO CIRCULAR.

1. The swamp contains $3-4$ of an acre.

2. The depth is $\mathbf{1 0}$ feet.

3. It is not drained.

4. The water is fresh.

5. It is dry for three or four months in summer, to the depth of $3 \frac{1}{2}$ feet.

6. No crops have been raised on it.

* Mostly sand and oxyd of iron with small quantities of carbonate and sulphate of lime.

$f$ The ash is white, and besides sand, contains little else than sulphate of lime. 


\section{6}

7. The neighboring and underlying soil is sand and coarse gravel.

8. It receives much wash from sandy hills and the highways which pass near it.

9. The swamp has neither inlet nor outlet. The water has a dark mahogany color.

10 and 11. Two samples were sent, taken from one to three feet from the surface. The surfice peat (No.4) is of a darkish brown for a depth of two feet. Below it is of a lighter color, (No. 5.)

12. Small maples, black alders and bilberry bushes; pine snd white hirch trees grow in the swamp. The last named predominates. Trunks of trees 3 feet in diameter have been found at a depth of several feet in the muck.

13. The fresh muck has never been applied to crops, but where it has been thrown out, vegetation in the shape of weeds has been rank on the top of the piles.

15. The weathered muck has not been used alone on crops.

15. The muck has been composted to good adrantage with horse, hog and cow manure.

16. In composting the materials have been put together in layers, one part manure to about three of muck.

17. I consider the surface peat to be the best.

18. It has not been used for fuel.

19. I find it a great benefit to my land.

Wyr. J. PoND.

No. 6.-Peat from Samuel Camp, Plainville. Dry hard Iumps, very black and uniform in appearance.

\section{Analysis.}

Organic matter soluble in carbonate of soda,

$$
\text { "Total, insoluble "6 "6 "6 }
$$

8.90

*Inorganic matter, Water,

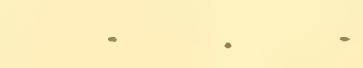


Soluble in water, 2.50 .

Nitrogen, $2.10=2.55$ ammonia.

\section{ANSIVERS TO CIRCULAR.}

1. Length of marsh $1 \frac{1}{2}$ miles, wiclth from 25 to 50 rocls.

2. Depth from 2 to 4 feet.

3. A small part has been drained 7 years to the depth of 1 feet.

4. It is a fresh water marsh.

5. The marsh is dry to the depth of one foot for 3 or 4 months; the portion dritined is dry to the bottom at all times.

6. The drained portion was sown with herdegrass and has lain in grass, the herdsgrass has run out and swamp grass has come in, except where a lind of clay or earth, a sumple of which I sent you, was thrown upon the surface and there is found a good quality of English grass, no other dressing has been given. The average yield is $1 \frac{1}{2}$ tons per acre.

7. The underlying soil is generally gravel and clay; around the marsh are oceasional beds of the before-mentioned clay.

S. It receives the wash of the mountain that extends through Farmington.

9. It has both inlet and outlet, a living stream of soft water sufficient to drive small mills, and subject to heavy freshets.

12. Oak prevails in the deposit; elm and maple were growing on the marsh when cleared.

13. When used fresh from the marsh but little advantage is derived from it, when long exposed and dried considerable advantage; but much the greatest by composting with some lind of manure, and the clay before mentioned, which is found in and about the marsh, does well used in that way.

14. This muck is worth for manure half as much as yard manure; when composted it is equal to yard manure. It makes a very good soil when used alone on sand.

15. I find it an excellent absorbent, and sometimes pump from a cistern in my yard the liquid it contains, and pour it upon piles of muck, which makes it a good fertilizer. I have used it with either yard namure, lime, ashes, guano or clay, with about equal success. 
16. To 1 load of muck, 1 of clay, or $\frac{1}{4}$ yard manure, or 2 bushels of lime, or $t$ bushels of ashes. The clay, lime and ashes may be mixerl, but the yard manure must be placed in layers so as to cause fermentation.

18. It burns freely, making a very hot fire.

19. The above described deposit is principally on one main stream, but there are spurs running toward the mountain where little streams come in that yield the best quality of muck by about one-third; from these I generally dig my supplies.

This muck deposit is on the east side of the great plain lying parallel with the Farmington mountain. On the northwest there is a deposit brought down by the Pequabue, covering perhaps a thonsand acres, very little of it is drained but that which is is very productive.

\section{Samuel Camp.}

No. 7.-Peat from Russell U. Peck, Berlin. Color chocolate brown.

\section{Analysis.}

Organic matter soluble in carbonate of soda,

$$
\text { " insoluble in " } \quad \text { " } \quad 30.51
$$

Total,

*Inorganic matter, - $\quad$ - $\quad$ - $\quad$ - $\quad 13.59$

Water, - . $\quad$ - $\quad$ - $\quad$ - $\quad$ - 17.41

100.00

\section{Soluble in water, $\quad 2.61$}

Nitrogen, 1.62=ammonia, 1.97

\section{ANSWERS TO CIRCULAR.}

1. The swamp is about 60 rods long and 40 broad. It contains about 5 acres.

2. The nuck is $\mathbf{1 0}$ feet deep one rod from the edge; at two rods from the elge it is over 15 feet deep. The greatest or average depth is unknown.

3. Two years ago it was partially drained to the depth of two feet.

* $\Lambda$ sh besides much sand, contains a large amount of carbonate and sulphate of lime and oxyd of iron. 
4. The water is fresh.

5. The surface is dry to the depth of one foot.

6. No crop has been grown on it except coarse grass.

7. The underlying and adjoining soil is clay and full of rock.

8. A large amount of water from the adjacent high woodland runs into the swamp. The soil of the hills is a reddish loam.

9. It has both inlet and outlet, and is also fed at the edges by springs of cold soft water. It is flooded by heary rains and dries up in summer.

10. The sample sent, was taken two feet below the surface.

11. At a depth of 4 feet, the inuck has more the appearance of leaves and wood; lut after long exposure to the weather it turns black and resembles the upper layer.

12. No trees now grow in the swamp. The vegetation consists of coarse grasses and brakes. The logs and branches found deep in the muck mostly appear to be red ash-none of them are pines.

13. The muck has been used fresh on corn and meadow with good effect.

14. The long exposed muck has been used and is equal to one-half as much barn-yard manure.

15. It has been composted with stable manure, with nightsoil, and hen-dung. The compost of the two latter has had wonderful effect upon tobacco.

16. The composts with night-soil and hen-dung have been marle under cover, using one prart of manure to ten of muck. Other manures have been mixed with their own bulk of muck in the field.

18. It has not been used as fuel.

R. U. PECK. 
No. S.-Swamp muck from Rev. B. F. Northrop, Griswold. The dried masses were light, coherent but easily crushed, were of a grayish hrown color, and much fine white sand was perceptible in them.

\section{Analysis.}

Organic matter soluble in carbonate of soda,

6 insoluble in

"6

6

10.15

Total,

*Inorganic matter,

34.70

Water,

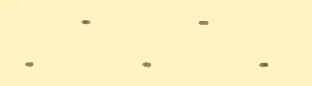

Soluble in water, 1.64.

Nitrogen $1.31=1.60$ ammonia.

ANSWERS TO CIRCULAR.

1. The swamp is nearly a triangle with irregular sides, containing about 1 acre, $3 \frac{1}{4}$ rods.

2. As to depth, the estimated average is $4 \frac{1}{2}$ feet. Greatest depth dug, 6 feet, from the dip of the sides, greatest estimated deptlı 16 fiet. $\Lambda$ similar muck bed in an adjoining lot has been penetrated to that depth.

3. It has been drained for 4 years to a depth of two feet.

4. The water is fresh.

5. Perfectly dry at the depth of two feet all summer.

6. It has grown no crop but grass, which has been improving in quality since I drained it. No manures have been tried.

7. As the ditch approached the shallow part of the bed, at the depth of 6 feet, a substritum resembling very fine clay, and of a very light color, was thrown out. The edges are a gravelly loam.

8. The muck bed receives no wash from hills.

9. A stream of soft water runs through the deposit, it comes from a large spring, and runs about a quarter of a mile before it

\footnotetext{
* The ash is almost entirely white quartz sand, with some sulphate of lime.
} 
enters my lot. In ordinary seasons it will fill a 4 inch pipe. IIeavy rains make a little torrent of it. But the surrounding hills are covered with grass and granitic rocks, so there is little wash. The stream never dries. It is turned on to the upland in summer.

10. Only one sample was sent.

11. For two feet in depth there is no deviation in quality or appearance of the muck. Below that depth, and conserpently below the water line-the muck assumes a brownish tinge, and appears as if the decompusition was not perfected, thrugh ou exposure to frost, I can discover but little difference.

12. The only vegetation is grass. Oak logs several inches through have been dug up, at depths varying from two to four feet. Hickory nuts with the shueks on have been formel at the depth of three feet. No inclications of resinous sulsitanees have been found. Maples and elms grow thriftily at one angle of the bog, where no effort has been made to eradicate them.

13 and 14. The muck has not been used as a manure.

15. It has been composted with horse-dung, and in some instances, ashes, in small quantities. I have raised excellent crops of com and oats, much to the wonder of my neighlors, who knew I had the manure of only one horse. I purchased a few loads of poor manure last, Spring, which together with what iny horse made, was composted with inuck and a few hushels of ashes, making about 8 or 10 cords. 'This was spread on 120 rods of gromel, and ploughed in. The lot was planterl with corn, (Rhode Island Premium.) The product was 99 mensured bushels of ears, which is considered a large yield for this section.

16. In composting, the muck and manure have been spread in alternate layers, three of the muck to one of manure.

19. But little if any use was made of the muck by former owners. The impression seemed to be that it would injure the land. When I first began to use it, I found many who were utterly skeptical as to its value as a manure.

B. F. Northrop. 
No. 9.-Peat from J. II. Stanmond, Colebrook. Came in hard lumps of a chocolate color. Well decomposed.

\section{Analysis.}

Organic matter soluble in carbonate of soda, $\quad 49.65$

$$
\begin{array}{lllll}
\text { " insoluble in " } & \text { " } & & \\
\text { Total, }
\end{array}
$$

*Inorganic matter, Water,

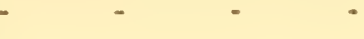

Soluble in water, 1.83 .

Nitrogen, $1.23=1.50$ ammonia.

ANSWERS TO CIRCULAR.

1. The swamp is about $1 \frac{1}{2}$ miles in length, and may be likener in form to a pair of spectacles. The widest portions are about eighty rods in width, and it contains in all abont one hundred and fifty acres.

2. The depth in the sonthern portion is probahly not more than four or five feet on the average; while in the northern portion, from which the sample was taken, the depth is so great that it cannot be ascertimed by any means which I have at hand. A pole has been pusherl down sixteen feet without touching bottom, at the distance of four or five rols from the margin.

3. The swamp has been for the most part drained.

4. The water is fresh.

5. The depth of drainage is from one to three fect, and the portion from which the sample was taken has been but partially drained until within the past four years.

6. The upper portions are usually dry during the summer to the depth of two or three feet.

7. Excellent crops of potatoes, carrots, turnips, oats and grass have been produced on some of the drained portions. The only manures used have been ashes and stable manure. Conld

* The ash prepared by me contains besides sand, much sulphate of lime, but no carhonate of lime. The ash sent hy Mr. Stanwood, the full analysis of which is given on another page was obviously obtained from a peat found in another part of the swamp. 


\section{3}

discover no effect from the ashes. Prefer horse manure to any other.

8. The soil underlying and at the elges of the swamp is white sand mixed with stones of various sizes.

9. The meadow is surrounderl with hills, and must undoubtedly receive considerable wash from them. Their soil is a sandy loam, rough and rocky in its natural state.

10. The swamp has both inlet and outlet. The water is soft. Shahangan Brook, which flows through it, is from two to three rouls in width, and is sulject to heary freshets Spring and Autumn, but these are of short duration.

11. Only one sample sent.

12. The quality of the muck at the place where the sample was tilken is quite miform to the depth of four or five feet. Below that is peat to depth unknown.

13. The original growth of timber was ash, maple and pine, with some hemlock. Many of the roots and stumps of pine still remain in a gool state of preservation. Black alder and sweet eller, together with the red raspberry, are found anong the undergrowth.

14. The muck has been used to some extent as a top-dressing for grass and other erops with satisfactory results, althongh no particular benefit was noticeable during the first year. After that the effects might be seen for a number of years.

15. I know of no experiments having been made with a view of testing its value after having been long dug, as compared with stable manure.

16. Composting has not, I believe, been practiced to much extent. Whenever it has been done, stable manure and ashes have been the materials nsed. Fixperiments made by inyself have confirmed me in the opinion that a compost of equal parts muck and stable manure is equal to the same quality of stable manure. I found a compost made of two bushels of mnleached ashes to twenty-five of muck superior to statble manure as a topdressing for grass on a warm, dry soil. Wre however use it mostly as an absorbent, the acidity is corrected by the exposure it receiven, and much fertilizing matter is saved that would otherwise be lost. 
17. My method of composting is as follows: I draw my muck to the barn-yard placing the loads as near together as I can tip them from the cart. Upon this I spread whatever manure or ashes I have at hand, and mix with the cattle's feet and heap up with a scraper. I have also my stables arranged under one of iny barns, so that the muck is mixed with the manure in a trench behind the cattle.

19. The peat has been used merely to test its value as fuel, and has proved a superior article, but so long as plenty of wood can he had for little more than the labor of getting it, few will be willing to substitute peat in its stead.

Colebrook, Nov. 13th, 1858.

\section{JoHN H. STANTOOD.}

No. 10. Peat from N. Hart, Jr., West Cornwall. Hard dry lumps of a dark brown, almost black color.

\section{Analysis.}

Organic matter, soluble in carbonate of soda,

" " Insoluble in carbonate of soda, 10.29 Total

*Inorganic matter,

19.71

Water,

0000

+Soluble in water, 6.20 .

100.00

Nitrogen, $2.10=2.55$ ammonia.

ANSWERS TO CIRCULAR.

1. The swanp is 100 rods long by 20 wide, contains $12 \frac{1}{2}$ acres.

2. Average depth 10 feet. Greatest depth 15 to 20 feet.

3. It is drained with a ditch four feet deep around the outside, and one 80 rods long through the middle north and south, and one east and west at the upper end of the middle.

4. It is a fresh water swamp. It has been dry 13 years.

5. It is dry enough the year through to go all over it with a team and loaded cart.

6. We have raised medium crops of corn, potatoes and

* The ash besides sand contains very much carbonate and sulphate of lime.

f In the soluble portion are no salts of iron. 
pumpkins. Five acres of it is in upland grasses, and has cut three tons per acre.

Have manured by spreading the ashes produced in burning the bogs, in the fall, and with stable manure the next spring, and with upland soil from old headlands.

7. Clay and sand form the adjacent underlying soil.

8. The swamp receives no wash from hills.

9. A small stream of soft water runs through the swamp, which is sometimes dry in summer, and is never high enough to flood the swamp.

11. The surface deposit to a depth of 18 inches is macle up of fine decomposed vegetable matter. Below this it is more like peat and coarse vegetable matter.

12. The trees in the swamp are black ash, white maple, and recently, willow. We often find the trunks of hemlock trees of various sizes, some, 18 inches in diameter, several feet below the surface.

13 and 14. The muck has never been used as a manure.

15. We formerly composted it with stable manure, and with ashes, but have remodeled our stables, and now use it as an absorlent and to increase the bulk of mame to donble its ciricinal quantity, and consider it more valublle than the same crumtity of stable manure.

16. Have composted in the yard by putting a layer of muck on the ground a foot thick, and then a layer of manure (by wheeling the cleanings of the stalles erery morning) of albout $\frac{2}{3}$ the quantity of the muck, and so on until the pile is completed. This should be turned some days before using.

I have mixed 25 bushels of ashes with the same number of loads of muck, and applied it to $\frac{3}{4}$ of an acre. The result was fir beyom that obtained by applying $300 \mathrm{lbs}$. best guano to the sime piece.

18. Have not given it a fair trial as to its burning qualities.

19. In the use of muck we proceed as follows: Soon after haying we throw up enough for a reatr's use, or severial hundred loats. In the fill the summer's accumulation in hog pens and barn cellars is spread upon the mowing grounds, and a liberal supply of muck carted in and spread in the bottoms of the cel- 
lars ready for the season for stabling eattle. When this is well saturated with the drippings of the stables a new supply is arded. The accumulation of the winter is usually applied to the land for the corn crop, except the finer portion which is used to top-dress mearlow land. $\Lambda$ new supply is then drawn in for the swine to work up. This is added to from time to time, and as the swine are fed on whey, they will convert a large quantity into valuable manure for top-dressing mowing land.

So successful has been the use of it, that we could hardly carry on our farming operations without it.

\section{N. HART, Jr.}

No. 11. Swamp-muck from A. L. Loveland, North Granby. This muck is black, and clried to very hard lumps, in which grains of quartz and mica sand are seen.

Analysis.

Organic matter soluble in carbonate of soda,

Total,

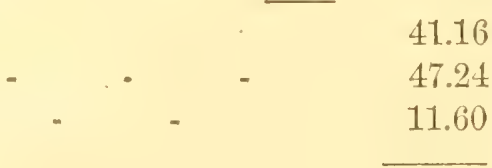

* Inorganic matter,

100.00

Soluble in water, 0.75 per cent.

Nitrogen $1.00=1.22$ ammonia.

ANSWERS TO CIRCULAR.

1. The place from which the specimen sent was taken, is a swale extending over a somewhat broken surfice of more than lialf a mile in length, though the width, on an average, is not more than 15 rods.

2. The greatest depth will not exceel six fect. Wherever the swale is broken, the separation is covered with timber, the land is quite stony, and the descent is such that the brook which passes through it runs quite rapidly.

* The ash is chiofly sand, with a little sulphate of lime. 
3. None of these lands (nor scarcely any in the town,) are drained, though nothing could return a better profit.

4. It is a fresh water marsh.

5. It is constantly wet from springs, and difficult to cross at any season. A yearling steer once sunk and perished in the muck. On some portions the surfice is tough with grass roots, and will roll beneath one's step like the waves upon a lake. Springs of water are underneath, and the mud is very soft.

6. No crops have ever been taken from these lands, except perhaps some coarse griss on linited portions. Alders and maples are cut off once in twelve years or so. No manures are ever put on, and the vast riches of such lands have been hidden until recent agitation of the subject has brought them to light.

7. The base of this muck is mostly a hard-pan mixed with stone. The borders have a deep, loamy soil on which appleorchards flourish. The white birch takes root in it whenever it is plowed for grain, until vast fields are covered with them. They grow rapielly, and when matured are cut and the ground cleared for potatoes and grain.

8. There is not much wash from the hills, but where there is any, the soil is a light lom, overlying gravel and sand mixed with much stone.

9. The swale has no inlet but abundant outlet. Springs of clear cold water well up mostly from the borders in never-failing quantity. These disappear slugrishly over a larese surfuce till they reach a rapid descent, when they take the form of a brook and circle round opposing elevations of land till they reach the larger mill streams in the valleys below. They are never dry, and are but slightly affected by storms.

10-11. The sample sent was from one place, which will fairly reprewnt most deposits in this township, as there is little variation in quality.

12. The vegetation consists of alders, maples, willows, grape vines, flages and a tall, conrse grass. It is pretty free from fillen trees. No pines grow on these lands.

13, 14 and 15. The muck has never been used for any purpose. It will be used next season for the first time. 
19. In the adjoinme town of Granville, Mass, similar swales, stretching along the base of hard-timbered hills, have been ditched and converted into mowings worth one hundred dollars per acre. Sand from the hills has been spreat on them, and the best grassus flourish. The material dug from the ditches has heen carted into barn-yards, and makes excellent manure. These lands are the very cream of the farms where they have been cleared up. There is no tough compact peat on such lands to work; the material is a rich fine muck or mould. As I have saik, there is a great extent of such lands, but the farmers have never dreamed of their worth. They will now begin to clear and ditch them, as most of them can be easily drained.

\section{A. I. LOVELAND.}

No. 12. Peat from Daniel Buck, Jr., Poquonock, came as itry, quite colherent, hrick-shaped cakes, well decomposed. Color a rich chocolate brown.

\section{Analysis.}

Organic matter soluble in carbonate of soda,

" insoluble in "6 "6 48.84

Total, 76.03 * Inorganic matter, . Water,

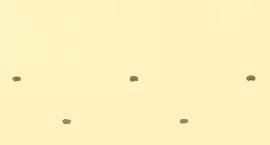

Soluble in water, 2.94 per cent.

Nitrogen, $2.40=2.92$ ammonia.

For answer to Circular see No. 13.

No. 13. Swamp muck from Daniel Buck, Jr., Poquonock. This muck forms the light loose surface layers of the peat No. 12, which it resembles in color.

\footnotetext{
* $\Lambda$ sh is chiefly carbonate and sulphate of lime, and magnesia.
} 


\section{Analysis.}

Organic matter, soluble in carbonate of soda,

" insoluble in " " $\quad$ " 40.51

Total,

*Inorganic matter,

74.17

8.63

Water, -

Soluble in water, 1.80 per cent.

Nitrogen, $2.40=2.92$ ammonia.

ANSWERS TO CIRCULAR.

1. The swamp contains about 15 acres.

2. Its depth at the upper end is about 3 fect; in the center 30 feet.

3. It was drained in 1851 to an average depth of 5 feet.

4. It is a fresh water marsh.

5. It is dry during the summer, say two feet in deptl.

6. It has grown potatoes, carrots, corn and cabbages. Cannot state amount per acre. Stable manure and ashes from burning bogs have been applied to it, but no special manures.

7. Sand is the underlying and adjacent soil.

8. 'T'he swamp receives no wash from hills.

9. It has no inlet; an outlet has been made by draining. It is fed by springs of soft water which suffer no freshets, and are never dry.

10. The sample is from one place, and is of average quality.

11. It does not occur in layers, but in masses, though there is found occasionally a layer of what is called "Stone Peat."

12. 'The trees were cut off in ' 49 and '50-oak, hackmatack, white pines.

13. 'The muck has been applied fresh with good results; the grass is not as tall but thicker and finer and of a darker green in the Spring, than when barn-yard manure is spread on in the Spring.

* $\Lambda$ sh is like that of $\mathrm{No}_{0}, 12$, carbonate and sulphate of lime. By comparing this with the preceding, it is seen that exposure to the air increases the amount of matters soluble in alkalies, but diminishes the portiou soluble in water. 
14. Experiments with the weathered muck have not been made in such a way as to give comparison.

15 and 16. The muck is composted with stable manure in proportion of 8 loads of muck and 4 of manure; but it is principally carted into the barn-yard and pig-styes. The 8 loads of muck and \pm of manure when properly forked orer, are equal to 12 loads barn-yard manure on sandy soil.

17. Muck is the upper crust of swamps, that is, the peat that has been exposed to action of frost and rain, of say 15 inches depth, under that is the peat.

19. As fuel it is equal to soft wood-makes as pleasant a fire to sit by as Cannel coal or hickory wood.

DANIEL BuCK, Jr.

No. 1t. Swamp muck from Philip, Scarborough, Brooklyn. Analysis.

Organic matter soluble in carbonate of soda, $\quad 51.45$

" insoluble " " " " $\quad 25.00$

Total,

*Inorganic matter, - $\quad$ - $\quad$ - $\quad$ - $\quad 7.67$

Water, - $\quad$ - $\quad$ - $\quad$. $\quad$ - $\quad 158$

100.00

Soluble in water, 1.43.

Nitrogen, $1.20=1.46$ ammonia.

ANSWERS TO CIRCULAR.

1. The swamp contains about one hundred acres.

2. No bottom has been found at a depth of 12 fcet. It is probably much deeper.

3. It is drained to about the depth of 2 feet, and has been so beyond my memory.

4. The water is fresh.

5. It is dry throughout the season to the depth of 1 foot.

6. It has once grown potatoes with all appearance of a good crop till they were destroyed by a flood.

* Ash is mostly sulphate of lime, with a little carbonate and some sand. 
7. The soil at the edges of the swamp is a yellow mould.

8. It receives much wash (yellow loam) from the adjacent hill.

9. A small brook runs through the swamp which is never quite dry, and is subject to heavy freshets.

10. The one sample sent is from the mpler end of the swanp.

11. The muck is of uniform quality-very open and porous, so far as has been observed.

12. The only trees in the swamp are maples.

13 and 14. The muck has been dry, and carted in the fall, spread and plowed in in the spring to great advantage for corn crops. I estimate its value at about one-third that of stable-nanure.

15 and 16. One load of muck to one of stable-cellar manure makes a compost equal to two loak of clear manure. In preparing the compost I begin with a layer of muck of 10 inches depth. Upon this the manure is spread, and the whole is covered with muck to the depth of one foot. In this way there is no loss either by volatilization or leaching.

18. It burns well when dry, with smell of sulphur.

(Signed) Philip Scarborougir.

In a communication in the Homestired, Mr. Searborongh say: : "When of the age of twelve years, my father and self, in the fall of the year, carted out of a poud hole upwards of 100 loads re muck, which lay during the winter in load heaps, and was spreat in the spring, plowed in and planted with com, and I have never seen so great a growth of corn since,-at that time, which was about fifty-eight years ago, it was a very common practice to hoe corn in August, and being the plow boy, I remember that when on the horse, the tassels were as high as my head, but the grain was lacking at harvesting, the yield being probably not over forty bushels to the acre; it ought to have gone to one hundred in proportion to the stalks.

I have never used the peat in any form when it was decomposed, but ample returns have been made; on corn, oats, rye, and grass, it has added one-third to the yield." 
No. 15.-Swamp muck from Adams Thite, Brooklyn. When dry formed hard chocolate brown lumps.

\section{Analysis.}

Organic matter soluble in carbonate of soda,

"6

$$
\text { insoluble in }
$$

"

23.14

$$
\text { Total, }
$$

*Inorganic matter, Water,

$$
6
$$

(6)

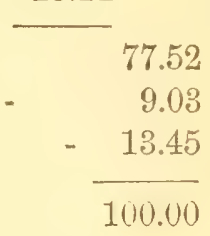

†Soluble in water, 5.90 .

Nitrogen $2.89=3.5 \pm$ ammonia.

ANSWERS TO CIRCULAR.

1. The deposit extends over one acre of surface.

2. The depth is from one to 5 feet-average $2 \frac{1}{2}$ feet.

3. It is undrained.

4. The water is fresh.

5. The surface is dry for two or three months in summer to the depth of 1 to $1 \frac{1}{2}$ feet.

6. No crops have been grown on it.

7. The soil adjoining and beneath is very hard-partly clay.

8. The swamp receives little wash.

9. There is now no inlet or outlet except an old ditch nearly filled up, which takes off a small portion of the surface water. In winter there is some overflow from rains and snows.

11. There is little variation in the quality of the muck, except that it is rather firmer in texture at or near the bottom.

12. The only vegetation on it is coarse grasses and briers.

13 and 14. No use has been made of the unmixed muck.

15. The muck has been composted with stable manure from attle, horses and hoge, ant also with hom-sharings and boneturnings.

16. In composting, 20 loads are drawn on to upland in September and thrown up in a long pile. 'Early in the Spring 20 louds of stable manure are latid along side, and covered with the

\footnotetext{
* Contains some sand and much sulphate, with a little carbonate of lime.

f This water solution contains no salts of iron.
} 
muck. As soon as it has heated moderatily, the whole is forked over and well mixed. This compost has been used for corn (with plaster in the hill,) on elry sindy soil to great alvintage. I consiler the compost worth more per cord than the barn-yard manure. A compost of $500 \mathrm{lbs}$. of horn-shavings to 10 loads of muck and 10 bushels of muleached ashes, mate the best manure I ever used; stable or yarrl manure used beside it did not produce more than half as much. I have used the compost principally for a com crop-alwitys with success-also for potatoes. It is not so good for that crop. For small grain it makes too much straw, and the grain seed is not so heavy.

18. It is a poor fuel.

\section{AdAMs White.}

Randres.-This muck, containing $3 \frac{1}{2}$ per cent. of potential ammonia, besides much salts of lime, is of excellent quality as a fertilizer. It is largely soluble in water, $(6$ per cent.) but no injurious iron compounds are found in the solution. It is to be regretted, that, as Mrr. White informs me, he cannot any more excatrate it exomomically, on accomnt of the obstrueterl draninge.

No. 16.-Swamp muck from Paris Dyer, Browklyn. Grayish black lumps much admixed with soil and easily crushed.

\section{Analysis.}

Organic matter soluble in carbonate of soda, $\quad 18.86$

" insoluble in "6 " $\quad$ " 5.02

Total,

*Inorganic matter,

Water,

Soluble in water, 2.63.

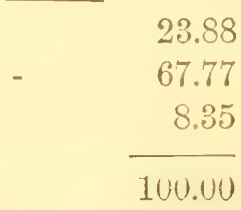

Nitrogen, $1.03=1.26$ ammonia.

No answer to the circular was received from Mr. Dyer. Though so largely mixed with soil, the muck yields a good percentage of nitrogen and would make a very good absorbent.

\footnotetext{
* The ash is mostly sand and soil, and contains but traces of sulphate of lime.
} 
No. 17.-Swamp mnck from Perrin Scarborough, Brooklyn. Color chocolate brown.

$$
\text { Analysis. }
$$

Organic matter *soluble in water,

"Insol.in water, but sol. in carb. soda, 35.10 .

"Insoluble in water and carb. soda, 16.83

Total,

+ Inorganic matter, soluble in water, $\quad 5.96$

" Insoluble in water, but sol. in carb. soda, 4.22

"Insoluble in water and carbonate soda, $\quad 15.60$

$$
\neq \text { Total, }
$$

Water,

Nitrogen, $0.86=1.05$ ammonia.

\section{ANSWER TO CIRCULAR.}

1. The meadow (bog ) is about 40 rods long by 12 rods wide.

2. The muck is $2 \frac{1}{2}$ to 3 feet deep.

3. It is partly drained by a small stream running along one side of the marsh, and also lyy a ditch dug ten years ago, to the depth of 3 feet, and extending one-hatf the length of the marsh.

4. It is a fresh water marsh.

5. The parts adjoining the ditch are rather dry for two or three months in summer.

6. The only yield from the marsh has been one-half ton of poor bog hay per acre.

7. The arljoining and muderlying soil is hard, and is made up of gravel stone and some clay.

8. There is no wash from the adjacent lands.

* This determination is not accurate, but includes some sulphuric acid expelled from sulphate of iron by the heat used in burning off the organic matter.

$\uparrow$ Consists mostly of sulphate of protoxyd of iron, (green vitriol) with much sulphate of lime, and a little sulphate of alumina and common salt.

$\ddagger$ The ash, chiefly oxyd of iron, contains also much sand, as well as the ingredients under $t$. 
9. The stream (of soft water) is not subject to any considerable freshets.

11. At the place where I took the sample, the surface muck to the depth of about 12 inches has a dark color, and then for about two feet, is of a reddish appearance and more compact, being mate up of decayed vexpetable matter and some derayed limbs of trees. When thrown up to the weather and dried, it is as light as a cork. Some portions of it when thrown out to the weather for a short tine, will he covered with a thin white crust that has the taste of alum or saltpetre.

12. No trees are now growing in the marsh. The branches found in the lower muck I should think were pine.

13, 14 and 15. About the only trial I have made was as follows: Seventy-five loads were dug, and left exposed to the weather for one year. I then mixed it with stable manure in the proportion of five loads of muck to one of manure, and applicel in the hill to corn, at the rate of alout twenty-five londs to the acre. The result was not what I expected, although I had a fair crop. After two years but little effect could be seen.

18. It has not been used as fuel.

\section{Perrin Scarborough.}

REMARKS.-As already mentioned, this is the best characterized vitriol-muck of any that I have examined. Mr. Scarborough says above of this muck, that "some portions of it when thrown out to the weather became covered with a thin white crust that has the taste of alum or saltpetre." Doubtless the sample sent for analysis is one of this kind, and therefore represents the worst quality. The "thin white crust" is the sulpluates of iron and alumina, and the presence of these matters in the lower muck accounts for the poor growth of grass, and for the indifferent results of the trial on corn.

The use of the fresh muck, if it contained nearly so much soluble iron compoumls as given in the ahove analysis, would probably be destructive to all crops. The use of lime and ashes, or long weathering, would correct these bad qualities; and so would composting with stathle manure, if the latter were used in sufficient quantity; but the analysis makes it fully evident that this is a material to be used with caution. 
No. 18.-Swamp muck from Geo. K. Virgin, Collinsville. Very dry and light, full of fine (grats.s) roots, which make it retain when dry the form in which it was cut out. Color light brownish gray. "Exposed since last winter." From the grass roots this is evidently the surface muck.

\section{Analysis.}

Organic matter soluble in water,

" insoluble in water but soluble in carbonate of soda, (treated four times,)

" insoluble in water and carbonate of soda,

Total, 31.03

Inorganic matter * soluble in water,

" Insoluble in water but soluble in carb. soda, (treated four times), 9.41

"6 insol. in water and carb. soda, 8.05

tTotal, 57.78 Water,

Nitrogen, $0.64=0.78$ ammonia.

No. 19.--Swamp muck from Geo. K. Virgin, Callinsville. Quite moist, crumbly; contains much micaceous sand. Color chocolate brown. "Taken four feet below the surface."

\section{Analysis.}

Organic matter soluble in water,

" insoluble in water, but soluble in carbonate of soda, (treated three times,)

66 insoluble in water and carbon-

$$
\text { ate of soda, }
$$

* Portion solnble in water consists chiefly of sulphate of lime and salts of iron; the latter in the larger proportion.

t The ash consists mostly of sand, yields to acids much iron, a minute quantity of sulphate of lime, some maguesia, and a trace of phosphoric acid. It contains no carbonate of lime. [See No. 20.] 
Total

* Inorganic matter, soluble in water,

" insoluble in water, but soluble in carbonate of soda, (treated three times,)

" insoluble in water and carbon-

$$
\text { ate of soda, } \quad-\quad \quad-\quad 48.65
$$

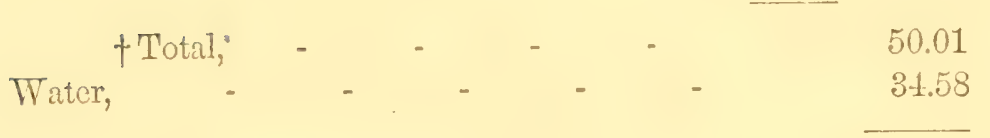

Nitrogen, $0.34=0.41$ ammonia,

No. 20.-Swamp muck from Geo. K. Virgin, Collinsville. Very moist, well decomposed-not lumpy or colierent. Color black. The label was defaced by decay, but the specimen was probibly takin at a dipth internenliate between Nos. Is and 19.

$$
\text { Analysis. }
$$

Organic matter, soluble in water, $\quad$ - $\quad$ - 0.72

"6 insoluble in water but soluble in carbonate of soda, (treated four times, ) $\quad$ - $\quad$ - $\quad 9.31$

" insoluble in water and carbonate of soda, $\quad-\quad \quad-\quad 3.65$

Total, - - - - - -

† Inorganic matter, soluble in water, - 0.25 13.68 insoluble in water but sol-
uble in carbonate of soda,
(treated four times, )
" $\begin{aligned} & \text { insoluble in water and car- } \\ & \text { bonate of soda, - }\end{aligned}$

* Portion soluble in water consists principally of sulphate of lime and salts of iron. + Ash is mostly sand, with a little sulphate of lime and considerable oxyd of iron, soluble in acids. Phosphoric acid and magnesia in traces. [See No. 20. $\ddagger$ Portion soluble in water consists of sulplate of lime with small quantity of salts of iron. 


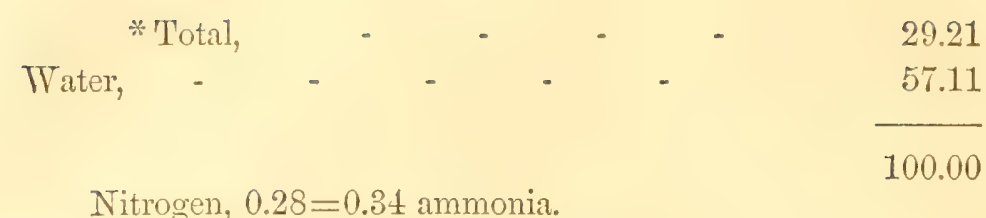

ANSWERS TO CIRCULAR.

1. The swamp contains 5 acres.

2. The greatest depth is 10 feet. The average depth 4 feet.

3. It is undrained.

4. The water is fresh.

5. Parts of the swamp are surface-dry in summer.

6. No erops have been raised on it.

7. On one side of the swamp the soil is a sandy loam, and the other side gravel.

8. It does not receive much wash from the surrounding lands.

9. A small stream fed by springs flows from the swamp.

10. The three samples were taken from one place.

11. Little difference in the quality of the muck at various depths is observed.

12. The swann is occupied by maple, oak and hemlock, with some pine and cedar trees.

$13,14,15$ and 16 . The only trial of this muck was made with a ferw loads that had been exposed to the frost one winter. It was applied to a piece of samily, poor land, and the eflects of it were astonishing.

It has not been used as fuel.

Geo. K. Virgin.

Remarks.-On reference to the table it will be seen that when these three mucks of Mr. Virgin are redueed to the same state of dryness, they agree quite closely in composition. As their content of ammonia when dry is only about 8-10 per cent, and the amount of soluble matters is likewise small, it is obvious that the "astonishing" results observed from its use must be chiefly ascribed to its physical characters-- to its effect in correcting the texture and dryness of the "sandy poor soil."

* Ash almost entirely sand and oxyd of iron, with traces of sulphate of lime and phosphoric acid. 
No. 21. Salt-marsh muck, Solomon Mead, New Haven. Light and porous, coherent from grass roots. Color, greyish brown. Had been long dug and exposed to air.

\section{Anatysis.}

Organic matter soluble in water,

" " insoluble in water but sol. in carb. soda, (treated 6 times,)

" " insoluble in water and carb. soda, 8.20

Total,

Inorganic matter, *soluble in water,

" " insoluble in water, but sol. in

carb. soda, (treated 6 times,) 10.02

6. $\quad$ insol. in water and carb. soda, 23.90

+ Total,

36.52

Thater,

Nitrogen, $1.51=1.81$ ammonia.

1. The marsh is 3 miles long and 80 rods wide. Its contents are estimated at 480 acres.

2. The average depth is 10 feet; greatest depth 1 is to 20 feet.

3. The marsh is partially drained, but cannot be made dry on account of the setting back of tide-water.

4. It is one-half salt, and one-half fresh water marsh. The sample was taken from the fresh water part.

5. The surface of the muck is usually dry in summer to the depth of one to two feet.

6. A few crops of potatoes have been grown on it with good results; but grass is the chicf prodnet. Guano and yatrl manure have been applied.

7 and 8. The marsh receives wash from a considerable extent of territory, the soil being a sand or sandy loam.

* Portion soluble in water contains lime and soda in moderate quantity, still more sulphuric acid and chlorine. No iron.

+ Ash mostly sand, with much oxyd of iron, some salt and sulphate of lime,

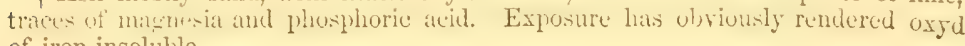
of iron insoluble. 
9. It has both inlet and outlet in a stream of soft water two rods wide that runs through it, and is subject to freshets, but does not dry up in summer.

11. But little variation in the quality of the muck is observed in digging down.

12. Beside bog-meadow grass, there flourish willow, elm, and soft maple trees. But few branches are found in the muck, of what kind it is difficult to determine.

13. The muck has been employed fresh dug for potatoes, \&c., with very favorable results.

14. The long dug muck has been applied to crops with less favorable results, as far as the present crop is concerned, than those furnished by good stable manure.

15. It has been extensively composted with ashes, bones, lime, white fish, yard manures, sty and slaughter-yard materials, plaster, guano, night soil, \&c., \&c., with great advantage.

16. In preparing composts, the pile is commenced by a layer of muck say one foot deep, then a layer of yard manure say 8 inches deep is laid on, and so alternately to the top. For composts with night soil, I use three or four times its bulk of muck; with guano or ashes the proportion of muck is still increased.

18. It has not been used to any extent as fuel.

S. MEAD.

No. 22. Swamp muck from Eilvin IIoyt, New Cinaan, light and loose in texture, not coherent, much intermixed with soil. Color, light brownish grey.

\section{Analysis.}

Organic matter, soluble in water,

" insoluble in water but soluble in carbonate of soda, (treated three times,) $\quad$ - 13.42

" insoluble in water and carbonate

$$
\text { of soda, - } \quad \text { - } \quad \text { - } \quad 7.55
$$

Total 
Inorganic matter *soluble in water, .

" insoluble in water but soluble

in carbonate of soda, (treated three times, - 19.88

66 insol. in water and carb. soda, 46.30

Water, Total, - . . . . -

Nitrogen, $0.45=0.54$ ammonia.

For answer to Circular see No. 24.

No. 23. Swamp muck (No. 22, saturated with horse urine, having been put under the stalls. Elwin Hoyt, New Cauaan. Color darker than No. 22.

Analysis.

Organic matter, soluble in water, - _ $\quad 2.34$

" insoluble in water but soluble in carbonate of soda, (treated three times,) " - " 13.49

" insol. in water and carb. soda, 8.05

Total,

† Inorganic matter, soluble in water, -

" insol. in water but sol. in carb.

" insol. in water and carb. soda, 56.20

Water,

§ Total,

Nitrogen $0.90=1.09$ ammonia.

For answer to circular see No. 24.

* Portiom soluble in water consists alunot cutirely of sulphate of iron, and perhaps organic salts of the same base. No lime.

+ Mostly sand and soil. In the acid solution were found much iron, a little sul. phuric acid lime and magnesia, and traces of phosphoric acid.

¥Portion soluhle in water contaius large quantities of lime, sulphuric acid, chlorine and carbonic acid, but only a slight trace of iron. It thus appear's that the iron existing in the peat (No. 22) in the soluble form, is rendered insolnule by composting.

$\$$ Ash, as No. 22, but containing larger quantities of sulphuric and phosphoric acids, of lime and magnesia. 


\section{2}

No. 21. Swamp muck No. 22 composted with white fish. Edwin Hoyt, New Canaan. Color darker than No. 23. No evidence of the fish except a few bones.

\section{Analysis.}

Organic matter, soluble in water,

" Insoluble in water but soluble in carbonate of soda, (treated three times,)

66

Insoluble in water and carbonate of soda, - $\quad$ - $\quad 8.00$

Total

* Inorganic matter, soluble in water,

26.44

" insol. in water but sol, in carb. soda, (treated three times,) 14.13

" insol. in water and carb. soda, 51.10

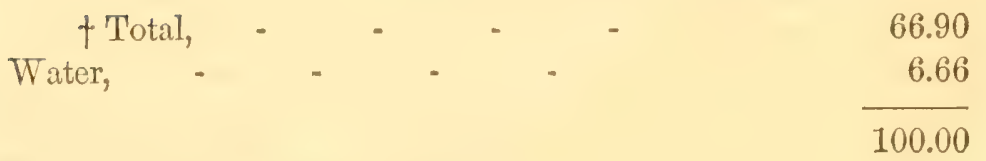

Nitrogen, $1.01=1.22$ ammonia.

ANSTERS TO CIRCULAR.

1. The swamp is nearly square, and contains about 10 acres.

2. The average depth of muck is about 5 feet. The greatest depth is 12 feet or more, although we do not take it out below 8 feet.

3. It was drained four years ago to the depth of 5 feet.

4. It is a fresh water marsh.

5. The upper portions are always dry to the level of the outlet, except as wetted by rains.

6. Four acres were thoroughly underdrained four years ago, and planted with corn and potatoes. The yield of potatoes was exceedingly fine. The crop of corn was good-more than an average yield. The tillage not being as complete as we desired

* Portion soluble in water consists principally of sulphate of lime, with only traces of iron. In this case, as in No. 23 , the soluble salts of iron contained in the peat are, by composting rendered insoluble.

+ Ash as Nos. 22 and 23, but sulphuric and phosphoric acids, lime and magnesia, present in still larger quantities. 


\section{3}

for seeding, it was planted with corn the second season. The yiekl was gond-full sixty bushels per acre. 'The third scason it was seeded with oats, which grew very rapidly and promised a large crop, but just as they began to fill, about one-third of them lorlged. That portion which stood up filled well, and yielded at the rate of fifty bushels per acre. This, the fourth season, the piece was in gruss, the crop was more than average, yet wonlil have been larger had not the young grass all been lilled under that portion of the field where the oats fell. No manure has been used on the swamp.

7. The surrounding soil is gravel, with a mixture of clay. The bed of the swamp after the muck is removed, presents a very stony surface like that of the neighboring uplands.

8. The swamp receives but little wash from the arljoining hills.

9. A small stream flows through it that is liable to freshets, but never dries up.

11. There are some variations in its appearance at different depths. The first two feet it is very black and crumbly, and is male up of very fine particles, I suppose on account of its being plowed and exposed to frost and weather. For the next three or four feet it has a reddish cast and considerable odur. This layer appears to contain more vegetable matter. At this depth we sometimes find logs as large as a man's body, and have traced out whole trees, which at first are as ensily cut through with the spade as any part of the muck, but after exposure, they become quite hard. This layer we consider the most valuable, and is such as I sent your. See No. 22. Below a depth of 6 feet it has a lighter color, and contains less vegetable matter. At a depth of 8 feet clay preilominates, and it is not worth carting out upon our soils.

12. The swamp was once covered with maple, elm, and redash trees. But for a number of years one-half has been in meatlow and the other half is covered with bogs. Near the main ditch the bogs are rapidly dying out and mity be easily licked to pieces, which I attribute to the draining.

13. It has not been used fresh from the swamp, as we con- 
sider this manner of application very wasteful. The have always composted it except in one instance, which is given below.

14. The long dug and exposed muck has been once experimented on as follows: Four years ago, this Autumn, (1858,) we drew a large quantity of it upon a field designed for corn the following season. A portion of this muck was conposted with horse-dung, (about 5 of muck to 1 of dung;) the pile heated and fermented well and was turned once before nsing. The remainder of the muck was left untouched until about the middle of May. At this time the muck and compost were each spread and plowed in on separate portions of the field at the rate of 40 loads per acre. 'The result was very marked, and was distinguishable as far as the field could be seen. 'The corn where the stable compost was applied showed a decicled gain over the other parts of the field after it was two weeks old, and kept ahear throughout the scasm. The yield by the compost was nearly double that of the clear muck. I do not think the yield was much increased by the application of muck alone. The oat crop following the corn, was also much the best where the stible compost was applied to the other ; so also the grass.

15. The muck has been much employed by us as an absorbent. Our horse stables are constructed with a movalble floor and pit beneath which holds 20 loads of muck of 25 bushels per luat. Spring and fill this pit is filled with fresh muck which receives all the urine of the horses, and being occasionally worker over and mixed fumishes us annually with 40 louds of the most valuable manure. See No. 23.

Our stables are sprinkled with muck every morning at the rate of one bushel per stall, and the smell of ammonia, de., so offensive in most stables, is never perceived in ours. Not only are the stables kept sweet, but the ammonia is saved by this procedure. Our privies are also deodorized by the use of muck, which is sprinkled over the surface of the pit once a werk, and from them alone we thus prepare ammally enongh "ponchette" to manure our com in the hill. The wagons we use in thawing fish in the summer shortly beeome very oftensive from the blood, oil, de., which actheres to them; but a slight sprinkling of muck renders them perfectly inodorous in a slourt space of time. 
16. Very much of our muck is composted with yard manure. Our proportions are one load of manure to three of muck. I think as much muck should be used as can be made to heat properly. The quantity varies of course with the kind of ma. nure employed.

We nse muck largely in our harn-yards, and after it beeomes thommlyly saturated and internixed with the droplungs of the stock, it is piled up to ferment, and the yard is covered again with fresh muck. Wre are convineed that the oftener a compost pile of yard manure and. muck is worked over after fermenting, the better. We work it over and add to it a little more muck and other material, and the air being thes allowerl to penetrate it, a new fermentation or heating talies place, rendering it more decomposable and valuable.

During the prestent season, (1858,) we have composterl about 200,000 white fish with about 700 loaks $(17,500$ luskels, of muck. We vary the proportions somewhat according to the crop the compost is intended for. For rye we apply 20 to 25

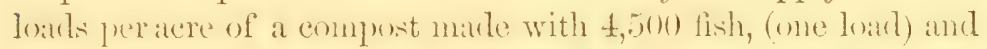
with this manuring, no matter how poor the soil, the rye will be as large as a man can cradle. Much of ours we have to reap. For oats we use less fish, as this crop is apt to lodge. For corn, one part fish to ten or twelve muck is about right, while for grass or any top-dressing, the proportion of fish may be increased.

We find it is best to mix the fish in the summer and not use the compost until the next spring and summer. Yet we are obliged to use in Sept. for our winter rye a great deal of the compust made in July. We usually compost the first arrivals of fish in June for our winter grain; after this pile has stood three or four weeks it is workerl over thoroughly. In this space of time the fish beenme pretty well decomposed, thongh they still preserve their form and smell outrageonsly. As the pile is worked over, a sprinkling of muck or plaster is given to retain any escaping ammonia. At the time of use in September the fisth have completely disappeared, bones and fins excepted.

The effect on the muck is to blacken it and make it more loose and crumbly. As to the results of the use of this compost, we 
find them in the highest degree satisfactory. We have raised 30 to 35 bushels of rye per acre on land that without it could have yielded 6 or 8 bushcls at the utmost. This year we have corn that will give 60 to 70 bushcls per acre, that otherwise woukl yield but 20 to 25 bushels. It makes large potatoes, excellent turnips and carrots.

18. It is not suitable for fuel.

19. I will add one other fact relative to its absorbent power. We collect the (human) urine in barrels conveniently disposed about our premises. One of these having become full and very offensive, I proposed to filter it throngh muck. Another barrel was accordingly filled with the latter and the putrid urine poured upon it. Although the stench of the urine was so intense that it was hardly possible to proceed with the operation, it was all filtered through the muck, and came out preffectly cleur, odorless, and with no more taste than pure water would acquire by running through the muck.

EDwin Hoyt.

REMARKS.- When we compare the quality of the muck employed by the Messrs. Hoyt, as shown by the analysis, with the great results they have made it yield in their favor, we have a fine illustration of the merits of muck as an absorbent and amendment.

The muck is of poor quality, eontaining in the dry state but twenty-six per cent of organic matter and one-half of one.per cent of potential ammonia, and being in the fresh state considerably charged with salts of iron. But the composts with horseunine and with fish are admirable fertilizers, as proved by analysis, and especially by the crops grown with their aid. In the composts we find all the iron insoluble, and as stated p.131, the pereentages of ammonia doubled. The Messrs. IIovt wonld have found it impossible to cconomize their manure in any other way to nearly the extent they are enabled to do by the use of muck, which, though it must be hauled up a long steep hill, at great expense, is of incalculable advantage to their farm. It must not be forgotton, however, that the success of the Messrs. Hoyt is due not only to the use of muck, but also to the enterprise which they expend in laying hold of every form of fertil- 
izing material within their reach, and to their systematic employment of thorough drainage, deep tillage and all other scientific improvements.

No. 25. Swamp muck from A. M. Maling, Rockville, fresh dug. Color snuff-brown, with a little white fiber.

\section{Analysis.}

Organic matter soluble in water, _ _ _ $\quad$ - 3.43

" insol. in water but sol. in carb. soda, (treated eight times,) $\quad-52.15$

" insol. in water and carb. soda, 8.65

Total, - $\quad$ - $\quad$ - $\quad$ - $\quad$ - 64.23

Inorganic matter *soluble in water, - - 0.35

"6 insol, in water but sol. in carb. soda, (treated eight times,) $\quad 0.16$

" insol. in water and carb. soda, 4.90

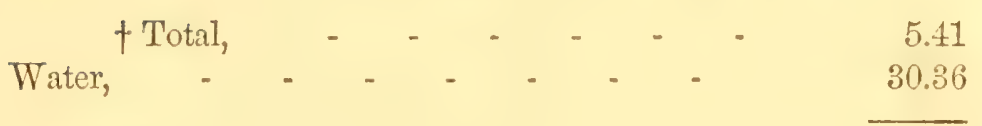

Nitrogen $1.62=1.97$ ammonia.

For answer to circular see No. 26.

No. 26. Swamp muck, A. M. Haling, Rockville, like No. 25 , but exposed two years.

* Portion soluble in water consists chiefly of sulphate of lime; contains a trace of salts of iron.

+ Contains much sand, no carbonate of lime, much oxyd of iron, some sulphate of lime and magnesia, and more phosphoric acid than most of the peats that I have $x$ amined. 
Analysis.

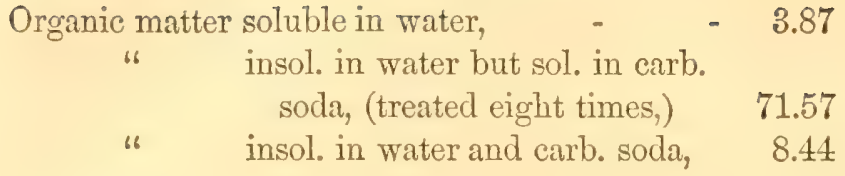

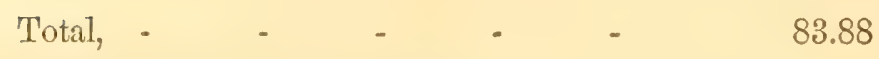

* Inorganic matter soluble in water, _ $\quad 0.23$

" insol, in water but sol, in

carb. soda, (treated eight times,) - - $\quad-0.00$

" insol. in water and carb.

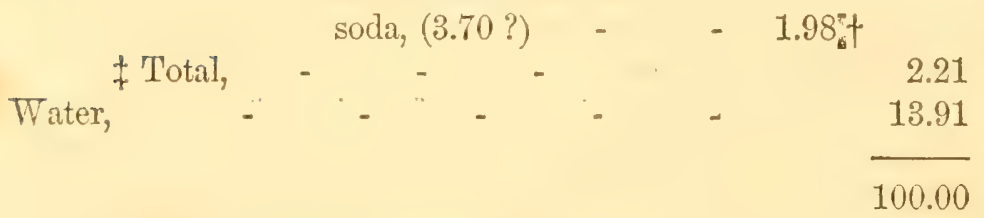

Nitrogen, $132=1.60$ ammenia.

ANSWERS TO CIRCULAR.

1. The swamp from which Nos. 25 and 26 were dug is oval in shape and contains about five acres.

2. The greatest depth of muck or peat is ten feet, averaging about two feet.

3. It is not drained.

4. It is fresh water.

5. It is dug in very dry summers to the depth of four to five fiet.

6. No crops have been raised on the swamp.

* Portion soluble in water consists chiefly of sulphate of lime and salts of iron.

+ This peat yields upon ignition 2.21 per cent of ash, (average of two determinations-2.18 per cent and 2.23 per cent). Deducting the amount of inorganic matter soluble in water, $(0.23$ per cent) there should remain 1.98 per cent as the amount of inorganic matter insoluble in water and carbonate of soda. But the residue, insoluble in carbonate of soda yields 3.70 per cent of ash. As all traces of carbonate of soda were thoroughly removed by repeated treatments with boiling water, may not this discrepancy in the result be due to the fuct that a portion of the soda has formed an insoluble combination with the organic matter that it was not capable of dissolving (?)

$\ddagger$ Ash as No. 25. 
7. The soil at the edges of the swamp is quite gravelly and open, underlaid with fine sand. At the depth of five to six fuet underlying the swamp, is the hardest kind of gravel that I ever saw.

8. The swamp does not receive wash from any source, the land surrounding it being nearly level.

9. The swamp has neither inlet or outlet.

10. The two samples 25 and 26 are from one place.

11. There is not any pereeptible variation in the cquality of the muck at different depths.

12. The swamp is covered with a small bush resembling the low laurel, with an occasional stunted maple.

$13,14,15,16,17$ and 18. Has not been used either as a manure absorbent or fuel.

\section{A. M. Haling.}

Reurarks-If Mr. Iniling succeeds in drying this swamp which he is engaged in trying to effect by digging a well near it, he will doubtless find this muck an exeellent absombent, and adjunct to mineral manures. The inorganic matters are small in quantity, but, after exposure, of good quality. Silts of lime and phospluoric acid are present in larger relative quintity than usual.

No. 27.-Swamp muck from $\Lambda$. Mr. Maling, Rockville. Fresh dug; color, snuff" brown. "A good substitute for barn-yard manure."

Analysis.

Organic matter soluble in water, $\quad-\quad-\quad-3.87$

" insol. in water but sol. in carb. soda, (treated seven times,) 44.04

" insol. in water and carb. soda, 4.25

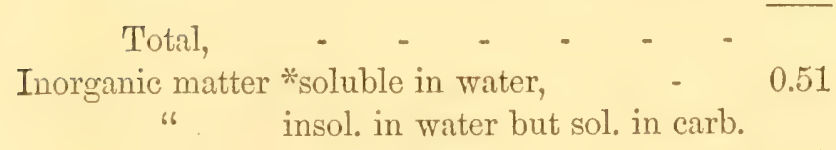

52.16 soda, (treated seven times,) 4.07

" insol, in water and carb. soda, 5.05

\footnotetext{
* Portion soluble in water contains iron and sulphuric acid in considerable quantities, lime and cerbonic acid small.
} 


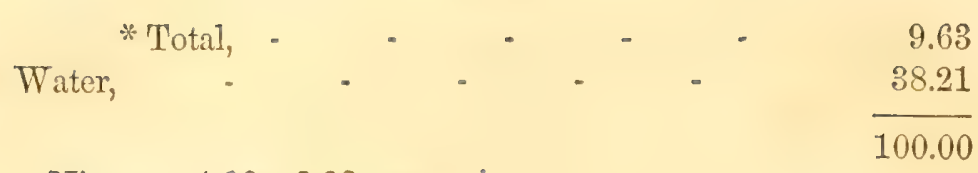

Nitrogen $1.88=2.28$ ammonia.

\section{ANSWERS TO CIRCULAR.}

1. The sample No. 27 is from a swamp of about 10 rods in width and 30 rods in length.

2. The average depth is about 18 inches, while in holes of 20 to .50 feet in diameter it is 8 to 10 feet $^{\circ}$ deep.

3 and 5. It is drained and is dry to the depth of 2 feet below the surface.

4. It is a fresh water swamp.

6. During the four years since it was drained it has produced grass at the rate of $1 \frac{1}{2}$ tons of hay per acre.

7. The adjoining and underlying soil is a black loam with clay subsoil, except at the lower end of the swamp where it is a coarse gravel.

8. It does not receive much wash, as there is no stream running through it,

12. Oak trees of 12 to 15 inches diameter have been found in some of the holes spoken of, at a depth of 2 to 4 feet below the surface.

13. The muck has only been used as a top-dresssing on grass and with excellent results.

A. M. HaLing.

Rex.1RKs.-Ammonia and phosphoric acid are both present in this muck in considerable quantity, the soluble salts of iron are not abundant enough to be detrimental; sulphates and carbonates of lime and magnesia are also contained in it. The swamp is small, is surrounded with a rich surface soil, rests on a retentive clay bottom, had no ontlet, and for years has been a repository for the leaves and debris of a hard-wood vegetation, latterly of grasses, so that taking into the account its amending qualities, we cannot wonder that it should be a "good substitute for barn-yard manure on light gravelly soils."

* Ash contains much sand and oxyd of iron, but also considerable quantities of magnesia, carbonate, sulphate and some phosphate of lime. 


\section{1}

No. 28. Peat from Albert Day, Brooklyn. Color very dark brown, almost black, quite coherent and hard, even when not dry. Thought to be injurious to crops.

Organic matter soluble in water, - - - $\quad$ - 2.45

" insol. in water but sol. in carb.

soda, (treated nine times,) $\quad 46.25$

" insol. in water and carb. soda, 6.35

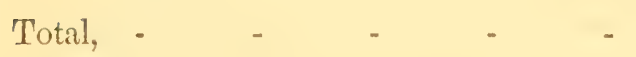

55.05

Inorganic matter *soluble in water, $\quad$ - $\quad 0.32$

" insol. in water but sol. in carb. soda, (treated nine times, $\quad 0.65$

" insol. in water and carb. soda, 5.40

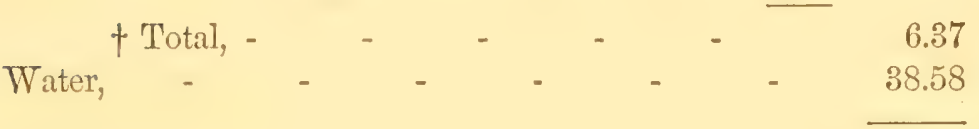

100.00

Nitrogen, $0.84=1.02$ ammonia.

ANSIEERS TO CIRCULAR.

1. The swamp is nearly circular, and covers about one-fourth of an acre.

2. It lies in a sort of basin; about twelve feet deep in the center, and but a few inches at the edge.

3. It is not drained.

4. It is a fresh water marsh.

5. The upper portion is dry eight or ten inches in very dry seasons only.

7. The soil underlying and at the edges of the swamp is sand and clay.

8. It does not receive any wash from hills.

9. The swamp has an outlet where a small quantity of water is discharged in wet weather only. I think the water is soft.

* Portion soluble in water consists mostly of sulphate of lime and a trace of iron. No carbonic acid.

+ Ash nearly free from sand, contains much iron, considerable sulphate of lime, a little carbonate of lime, and traces of magnesia and phosphoric acid. 


\section{2}

10. Two smples sent in one box from different places in the swamp.*

11. The muck at the surfice to the depth of sixteen or eighteen inches is quite black, with less appearance of undecayed vegetable matter than it has below that depth, where it leegins to have a reddish color, and at the depth of $2 \frac{1}{2}$ or 3 feet is quite red, or brown, to the bottom of the deposit.

12. A few stinted maples, coarse grass and moss grow on it. $\Lambda$ the depth of four or six feet, logs and limbs are found, which resemble cedar or hemlock more nearly than anything else.

13. It has not been used fresh.

14. This muck was applied 20 years ago by my father, and he thought it very useful, thongh no such definite trials were made as to test its value satisfactorily. I have used it in large quantities in my hog and cattle yards, (before completing my barn-cedlar) but have seen no more benefit from it thus employed than form loam (from the romleside or head-lands on my fields) used in the same manner. This led me to attempt testing it more carefully.

In 1852 I carted out 250 to 300 loads of the peat and piled it on a lot adjoining the swamp. After six monthis had expired I drew most of it into my yarls, leaving 8 or 10 loads in the field. Iere it remained two winters, covering a space of about a square rod to the depth of six inches. It was then plowed in and the field planted to corn. The soil was light and friable, resting on a loose sandy or gravelly sub-soil. The whole field was otherwise manured alike. The only difference I could perceive in the corn upon the two portions, was not in favor of the peat; it diminished rather than inereased the growth, and during several following years the succecling crops of oats and grass were less where the peat had been applied. One load of muck was used as a top-dressing for grass which looked fresh for a few days, but no material effect was produced upon the quantity of hay. Two loads were taken to my orchard and a bushel put around each tree and worked into the soil, and the growth was less than during any previous year.

* When the box was opened the different samples could not be distinguished by appearance, and one analysis was made on a mixture of several fragments. 
15) and 16. Having hearl of the adrantages of eomposting muck with soda asth and guano, I purchised a quantity of each for trial. Ten loads (thirty bushels each) of muck were composted with $175 \mathrm{lbs}$. soda ash, and ten lomeds of muck with 175 lbs. of guano, * and these compustis were used separately on my corn land at the rate of 50 loads per acre, sown broadcast and thoronghly harrowed in. The corn on the plots thus treated, gave about the same yield as on the remainder of the field that was dressed with 12 loads of hog-manure per acre. An adjoining field harl been manured with long mamure and planted with potatoes. I selected twelve rows and put into each bill, on six of them, a full shovel full of the sorla-ash compost, and on the remainder as much of the grano compost, and I am decibelly of the opinion that the corn was poorer where the muck composts were applied, than elsewhere.

18. The peat has not been used as fuel.

Alibert Day.

Resarks.-I could but feel mueh interest in the result of the analysis of Mr. Day's muck after hearing from lise orn lips the account of its failure to do any good, or rather of its positively deleterious action. I was therefore surprised to find nothing in the sample he sent that would accomt for its ill eflects. Still I am able to gather from the letter's of Mr. Inar, what is desibtless the true state of the case.

Mr. Day wrote me in one of his interesting letters as follows: "I have noticed when plowing the field adjoining the muck swamp, that near the latter a decp furrow of eight or ten inches would bring up a reddish, rather hard substance, resembliner iron rust, and the peat at the depth of four feet has nearly the same reddish color."

Fiuther, the muck of Mrr. Day's sending, thongh containing but very little soluble salts of iron, does contain much oxyd of iron, and ats Mr. Day exeuses his delay in sending it (Junt 1sis, ) on account of water in the swamp, it is probable that the samples he did semt were surfure specinems perhalps from the muryin of the swany, that had been, aceordingly, exposed to air and washed

* I have always doubted the genuineness of this guano. 
so that they do not represent the mass of the muck, which is probably more or less impregnated with soluble iron compound.

The swamp is an undrained basin that only discharges water in wet weather, consequently the mass of muck retains any injurious matters that may find their way into it.

But why should these ill results follow when "the muck in each instance of experiment has been exposed to the atmosphere a year or more and not used in a raw state?" The muck itself is quite coherent and hard even when not dry, and we can readily understand that if thrown up in a high heap, a year's exposure might not suffice to oxydize or wash out the iron, and from the trials with it after use as an absorbent in the yards, it would seem that the quantity of injurious iron compounds in it is quite large at first.

No. 29.-Peat from Chamecy Goodyear, Beaver Pond, New Inaven. Tery hard, tough, black cakes, that had to be eut with a hatchet in order to be reducel to powder. "As good as fresh cow-dung."

Analysis.

Organic matter soluble in water, - $\quad 1.80$

" insoluble in water but soluble in

carbonate of soda, (treated eight times, ) - $\quad$ - $\quad 45.42$

" insoluble in water and carbonate

of soda, - - $\quad$ - $\quad 10.35$

\section{Total;}

57.57

Inorganic matter *soluble in water,

0.35

" Insoluble in water but soluble in

carb. soda, (treated eight times), 7.98

" insol. in water and carb. soda, 18.80

Water, Hotal, - - . - - $\begin{array}{r}27.13 \\ 15.30 \\ \hline 100.00\end{array}$

Nitrogen, $1.68=2.04$ ammonia.

* Portion soluble in water consists principally of sulphate and carbonate of lime and salts of iron; contains traces of chlorine.

+ Much fine sand, with oxyd of iron, and some carbonate and sulphate of lime, and traces of phosphoric acid and magnesia. 


\section{ANSWERS TO CIRCULAR.}

1. The Beaver Pond swamp is about one mile long by onefourth of a mile wide.

2. The muck has been excavated to the depth of eight feet, and is probably much deeper.

3. The swamp has been more or less ditched, but not drained.

4 and 5 . The water is fresh and soft, and stands at nearly the same level throughout the year, except at-

6. The upper end which is higher and where several acres have been cultivated, and always give good crops even in the dryest seasons.

7. The soil adjoining is sand and gravel.

8. There is some wash from the adjacent lands.

11. Where the sample was taken, the muck is of nearly miform quality at all depths, though somewhat lighter at the depth of four feet.

12. The vegetation in the swamp consists of coarse grass and other aquatic herbage together with willow and cedar trees.

13. The muck has been largely used in the fresh state, and in this condition is as good as cow-dung.

15. The muck has been variously composted, especially with fish and with excellent results.

18. It makes good fuel.

\section{Chauncey Goodyear.}

ReMARKs.-This muck lying near the city of New Haven, is in great request in the city gardens, and the ownership of the swamp itself is divided among many persons, who find it extremely useful to give body and retentiveness to the hungry city soil. The analysis shows that its direct fertilizing qualities are also by no neans inconsiderable, and it deserves to come into still more extensive use.

No. 30.-Salt marsh muck from Rev. Wm. Clift, Stonington. Color rich snuff-brown. 


\section{Analysis.}

Organic matter soluble in water,

"Insol. in water, but sol. in carb. soda, 51.68

" Insoluble in water and carb. soda, $\quad 9.80$

$$
\text { Total, }
$$

* Inorganic matter, soluble in water,

"Insol. in water, but sol. in carb. soda, 7. 0.00

" $\quad$ Insol. in water and carbonate soda, (7.45?) 5.16

$$
\begin{aligned}
& \text { ₹ Total, } \\
& \text { Water, }
\end{aligned}
$$

Nitrogen, $0.95=1.16$ ammonia.

\section{ANSIVERS TO CIRCULAR.}

1. The marsh embraces about nine acres, lying immediately north of the track of the Proviclence \& Stonington railroad. It is about three times as long as broad.

2. Average depth 5 feet; greatest 8 feet.

3. Drained 18 inches deep.

4. Originally a fresh-water swamp, until a hundred years ago or more, when the tide broke in. A foot or more on top is made up of marine deposite. $\Lambda$ tide gate was put in in the fall of 1855 .

5. The water stands about 18 inches below the surfice during the summer.

6. Fine crops have grown upon it this season; two tons or more to the acre of herds-grass and clover, good corn, potatoes, beans and turnips on a small portion. The manures used were pig-clung, superphosphate of lime and horse flesh composted with muck for the hoed crops.

* Portion soluble in water contains sulpluric acid, soda and chlorine in considerable quantities, as also traces of lime and iron. No carbonic acid.

t See noto under No. 26.

$\ddagger$ Asl contains large quantities of sulyhuric acid, lime and magnesia, considerable common salt, traces of phosphoric acid. 
7. The soil underlying and near is a clayey gravel and yellowish loam.

8. Very little wash is received by the marsh.

9. A small brook runs through the marsh, say four months in winter and spring, coming down from drained swamps above. The brook is sometimes swollen full, but is dry in surnmer.

10. The sample was taken from various parts of the marsh.

11. Not much difference is observable in the character of the muck at various depths after passing through the salt marsh turf-decayed stumps and logs are common, mostly majle.

12. Once the whole was probibly a maple swamp, with other swamp brush-wood.

13. It has not been used fresh; is too acid; even potatoes do not yield well in it the first season, without manure.

14 and 15. Nearly all the muck used has been composted with stable manures-fish, lime, se. It makes excellent berding liept in the stables, and when applied to crops has always given good returns.

16. No accurate rules are observed in composting. Three or four loads of muck to one of stable manure, put together in the fall or winter in alternate layers, and forked over twice before spreading and plowing in, may represent the method of composting.

I consider a compost made of one load of stable manure and three of muck, equal in value to four loads of yard manure. Almost all garden plants, particularly grape vines and strawlerrer plants, show a strong affinity for the undecomposed bits of salt marsh turf in the soil. The roots are matted in with it, so that it is impossible to separate them.

18. It has been used some for fuel, and though not first rate, burns well.

19. I consider the salt marsh as reclaimed worth three hundred dollars an acre, and think it will pay the interest on that sum as long as it is properly cared for. These marshes are anong the most valuable grass lands in the state, and ought to receive the immediate attention of their owners. 
Remarks.-There is one point in the history of this muck that deserves further notice. Mr. Clift mentions that it is not applied in the fresh state- "it is too acid" and requires exposure before it can be used profitably.

By the term "too acid" Mr. Clift cloubtless intends merely to designate in the customary manner its hurtful quality when fresh, without expressing a definite opinion as to the cause. The presence of so much ( 8.4 per cent. of the dry muck) soluble matters is the reason why it must be weathered or composted, and these soluble bodies are chiefly common salt, sulphate of magnesia, and perhaps alkaline crenates and humates, which are partly washed ont or destroyed by weathering. It is probably these saline matters toward which the affinity of the roots of vegetables and garden plants is especially manifested.

It is not unlikely that in some parts of the marsh, sulphate of iron may be found, as is the case with the salt marsh mud, No. 33 from the same vicinity.

No. 31.-Swamp muck from Henry Keeler, South Salem, N. Y. Dug April, 1858. Color, light snuff-brown. Analysis.

Organic matter soluble in water,

" " insoluble in water but sol. in carb. soda, (treated 8 times,)

" " insoluble in water and ćarb. soda, 12.05

Total, 59.30

Inorganic matter, *soluble in water,

0.78

" " insoluble in water, but sol. in carb. soda, (treated 8 times, $\quad 3.79$

" " insol. in water and carb. soda, 16.70 †Total,
Water, (1)

Nitrogen, 1.57-1.90 ammonia.

* Portion soluble in water contains much sulphuric acid and iron, also lime in considerable quantity.

+ Ash contains much sand, and large quantities of carbonate and sulphate of lime, with oxyd of iron, magnesia and phosphoric acid. 


\section{ANSWERS TO CIRCULAR.}

1. The swamp contains about one-half acre.

2. The greatest depth of muck is 10 feet, the average 5 feet.

3. It was partially draiued a few years ago by ditches 3 or 4 feet deep.

4. The water is fresh.

5. During summer the muck is dry to the depth of 3 to $4 \mathrm{ft}$.

6. No crops have been cultivated in the swamp.

7. The swamp is underlaid by rock, the soil about is clay loam.

8. The swamp receives some wash from a steep granite hill covered with a rocky soil.

9. The inlets and outlets are small but permanent springs.

11. The muck is alike at all depths as far as drained.

12. The vegetation consists of a few small ash, white wood, and soft maple trees and swamp weeds. It is too much shaded for grasses.

13. Has been used in the fresh state applied to com and potatoes, and appears to be equal to good barn manure.

14. It has rarely been weathered more than two months, and then applied side by side with the best yard manure has given equally good results.

15 aud 16. Was been composted with an equal quantity of yard manure to advantage.

19. When dry this muck is friable and easily putrerized. I have used it fresh dug with potatoes, putting about two quarts in the hill and dropping the potato on it, and the yicld was oneeight more than on the same soil without muck.

\section{Henry Keeler.}

Remarks.-This muck hardly differs from leaf-monld, and since it contains all the mineral matters of leaves as well as a grood pereentage of potential ammonia, it is readily understood how it may equal good yard manure in its effects.

No. 32.-Peat from John Arams, Salisbury, (Falls Village.) Color, light snuff-brown, overlies a bed of shell-marl. 


\section{Analysis.}

Organic matter, soluble in water,

" insoluble in water but soluble in carbonate of soda, (treated eight times, ) - $\quad$ - 42.87

" insoluble in water and carbonate

$$
\text { of soda, - } \quad \text { - } \quad \text { - } 10.65
$$

\section{Total,}

* Inorganic matter, soluble in water,

" insoluble in water, but sol.

able in carbonate of soda, (treated eight times, )

" insoluble in water and carbon-

$$
\text { ate of soda, } \quad-\quad \quad-14.35
$$

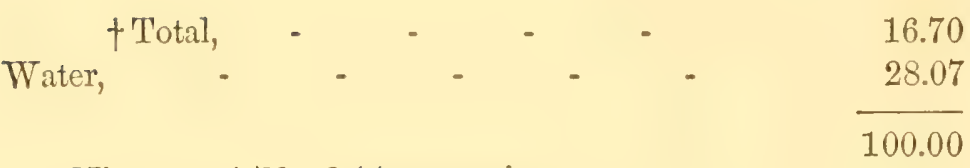

Nitrogen, $1.76=2.14$ ammonia,

ANSWERS TO CIRCULAR.

1. The lot containing the muck and marl (No. 34, is about 50 rods long, and from 15 to 20 wide, and contains about 5 acres.

2. The average depth of the muck is about 5 feet and in some places it is 12 feet deep.

3. It is drained 12 inches deep.

4. It is a fresh water swamp.

5. It is difficult to drive oxen on most of it except in the very dryest times.

6. Never has been cultivated; produces nothing but coarse grass.

7. The neighboring soil is sand underlaid by a blue hard pan.

* Portion soluble in water contains much sulphate of lime, with traces of salts of iron, chloride of sodium and silica. The ash contains some carbonic acid.

+ Ash consists of sand, with much oxyd of iron, much carbonate and sulphate of lime, traces of magnesia and phosphoric acid, no potash. 


\section{1}

8. The swamp receives a good deal of wash from the high hills west of it.

9. It has large springs for inlets, and sufficient outlet. The water is hard. In freshets has a quick flooding of water from large hills.

11. There appears not to be any pereeptible differences in the layers of muck.

12. The swamp was formerly covered with alders, should think pine had grown there generations ago.

13. Sume of the muck has been used fresh from the swamp with very little effect.

1t. The exposed muck does not compare as a fertilizer with any of the ordinary manure.

15. I have used the muck as an absorbent in my log-pen, and also mixed with stable manure, with good results.

16. IIave not composted in any other way than specified in 15 .

18. The muck burns pretty well as fuel.

JOHN ADAMIS. 


\section{A P PENDIX.}

No. 33.- Salt marsh mud from Rev. Wm. Clift, Stonington. Color when dry dark ash-gray.

Analysis.

Organic matter, soluble in water,

" insoluble in water but soluble in carbonate of soda, (treated five times, ) - $\quad$ - 16.72

" insoluble in water and carbonate of soda, $\quad-\quad \cdot \quad 7.25$

Total, - $\quad$ - $\quad$ - $\quad$ -

* Inorganic matter, soluble in water, - $\quad 7.40$

" insoluble in water but soluble in carbonate of soda, (treated five times, )

" insoluble in water and carbonate of soda, - $\quad 48.05$

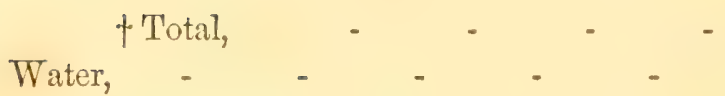

Nitrogen, $1.32=1.59$ ammonia.

REMARKs.-This mud is "from the bottom of a salt marsh ditch where the tide flows daily." After such treatment as is adapted to remove or decompose the soluble iron salts, (compost-

* Portion soluble in water contains sulphuric acid, chlorine, iron, lime, potash and soda in large quantities.

+ Ash chiefly sand, yields to acids much oxyd of iron, sulphates of lime, iron and magnesia, also potash and soda with traces of phosphoric acid. This marsh mud yields to pure water sulphate of protoxyd of iron (green vitriol,) in small quantities, and when burned, pungent vapors of sulphuric acid are expelled from it. 
ing with lime, fish or stable manure,) this mud must make an excellent fertilizer, as it contains much more saline matters thim are met with in any muck or peat, and is by no means deficient in nitrogen. The quantities at the disposal of the farmers along Long Island Sound are immense.

No. 34.- Shell marl, from John Adams, Salisbury (Falls Village P. O.) This material underlies the muck No. 32, forming a bed 8 or 10 feet thick. When air dry it gave the following results:

$$
\text { Analysis. }
$$

Organic matter soluble in water,

" insoluble in water, - $\quad 5.82$

$$
\text { Total, }
$$

Inorganic matter, *soluble in water,

6

$$
\text { insoluble }
$$

" -

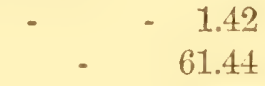

W Total,

Water,

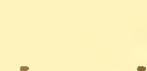

62.86

30.62

100.00

Rexarks.-Mr. Adams writes that he has applied this marl to grass land without perceiving any benefit. Probakly an application of it to light poor land would be found useful, and it is worth extended trial.

No. 35.-Mud from beneath marsh muck No. 21, from Solomon Mead, New Haven. Deseribed as "clay muck." "Has

\footnotetext{
* Portion soluble in water consists chiefly of sulphate of lime, with traces of salts of iron and potash.

+ An analysis of this marl made by Mr. E. HL Twining, aftor drying it completely, is as follows:-

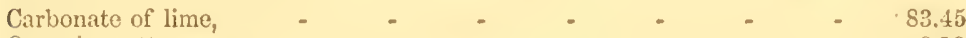

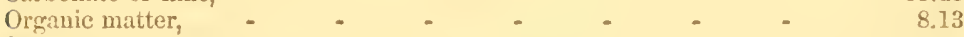

Sand, - $\quad$ - $\quad$ - $\quad$ - $\quad$ - $\quad$ - $\quad 2.71$

Oxyd of iron and alumina with traces of sulphuric acid, phosphoric acid,
potash and magnesia,

potash and magnesia, $\quad \cdot \quad \cdot \frac{5.71}{100.00}$
} 
sufficient tenacity to make bricks." "Excellent for improving the physical characters of sandy soils."

$$
\text { Analysis. }
$$

Organic matter soluble in water, $-0.88$

" insol: in water but sol. in carb.

" insol. in water and carb soda, 3.95

$$
\text { soda, (treated three times,) } \quad 3.70
$$

Thto-

Inorganic matter *soluble in water, - $\quad-1.90$

" insol. in water but sol in carb.

$$
\text { soda, (treated three times,) } 18.37
$$

" insol in water and carb soda, $\quad 67.35$

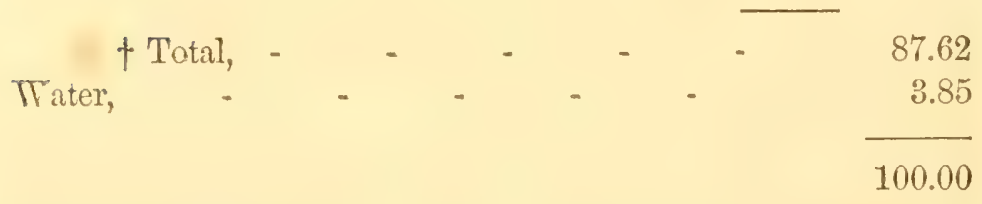

* Portion soluble in wator contains much sulpluate of lime and some salts of iron. with a small quantity of chloride of solium. Contains also some silica, but no carbonic acid.

† Ash mostly a fine sand, with some clay; yields much iron and some sulphato of lime, and magnesia to acids. 
11. Tabulated Analyses.

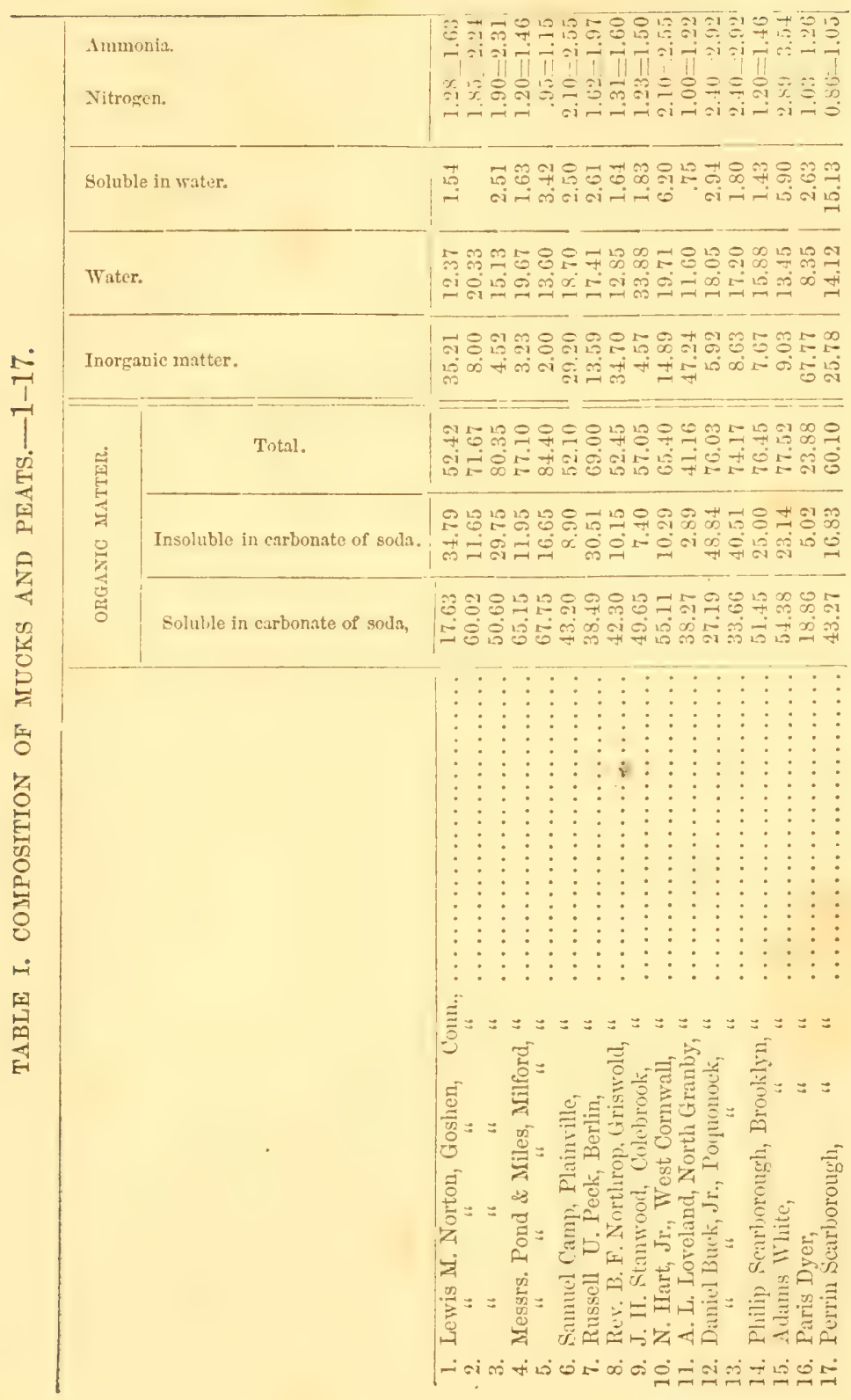




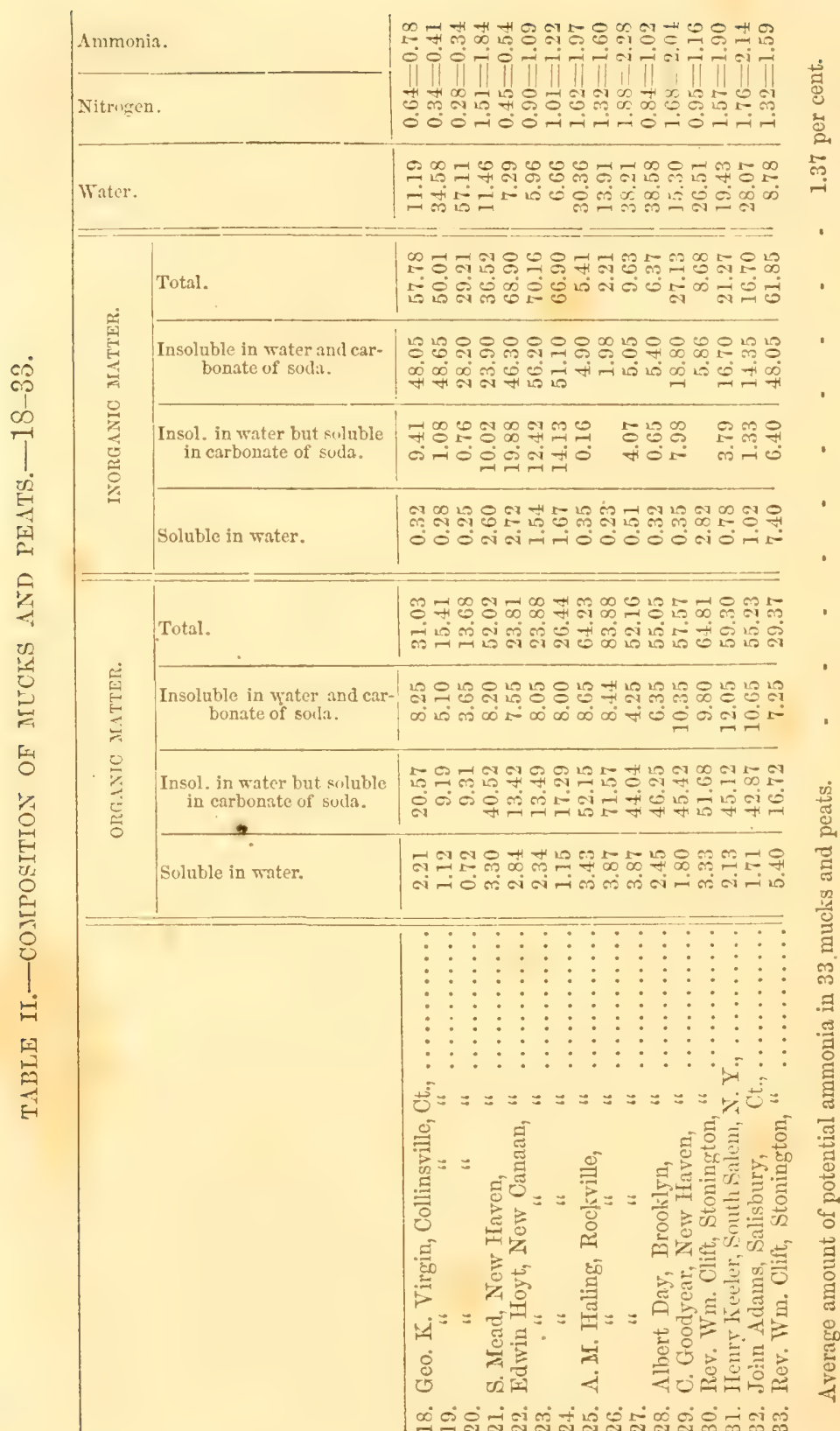




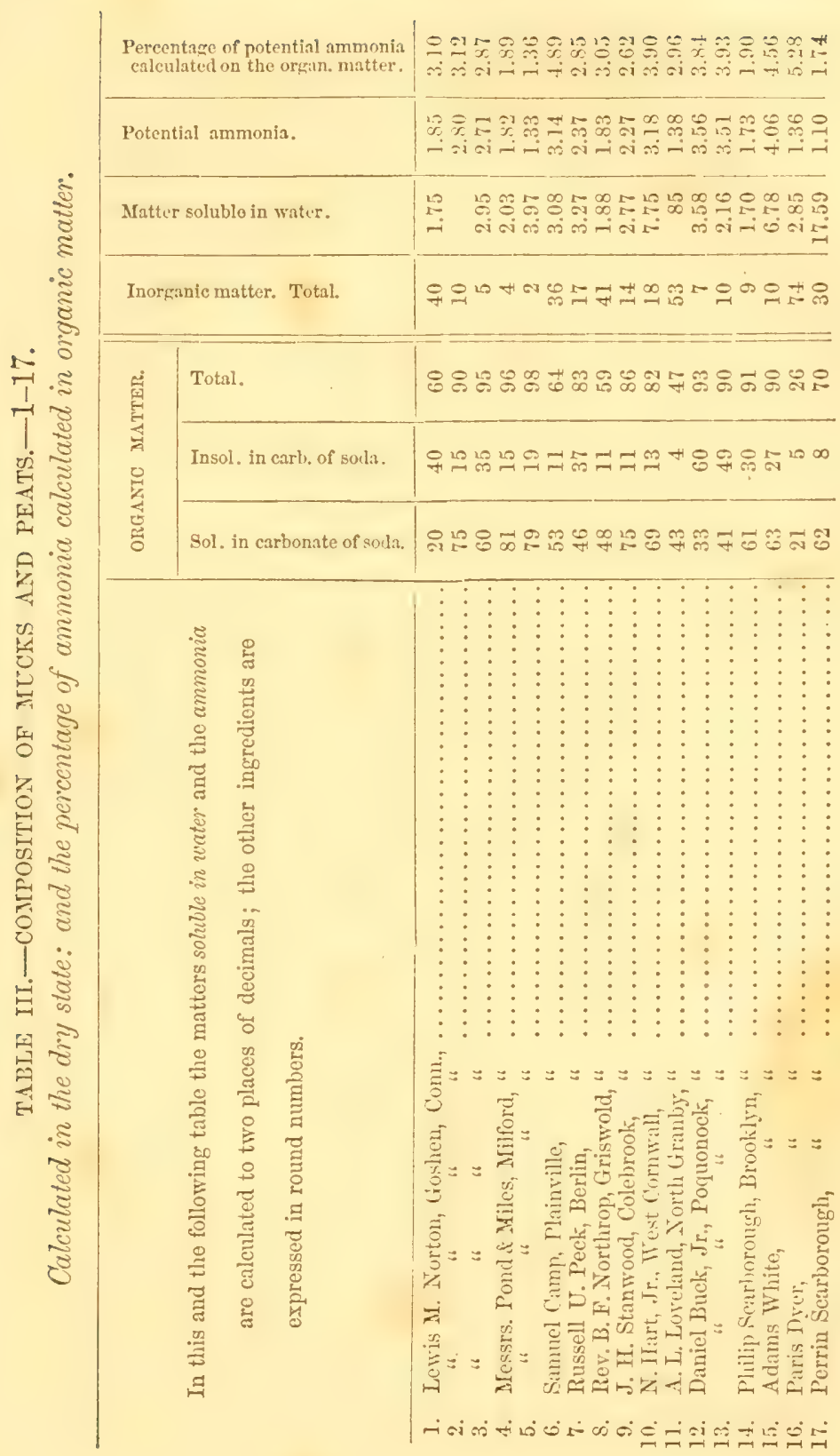




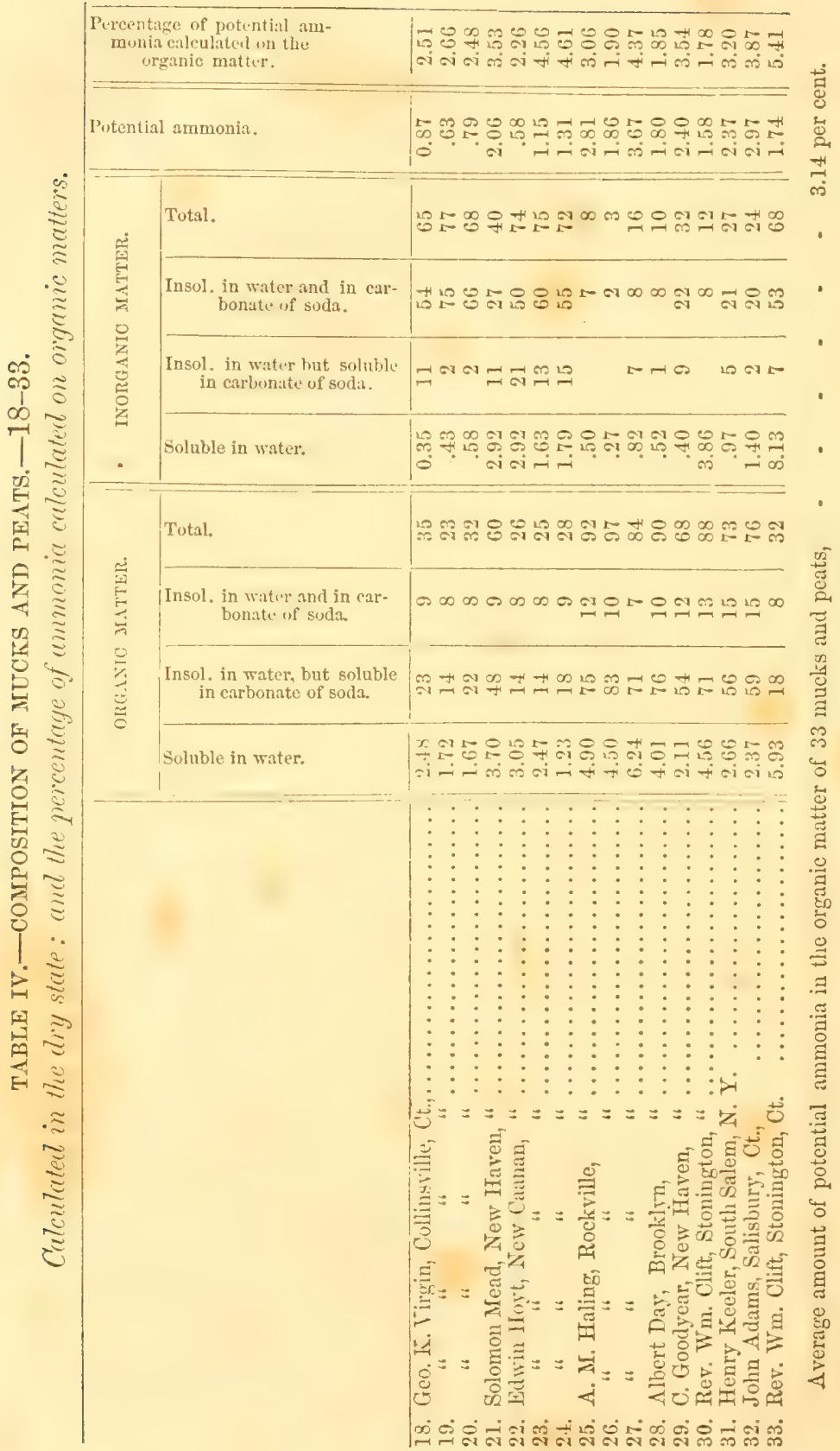




\section{COMNERCLUL FERTILIZERS.}

\section{SCALE: OF PRICES.}

The valuation of the chief ingredients of commercial fertilizers remains as in my First Report, and is as follows:

Potash............................... 4 cts. per lb.

Insoluble phosphoric acid, ................. $4 \frac{1}{2}$ "

Soluble " " $\quad$ " $\ldots \ldots \ldots \ldots \ldots \ldots \ldots \ldots \ldots \ldots 12 \frac{1}{2}$ "

Ammonia,............................. 14

THE QUINNIPIAC COMPANY'S FISH MANURE.

In March, 1558, I was consulted by the Quimipiac Comnany of Wallingford, Conn., with reference to a fish manure which they manufacture, and obtained their consent to pullish the result of the analyses that were made. Nothing is more obvious than that the true interests of the manuficturer and of the firmer are identical, and equally promoted as well by an exposure of what is worthless, as by commendation of what is useful. The Quimipiac Comprany employed me to analyze their fish manure in order to ascertain definitely for themselves, how it compares with standard fertilizers, and are willing that I should pronounce public judgment on it according to its merits.

The quality and price of the fish manure is such that it deserves to be commended to our farmers; especially since, as I an eredibly informed, the Company bears a high reputation, which is a guaranty that they will contimue to manufacture an article as good as they have submitted for analysis. 


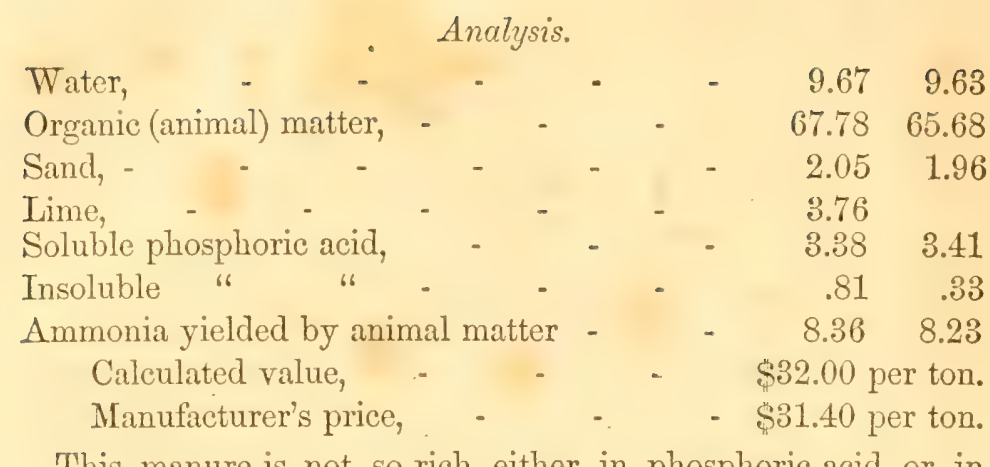

This manure is not so rich either in phosphoric acid or in ammonia as the best qualities of fish manure; but it is nevertheless entitled to a high rank among concentrated fertilizers. It yickls fully one-half as much ammonia as the best Peruvian guano, and nearly all the phosphoric acid it contains is in a form sóluble in water.

The calculated value is estimated from the prices adopted in my First Annual Report.

The manure is sold by measure. The Company inform me that it weighs 35 pounds, and is sold at 55 cents, per struck bushel. From these figures the price per ton, as given above, is reckoned.

The mechanical condition is very good. In employing this manure it must be borne in mind that, like Peruvian gramo, it is caprable of supplying only a part of the wants of vegetation, so that the use of some phosphatic manure and of leached ashes, muck or stable manure, with it, will be better economy in inost cases than depending on it alone.

The manuficturers recommend to apply it to Indian corn, for example, either broadcast at the rate of 20 to 40 bushels per acre or 3 bushels in the hill. It is cluubtless generatly the best plan to manure the plant rather than the soil, i.e., if a crop grows in hills or drills, to manure in the hill or drill; if the crop is sown broadeast, manure in the same manner. If I understand rightly, a much larger application in the hill than three bushels per acre, is likely to prove detrimental.

It is to be hoped that this successful attempt to manufacture a substitute for Peruvian guano in our own Ștate, will meet 
with such encouragement as to make fish manure a staple fertilizer. With the stimulus of abundant patronage, this kind of manure can be prepared of better quality and furnished at a less prier ; while if judiciously used, it camot fail to improve our lanks permanently, at the same time that it yields better yearly crops.

\section{THE GREEN SAND MARL OF NEW JERSEY.}

In the Spring of 1858 I was informed that the "New Jersey Fertilizer Company" intended shipping to this State some cargoes of this material, and although I am not aware that their intention has been carried out as yet, there is apparently no reason why the Green Sand Marl may not become an article of conmeres between Connecticut and New Jersey, and I therefore communimite to the publie such account of its nature and use as I have been able to collect.

The Green Sand Marl is a peculiar geological deposit, met with in various parts of this and other comntries, but most largely developed in the state of New Jersey, where it oceupies or underlies an area of 900 square miles. This tract extends from Sandy Ilook south westwardly to Salem, on the Delaware River, a distance of ninety miles, and is six to fourteen miles in breadth. It is only in a few locililies, however, that it is found on the surfice of the earth; it being overlaicl with soil thronghout the great share of this vast district. It has long been known that this marl, as it is called, is exceedingly useful as a fertilizer when applied upon the contignous lands. The discovery is said to have been made by accident, and the effects were so striking; that in those parts of New Jersey, where it is easily accessible, it is now one of the chief reliances of the farmer.

The deposit of green sand narl has a variable thickness, and is by no uneans uniform in appearance. It often has a fine green color. This color is due to the green sand which is its characteristic ingredient. Often, and indeed generally, the color of the marl is greenish-gray or brown, from an admixture of clay and other substances. The green sand itself occurs in the form of grains like gunpowder. These grains are brown externally, if they have heen exposed to the air, owing to the higher oxydation (or rusting, ) of the protoxyd of iron contained in them; 
but if washed or broken, their proper green color is always manifested. This color enables us to distinguish the green sand from all other sands by the eye alone.

The green sand has a nearly uniform composition, and hence is considered a distinct mineral, and for the sake of distinction is called Glunconite (which means "sea-green stone,") by the mineralogists.

In virtue of its composition and easy decomposability, green sand is an excellent fërtilizer.

Its average composition in 100 parts is :

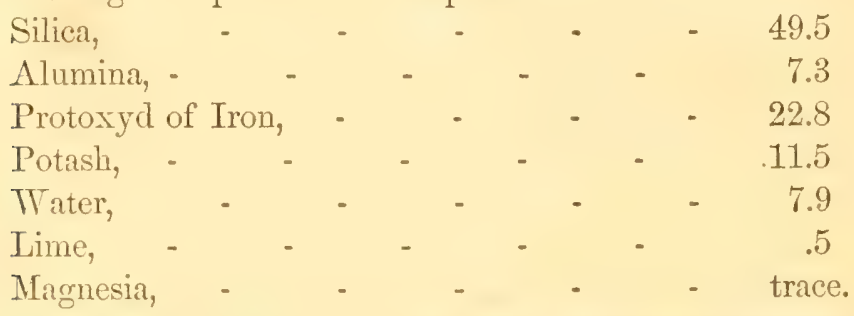

On aceount of its fincly divided state, when freely exposed to the air and water of the soil it gradually decomposes, and its potash, siliea and protoxyd of iron become soluble, or at any rate available to vegetation. The protoxyd of iron which is useful in small quantity, but detrinental if largely present in the soil, in prevented from accumulating to exeess by the fact that it rapidly absorbs oxygen from the air, and passes into peroxyd (iron rust.) The peroxyd of iron and alumina together with the silica, are important means of increasing the power of the soil to absorb and retain manures.

Many sunty and light soils are defteient in potash, and hence the green sand is useful when applied to them. It has indeed been supposed that this fertilizer owes its efinciency chiefly to its large content of potash. The other ingredients that we have mentioned are, however, useful to a greater or less degree.

Not only the green sand itself, but likewise the other matters which, with it, make up the marl, must be taken account of in consilering its fertilizing value. The adnixtures of clay, quartz sand, ete, are quite variable, ranging in quantity from 10 to 60 per cent. of the whole; thus more or less reducing the amount of manurial matters, and at the same time either improving or 


\section{3}

injuring the general composition by their own accidental ingredients.

The clay mixed with or overlying the green sand, in many localities contains quantities of a shining yellow mineral called iron pyrites or "fool's gold," which consists of iron and sulphur, and by exposure to the atmosphere is converted into sulphate of iron, (common copperas or green vitriol.) From this source the marl is sometimes so impregnated with sulphate of iron as to be destructive to vegetation when applied fresh from the pits. This difficulty is not, however, general, so far as I can learn, and in all eases is obviated by exposing the marl for a year or so to the weather, and by composting it with lime or with stable manure. By these means the iron is changed from the protoxyd to the peroxyd, which latter is harmless under all cireumstances.

In some localities the marl is mixed with a large proportion of fragments of shells, and thus contains considerable carbonate and a small amount of phosphate of lime. Sulphate of lime or plaster, is also an occasional ingredient.

The following analyses copied from Professor Cook's Report on the Geology of New Jersey, clearly show the nature and extent of the variations in composition, to which the marl as employed for agricultural purposes is subject.

Analyses.*

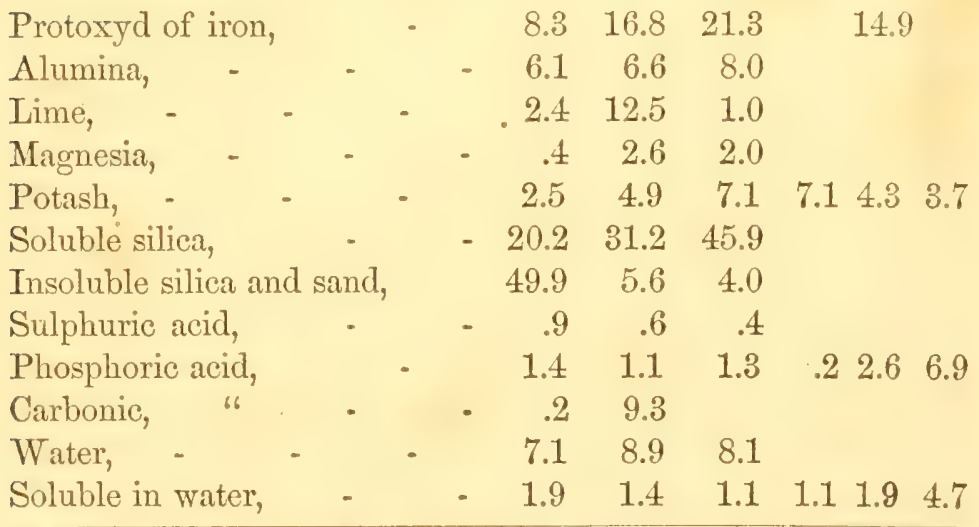

* In copying the analyses, the decimals of the percentages have been abridged from two figures to one. 


\section{4}

Potash it is seen ranges from $2 \frac{1}{2}$ to 7 per cent. The average is about $\frac{1}{2}$ per cent. One of the specimens is half sand and insoluble matters. No. 2 contains $12 \frac{1}{2}$ per cent. of lime, and 9 per cent. of carbonic acid, or 21 per cent. of carbonate of lime. Phosploric acid is almost wanting in No. 4 ; but in No. 6 exists to the amount of 7 per cent. The usual quantity of phosphoric acid however, does not exceed 1 to 2 per cent.

From the composition of the green sand marl we might know that it is a good manure withont any actual trials; but the experience of the New Jersey farmers during many years has so fully demonstrated its value, that the question arises-may it not be procured and transported so cheaply as to admit of profitable use in this State? The following quotation from Professor Cook's Report may serve to assist us in answering this question.

"The absolute worth of the marl to farmers it is difficult to estimate. The region of country in which it is found has been ahnost made by it. Before its use the soil was exhausted, and much of the land had so lessened in value that its price was but little, if any more than that of government lands at the West; while now, by the use of the marl, these worn out soils have been bronght to more than native fertility, and the value of the land increased from fifty to a hundred fold. In these districts as a general fact, the marl has been obtained at little more than the cost of digging and hauling but a short distance. There are instances however, in which large districts of worn out land have been entirely renovated by the use of these substances, though situated from five to fifteen miles from the marl beds, and when, if a fair allowanee is made for labor, the cost per bushel could not have been less than from twclve to sixteen cents. Instances are known when it has been thought remunerative at twenty. five cents per bushel."

The New Jersey Fertilizer Company deliver the marl on board vessels at their wharf at Portland Heights, N. J., for seven cents per bushel. The bushel when first raised weighs $100 \mathrm{lbs}$; when dry 80 lbs. I doubt not that the average qualities of this marl are better bushel for bushel, than leached ashes. The best kinds are much superior, and in the inferior sorts there is much more weight of valuable fertilizing matters than in an equal bulk of 


\section{5}

leached ashes; but this advantage has its offset in the superior finenes, and consequent greater activity of the leached alshes. If then the expenses of transportation are small, as they are when large quantities are shipped, there is no reason why our farmers, who are located near tide water, may not use this fertilizer to great advantage, especially if they ean have a good article guaranteed them.

The marl is especially useful for potatoes and root crops, but on poor soils is good for any crop. It is applied at the rate of one to two hundred bushels per acre.

\section{"ANIMALIZED PHOSPHATE OF LIME."}

A specimen of the so-called "Animalized Phosphate of Lime," made ly Hartley \& Co., of Plymouth, Conn., received from Mr. Dyer, was analyzed with the following results, per cent.:

Water,

Sand and silica,

Organic and volatile matter,

IIydrated sulphate of lime, (unburned plaster, -

Carbonate of lime,

Magnesia,

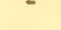

Ammonia yielded by organic matter, - - $0.33 \quad 0.35$

The analysis is not fully carried out, separate determinations of the quantity of phosphoric aciel and of potash not having been mate. The phosphoric acid cannot amount to more than $1 \frac{1}{2}$ per cent., the potash not more than 3 per cent. These quantities are of small account in a high-priced fertilizer. To finish the analysis in these particulars would serve no important use.

I find by a simple calculation that a manure equal, and indeed superior to the above, in eomposition and value, weirhy for weight, may be made after the following recipe:

60 pounds of ground plaster.

37 " hard wood ashes (unleached.)

3 " $"$ Peruvian guano. 
Such a mixture can be manufactured at a profit for $\$ 10$ per per ton, and if I do not greatly mistake, most farmers can get the ingredients for $\$ 5$ to $\$ 7$ per ton.

This article claims to be "made from the bones, blood and flesh of animals, digested in acid liquors, and dessicated with various saline fertilizers, in such a manner that all the valuable gases and salts are retained in a dry powder." It is seen that the quantity of "various saline fertilizers," is so large compared with the "bones, blood and flesh of animals," that the result is comparatively worthless commercially speaking. When we consider that 75 to 80 per cent. of a dearl animal is water, it is easy to understand that it requires careful manufacturing to make a concentrated manure from the carcasses of horses, \&c.

It is usual to employ oil-of-vitriol to decompose and deorlorize animal matters in preparing manures. This is very well, but if a large quantity of cheap materials are afterward mixed up with the product, the value of the whole becomes so reduced, that the expense of manufacturing is a dead loss to the farmer who in the end pays for it, in ease the manure finds a marliet.

If the sample furmished me represents the average quality of this manure, it may be conficlently asserted that those who pay for it $\$ 50$ per ton, (the manufacturers price,) will lose the better share of their money.

PERUVIAN GUANO.

From the store of Wm. Kellogg, Hartford.

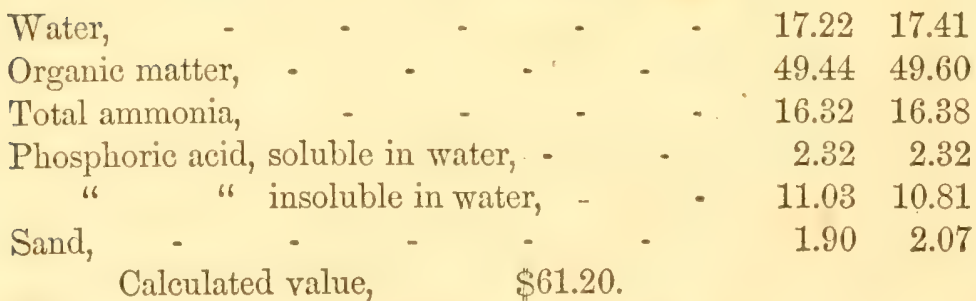

The above figures show that this fertilizer maintains its uniformity and excellence of composition to a remarkable degree.

The soluble phosphoric acid, it should be remembered, is equal in quantity to the average amount of this ingredient in our com- 
mercial superphosphates, and is accompanied with two to three per cent. of potash, which, though of trifling commercial value by the side of ammonia, is nevertheless of great manurial worth on the light soils where guano is most often applied.

\section{ELIDE GUANO.}

This is an article that purports to come from the coast of California. It is a genuine gutuno, similar though inferior to Peruvian. It is afforded at two-thirds the price of Peruvian, and an analysis is of much interest as showing its real commereial value. It appeare from the analyses of other chemists that this guano is quite variable in composition, at least so far as the quantity of moisture is concerned. I grive some of the results of Dr. Stewart, chemist to the Maryland Agrieultural Socicty, and of Dr. Deck, of New York, by way of comparison. I shoukl say with regard to its texture, that at first sight it is rather unpromising, containing some genume stunes and a good many hard lumps that are diflicult to crush unless they are dried.

A mechanical analysis gave per cent.:

Fine portion passing a sieve of 20 holes per inch, _ $\quad 74$

Lumps easily reduced after drying, - - $\quad 22$

Pebbles,

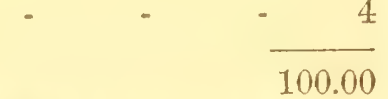

When irierl, howerer, the whole is as easily crushed as Peruvian guano, the pebbles of course excepted.

The analysis of the whole, rejecting the pebbles only, is given under I. Linder II. are figures from Dr. Stewart's, and under III. from Dr. Deck's analysis.

I.

II. III.

Water

27.34

27.60

18.90

22.64

Organic and volatile matter,

(Yielding ammonia, )

$39.20 \quad 38.75$

43.30

43.53

Phos. acid soluble in water,

" " insol. in water,

(10.00) (10.06)

Sulphuric acid,

5.07

6.46

5.31

11.00

Lime,

Potash and a little soda,

$$
\text { - } 4.94
$$

- $\quad 9.67 \quad 9.36$

Sand and insoluble matters, $\begin{array}{lll}2.50 & 2.52 & 4.70\end{array}$ 
The high percentage of soluble phosphoric acid depends upon the presence of potash and soda.

It must be borne in mind that this manure is considerably variable in composition, and is so moist that it may easily deteriorate by keeping.

The specimen I have analyzed is considerably cheaper than Perurian guano. It remains to be seen, however, whether other cargoes or other lots are equal to this, before the reputation of the Elide guano can be established.

\section{SUPERPHOSPIATES OF LIME.}

But four specimens of this manure have been analyzed this year. Two of these, I. and II., were from the store of Messrs: Backus and Barstow, Norwich; the others, III. and IV., from Wm. Kellogg, Hartford.

I.

II.

III.

IV.

\begin{tabular}{|c|c|c|c|c|}
\hline & $\begin{array}{l}\text { Pike \& Co. } \\
\text { av. } 10 \text { b'gs. }\end{array}$ & $\begin{array}{c}\text { Coe \& Co. } \\
\text { av. } 25 \text { b'gs. }\end{array}$ & $\begin{array}{l}\text { Greene \& } \\
\text { Preston. }\end{array}$ & Coe's. \\
\hline & $\left|\begin{array}{ll}38.50 & 38.50\end{array}\right|$ & 36.5536 .15 & $\mid 32.96-32.28$ & .55 \\
\hline & $28.85 \quad 28.80$ & $2.70 \quad 2.80$ & $2.45-2.80$ & \\
\hline acid, & $1.28 \quad 2.22$ & $2.55 \quad 2.02$ & $2.2 S-2.13$ & 2.8 \\
\hline & 2.29 & i8.13 17.78 & $19.12-17.64$ & $15.76-16.30$ \\
\hline Ammonia, - - . & $2.44 \quad 2.45$ & $\begin{array}{cc}3.14 & 3.11 \\
\$ 32.00\end{array}$ & $\begin{array}{c}1.39-1.39 \\
\$ 26.31\end{array}$ & $\begin{array}{l}2.97-2.74 \\
\$ 37.81 \text { ton }\end{array}$ \\
\hline
\end{tabular}

I. Is seen to be a very inferior article; more than one-quarter of it (28 per cent) is sand! This fact indicates that it is most probilbly some manuficturing refuse. The calculated ralue will give the farmer an iclea how much he can afford to pay for it; but manures so largely mixed with sand, camnot be carefully prepared; and as other samples may contain much more sand, it is best not to buy this manure at all unless on an analysis.

II. III. and IV. are all fair samples of "superphosphates," as that word is now used, though none of them contain appreciably more soluble phasphoric acid than Peruvian guano. It seems, as yet, impossible to find a real superphosphate (yiclding 10-15 per cent. of soluble phosphoric acid) in the Connecticut market.

The above analyses do not accord very closely in sume particulars. This is due to the fact that the samples were too moist 
to allow of intimate mixture. The slight differences are, howerer, of no importance in estimating the value of these artieles.

All these specimens were in good mechanical condition. The first sample of Coe's superphosplate is of the same quality which it has hitherto possessed. The analyses of it read almost precisely like those made last year; but there is some filling ofl in the other sample IV., in which the pereentages of sand and water are both somewhat larger, and all the active ingredients are accordingly reduced in proportion.

The difference in value between II. and IV. amounts to \$1.20 per ton.

Green \& Preston's is still inferior to IV. chiefly from containing less ammonia.

\section{CASTOR PUMMACE.}

Messrs. Baker, Latourette \& Co., 142 Water St., New York City; manufacturers of linseed and castor oils, have recently undertaken the now enterprise of importing the castor bean from Inclia, and expressing the oil from it in New York. The cake or pummace remaining from this operation, has been found to possess valuable fertilizing properties, and is already employed as a manure in England. I hare been employed to analyze the castor pummace, and it has turned out so satisfactorily, that in my opinion it will be doing the members of the State Society a service, to commmicate the results, and do so herewith, having obtained permission of the manufacturers.

\section{Analysis.}

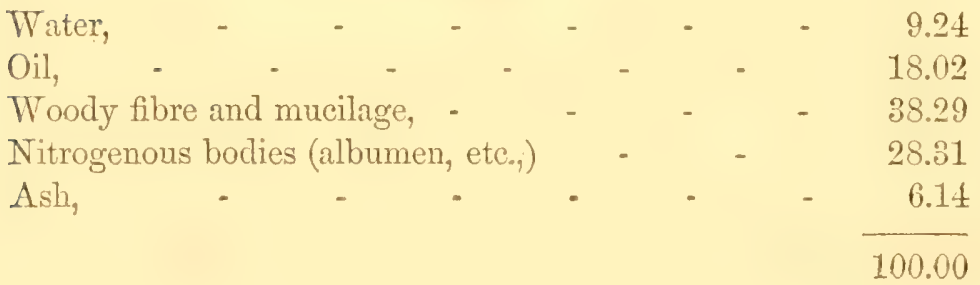




\section{In the ash were found-}

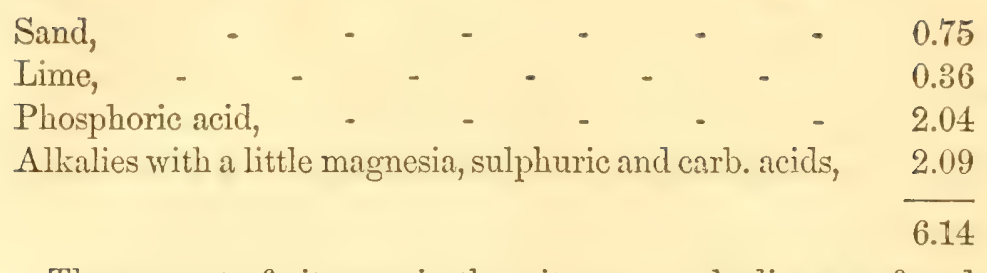

The amount of nitrogen in the nitrogenous bodies was found to be 4.32 per cent., corresponding to 5.48 per cent. of potential ammonia.

On account of the purgative effect of the castor oil, the pummace cannot be employed as food for cattle, and its whole agricultural value must consist in its fertilizing applications.

Its worth commercially considered, lies exclusively" in its content of phosphoric acid and ammonia. Its calculated value, using the prices adopted in my first annual report, viz., four and a half cents per pound for insoluble phosphoric acid, and fourteen cents per pound for ammonia, is $\$ 17.20$ per ton (2000 lbs.)

The manufacturers inform me that hitherto they have sent the castor pummace to England, where it commands a price of $£ 4$ 10s. sterling per ton (the English ton of 2240 pounds I suppose.) They now intend bringing it into the home market, and there seems no reason why we cannot use it to as good advantage as English farmers can, if it is afforded at a fair price. $\dagger$

The pummace is not hard like linseed-cake, but easily crum1,les to pieces, and is sufficiently fine to be convenient in application.

It belongs to what are usually termed the stimulating manures, and is rapid in action, usually spending itself in one season.

It may be applied directly to the soil and harrowed in, or used in the preparation of composts. I should judge it would be found exceedingly servicable in composting muck, ete.

Some caution must be exereised in the use of this class of

* The opinion has been entertained that oil is a fertilizer; but numerous careful trials made in England and elsewhere have proved that pure oil is quite inert, and only such impure oils as contain nitrogenous animal matters produce any perceptible effects.

† I see by the advertisements of Messrs. Baker \& Co., that they sell eastor pummace at from $\$ 12$ to $\$ 16$ per ton, according to the quality. It is a cheap maure. 


\section{1}

manures, because their action is so powerful that in very heavy doses they may overforce the crop, or even destroy the seed when put in contact with it at the time of planting. It has licen asserted that the content of oil of the oil-cakes hinders the germination of seeds, by preventing access of water to them. I am inclined to believe however, that their detrimental action is due to their readiness of decomposition, whereby the seed is caused to rot. In fict there are only a few instances on recort of their occasioning this sort of injury, and in these they appear to have been applied in very large quantity. We can estimate the proper allowance per acre of castor pummace, by comparing its per cent. of ammonia with that of guano. It contains just about one-third as much of this ingredient, and aceordingly we may safely use three times as much of it. We lnow that 600 pounds of guano per acre is a very large manuring, and 200 or 300 pounts is usually the most profitable in the long run. These quantities correspond to 1800,600 and 900 respectively of castor pummace. I find that the largest doses of rape cake, (a manure of almost identical composition, rather inferior in amount of ammonia perhaps) given in English and Saxon hushandry, are 1500 to 2000 pounds per acre, while 600 to 800 pounds are the customary applications. More is needed on heavy than on light soils.

It is frequently urged as an objection to manures of this sort that they exhaust the soil. It is however always the crops that are removed, and never the manure applied, which exhansts the soil. The exclusive and continued use of this or any similar fertilizer will be followed by exbaustion; but by jucliciously alternating or combining it with mineral manures, as wool ashes leached or unleached, New Jersey green-sand, superphosphate of lime, or phosphatic guano, it may be used with safety and advantage. 
BONE DUST AND BONE-MEAL.

These articles from the store of Wm. Kellogg, Hartfort, have been analyzed with results as follows:

Bone Dust.

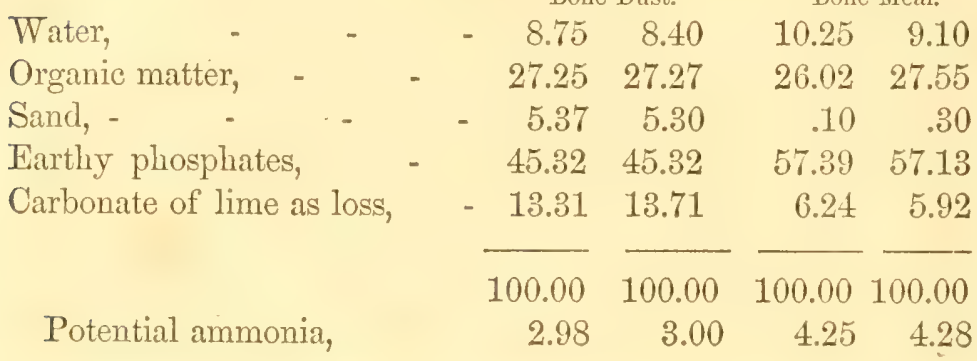

Of the bone dust a more extended analysis was marle, in which the amount of phosphoric acid was determined with more accuracy than in the above analyses. It was undertatien on accomt of the high percentage of carbonate of lime inclicated, but not satisfactorily proved to be present by the first examinations. It confirms them as the following results show:

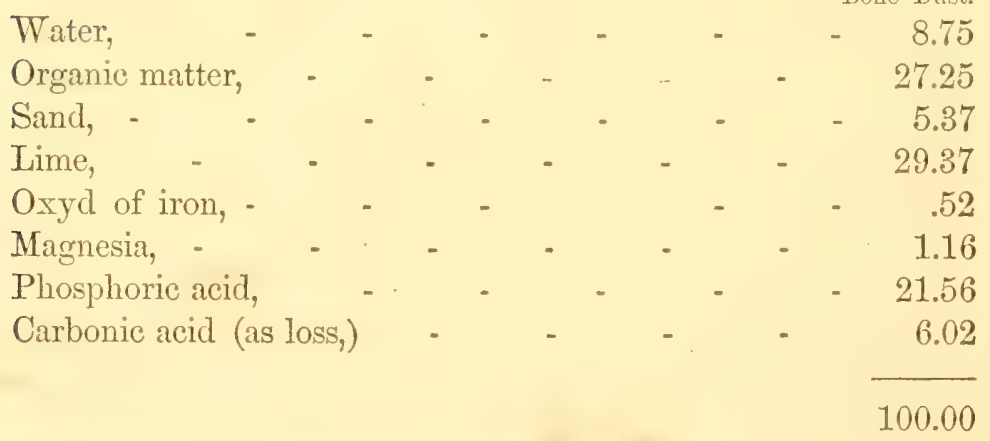

The bone meal is of the kind used for feeding, and is a very finely-divided white and pure article, consisting apparently of turnings of bone, and is well adapted for its purpose.

The bone dust is obviously ground from bones that have been boiled, or steamed to extract their fat, and have also parted with 
a portion of cartilage (animal tissue, as is evident from the small percentage of potential ammonia.

In the collection of the bones, no great eare has been taken to remove adhering dirt and sand, for we find more than five per cent. of this impurity. There is also thirteen and a half per cent. of carlonate of lime, which is more by five or six per cent. than is usually found in steamed or boiled bones. When we compare the composition of the dust with that of the meal, the latter representing pure bone, we find that there is a difference of twelve per cent. of phosphates (nearly six per cent. of phosphoric acirl, and one and a quarter per cent. of potential ammonia. Doubtless there has been no intentional adulteration practised on this bone dust; but it is not quite so pure as it onght to be. The sample is hardly so fine as to descrve the name of dust, as it contains a good share of unground fragments. Few of these, however, would not pass a sieve with eight holes to the linear inch, and it is therefore in a good form for use.

$\Lambda$ few words with regard to the use of bone meal for feeding. Then employed for this purpose, bone meal is intended to supply, especially to milch cows, the lack of phosphates in the food. It appears pretty well established that the soil of many pasture lands may become so exhausted of phosphoric acid, that the herbagre does not yield to cows, enough of this ingredient for the proper nutriment of their bony system, and at the same time supply the large demand for phosphates made by the milk secreting organs. Cows thus poorly feel, turn instinctively to the proper remedy, and neglect no opportunity to gnaw upon any old bones they may be able to find. The results of continued feeding on such poor pastures, are a loss.of health on the part of the cows, especially manifested in a weakening or softening of the hones-the bone alisease, that is not now uncommon in our older dairy districts. It is found, if we may rely on the experience of our best furmers, that this evil "can be partially remedied by directly feeding fincly ground bone meal to the cows." Other phospluates have been found to answer the same purpose, and doubtless the cheapest materials for this purpose are some of the "rock guanos" now common in our markets. The true remedy for bone disease, however, consists not in closing the an- 
imal, but in so improving the soil that it shall produce a perfect food. A liberal application of some phosphatic manure is the obvious resort in extreme cases where the soil is absolutely deficient in phosphoric acid; but in my opinion there are few soils in New England (always excepting mere sand barrens) that do not originally contain enough of all the mineral food of plants, to yield perfectly nutritions fodder for an indefinitely long period, without the necessity for outlay in commercial or concentrated fertilizers, if they are brought into the proper physical conditions and manured with all the dung and urine that can be produced on them. 


\section{APPENDIX.}

\section{SOMBRERO GUANO.}

So fur as present data afford the means of judging; the Sombrero guano is the cheapest, and in composition the richest and most uniform of the phosphatic guanos. It comes from an island in the Caribbean, where it occurs as a porous rock of a yellowish white, pink or brown color, which, though quite firm in the mass, may yet be easily reduced to a fine powder.

This rock guano has been formed, doubtless, from the excre. ments of sea-fowl, which, exposed to alternate rains and sum, have entirely lost their animal matters, and soluzle salts; and by processes familiar to the geologist, have left finally a cemented and hardened residue of phosphates of lime, magnesia and iron. This guano is of the same general character as the Columbian guano, which was in market some years ago, and much of the American guano now imported has a similar rock-like character.

The first importation into this State was male in the early part of this year $(1859$, ) per schr. Telegralph, by Messis. J. M. IIuntington \& Co, of Norwich; and in June the same house received another cargo by the schr. "Ik. Marvel."

I have analyzed eight samples, viz.: of the first importation:

I. From Backus and Barstow, Norwich, ground sample.

II. From the importers. Average made by myself from a large number of rock-specimens.

III. Ground guano from Backus \& Barstow, Hartford.

And from the second cargo:

IV. A rock sample of the white variety.

V. Ditto of the buff.

VI. Ditto of the pink.

VII. Ground sample obtained by me from the mills at Norwich. VIII. Furnished by Win. B. Johnson \& Co of New Haven. The analyses are given in the following table: 


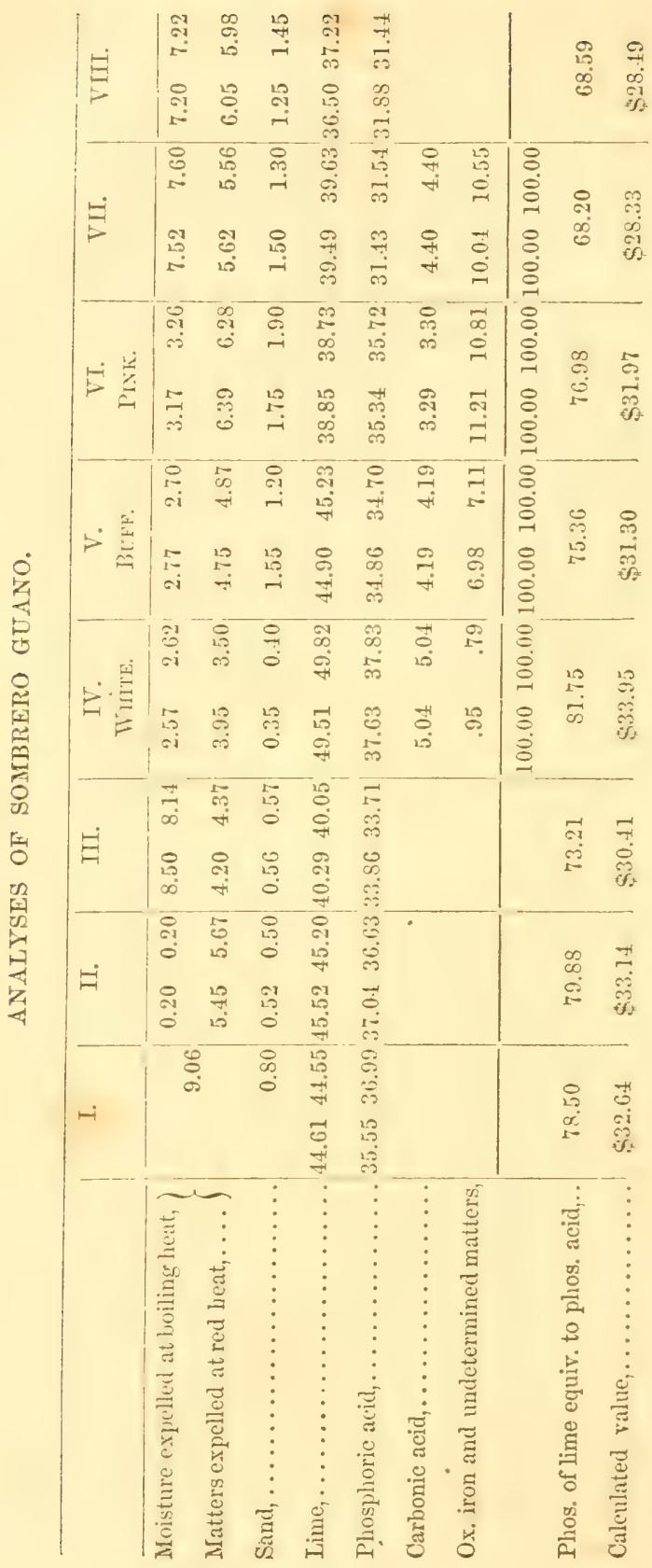


This guano is sold at $\$ 30$ per ton, and as the price of the best samples nearly reaches this figure when calculated with the valuation of phosphoric acid at 4 cents per pound, I was led to hope that we were warranted in estimating the price of this substance at 4 insteal of $\frac{1}{2}$ cents per pound, as has been previously done. The analyses, however, show that this guano is liable to contain a not inconsiderable amount (S per cent.) of moisture, and thus the percentage of phosphorie acid is somewhat reduced.

It is seen that the ground samples are not quite so rich in phosphoric acict as the mbroken lumps. This is dne to two causes. 1st. There is unavoidably introducerl into the cargo a certain anount of fine soil and other worthless matters during the louling of the ressel. 2l. The guano is impregnated with salt water, and the chlorids of sodium, calcium and magnesium thus introdnced into it, rapilly absorb moisture from the air when the guano is ground, especially if the weather be damp. I have found that these ground samples when put into a perfectly dry atmosphere, at ordinary temperatures, luse six to seven per cent. of noisture in twenty-four homrs, and recover it again in an equal time if exposed to moist air. The analyses III., VII. and VIII. show that the maximum amount of moisture is seven to eight per cent.

It is scen then that the Sombrero guano has withstood the most severe tests, and may be relied upon, especially since the importers use great care to select a pure material, and to reject the worthless or inferior rocks which oceur with the native deposits.

The old notion that a good manure must have a bad smell is still entertained, even among very intelligent farmers. I have had the pleasure of giving my testmony personally against this prejudice, to some of them in reference to this guano, and it may not be useless here to repeat that "not all which stinlis is good for manure, and not all which is good for manure stinks!" Asafoetida is no fertilizer, ancl plaster or lime, which everybody knows to be grool manures, are alinost entirely destitute of odor. So this guano is a powerful fertilizer when used where there is need of it; though it has no more smell than sand.

It has been questioned whether these rock phosphates really possess the fertilizing value which is deluced from their content 
of phosphoric acid. Experience has proved that the erystalized, or the more compact massive varieties of phosphorite (native phosphate of lime, are very inefficient, or in some cases quite inert when used in coarse powder. This fact is due to their density and want of porosity, in conscquence of which they are very slowly soluble.

The notion that there is a difference in the value of phosphates coming from mineral or organic sources, a difference depending upon the simple fact of origin, and that a phospluate or other plant food, is made more efficacious as a fertilizer, by having been a constituent of an animal or plant, is merely ridiculous, and is not supported by a single fact.

This doctrine of the "Progression of Primaries," as it has been termed, though vigorously advocated by the Wrorting Farmer, is daily disproved by agricultural experience.

If these phosphates are acted upon by sulphuric acid, they yield a superphosphate which is as beneficial as any, and the only question of the activity of this Sombrero guano lies in its solubility, or what amounts to the same thing, its fineness.

The rock, as I have said, is for the most part extremely porous, and easily ground to powder when once reduced to small frugments. It is furthermore somewhat dissolved by pure water, and, in fact, to a greater extent than bone-ash, this being due to its containing the intermediate or neuticl phospluate of lime.

From these considerations, I should not hesitate to believe that this guano would prove a sufficiently active phosphatic fertilizer, when used alone, in soils not altogether too dry or deficient in vegretable matter. The recommendation of the importers to use it in conjunction with Peruvian guano is one that will be found advantageous. 



